\title{
Energy Efficiency Improvement and Cost Saving Opportunities for the Corn Wet Milling Industry
}

\author{
An ENERGY STAR ${ }^{\circledR}$ Guide for Energy and Plant Managers
}

Christina Galitsky, Ernst Worrell and Michael Ruth

\author{
Energy Analysis Department \\ Environmental Energy Technologies Division \\ Ernest Orlando Lawrence Berkeley National Laboratory \\ University of California \\ Berkeley, CA 94720
}

July 2003

This report was funded by the U.S. Environmental Protection Agency's Climate Protection Partnerships Division as part of ENERGY STAR. ENERGY STAR is a government-backed program that helps businesses protect the environment through superior energy efficiency. The work was supported by EPA Contract DW-89-93934401-1 through the U.S. Department of Energy Contract under No. DE-AC03$76 \mathrm{SF} 00098$. 



\title{
Energy Efficiency Improvement and Cost Saving Opportunities for the Corn Wet Milling Industry
}

\author{
An ENERGY STAR Guide for Energy and Plant Managers \\ Christina Galitsky, Ernst Worrell and Michael Ruth \\ Energy Analysis Department \\ Environmental Energy Technologies Division \\ Ernest Orlando Lawrence Berkeley National Laboratory
}

July 2003

\begin{abstract}
Corn wet milling is the most energy intensive industry within the food and kindred products group (SIC 20 ), using $15 \%$ of the energy in the entire food industry. After corn, energy is the second largest operating cost for corn wet millers in the United States. A typical corn wet milling plant in the United States spends approximately $\$ 20$ to $\$ 30$ million per year on energy, making energy efficiency improvement an important way to reduce costs and increase predictable earnings, especially in times of high energy-price volatility.

This report shows energy efficiency opportunities available for corn wet millers. It begins with descriptions of the trends, structure and production of the corn wet milling industry and the energy used in the milling and refining process. Specific primary energy savings for each energy efficiency measure based on case studies of plants and references to technical literature are provided. If available, typical payback periods are also listed. The report draws upon the experiences of corn, wheat and other starch processing plants worldwide for energy efficiency measures. The findings suggest that given available resources and technology, there are opportunities to reduce energy consumption cost-effectively in the corn wet milling industry while maintaining the quality of the products manufactured. Further research on the economics of the measures, as well as the applicability of these to different wet milling practices, is needed to assess the feasibility of implementation of selected technologies at individual plants.
\end{abstract}




\section{Table of Contents}

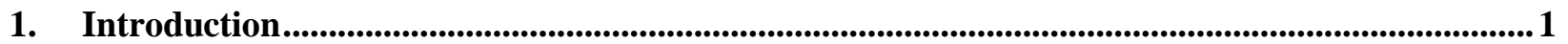

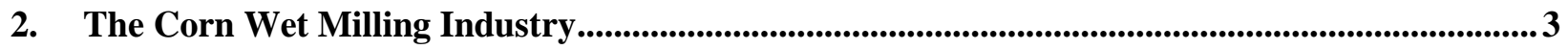

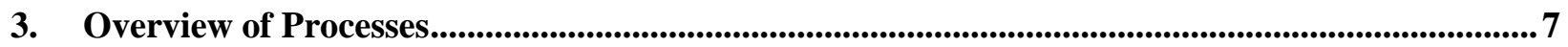

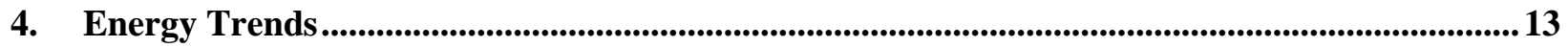

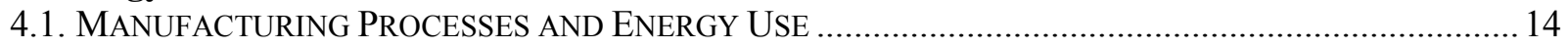

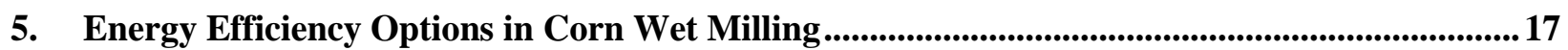

5.1. ENERGY MANAGEMENT AND GENERAL EQUIPMENT/UTILITIES APPROACHES..............................20

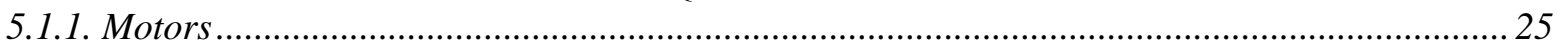

5.1.2. Pumps

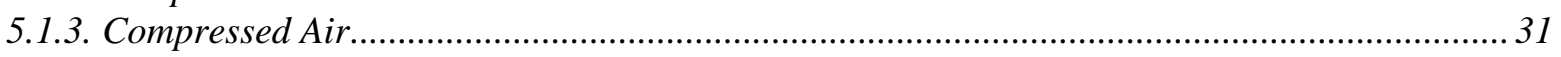

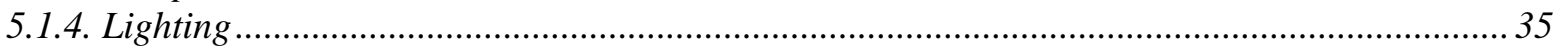

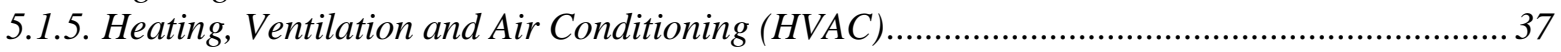

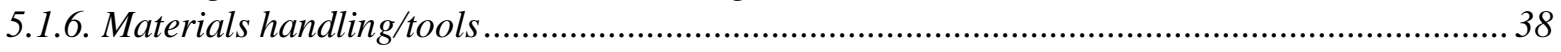

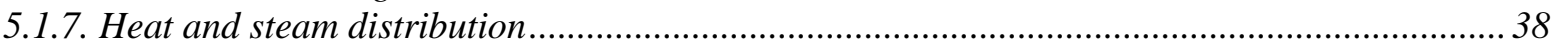

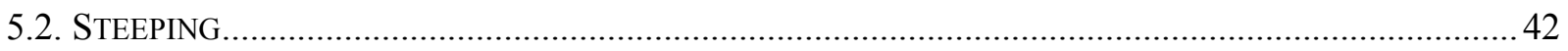

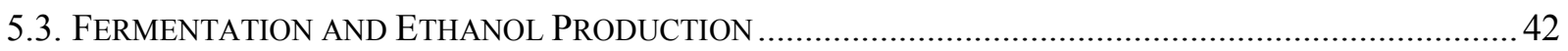

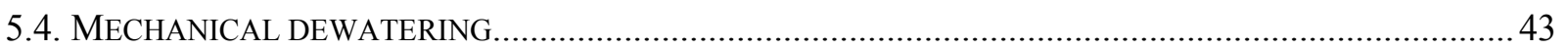

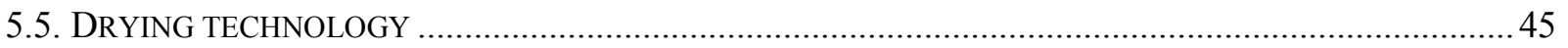

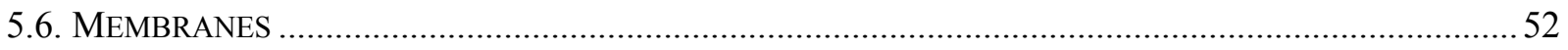

5.6.1. Membranes for Steepwater Concentration ........................................................................ 53

5.6.2. Membranes to Recycle Starch Wash Water, Reduce Water Used in Steeping.......................... 54

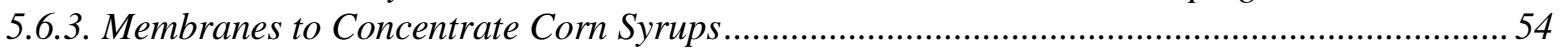

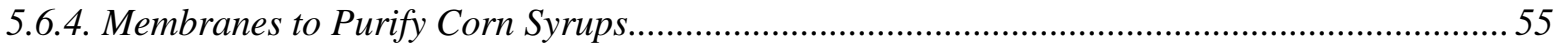

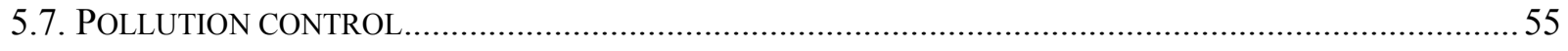

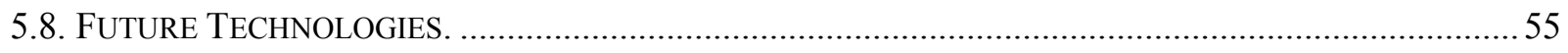

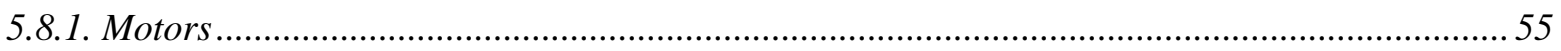

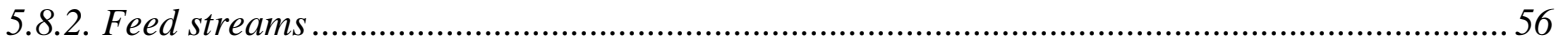

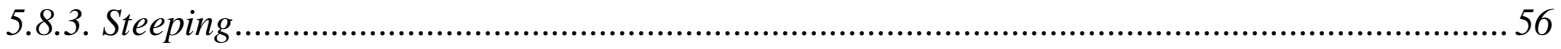

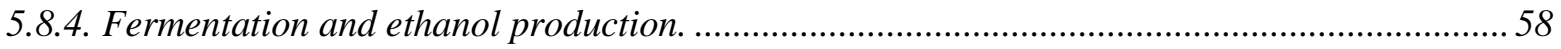

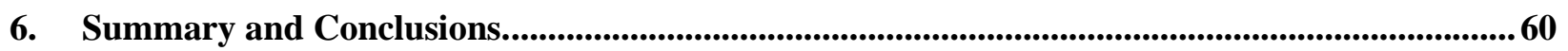

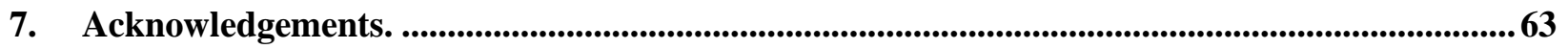

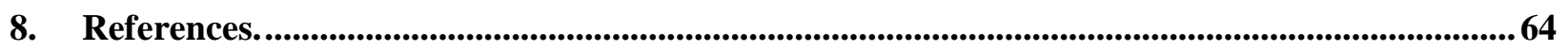




\section{Tables}

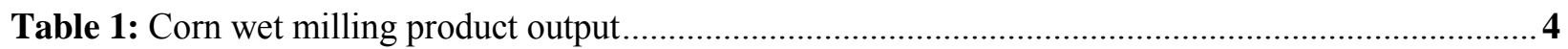

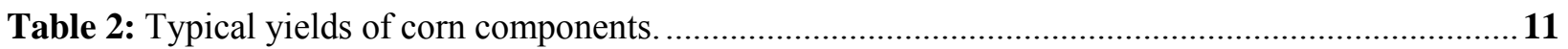

Table 3: Typical final product yields for one bushel of corn ................................................................ 11

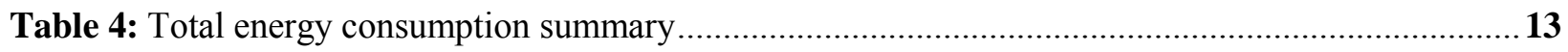

Table 5: Estimated energy consumption for processes in corn wet milling operations ...........................14

Table 6: Cross-cutting energy efficiency measures for the corn wet milling industry. ...........................19

Table 7: Process-related energy efficiency measures for the corn wet milling industry .........................20

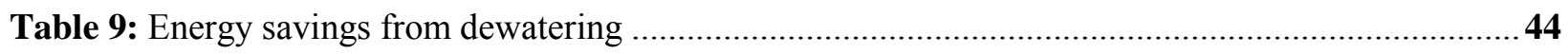

Table 10: Efficiencies of dryers using direct and indirect heating.......................................................47

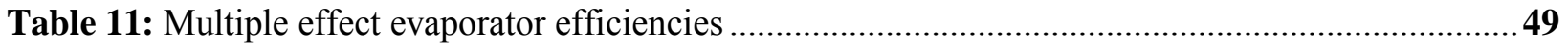

Table 12: Energy requirements for concentrating steepwater to corn steep liquor using mechanical vapor recompression or using MVR in combination with reverse osmosis..............................................53

Table 13: Intermittent Milling and Dynamic Steeping compared to conventional steeping.....................57

Table 14: Cross-cutting energy efficiency measures for the corn wet milling industry ...........................60

Table 15: Process-related energy efficiency measures for the corn wet milling industry.........................61

Appendix A: Estimated corn wet milling company capacities grouped by main product.........................73

Appendix B: Corn wet milling companies' headquarters, plant locations and products ........................74

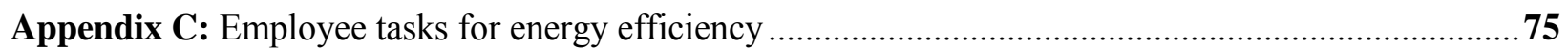

Appendix D: Energy management system assessment for best practices in energy efficiency.................76

Appendix E: Support Programs for Industrial Energy Efficiency Improvement ..................................78

\section{Figures}

Figure 1: Product output from corn wet milling industries, 1978-1998 ...............................................5

Figure 2: Trend in prices for corn wet milling products, 1981-2001 ...................................................5

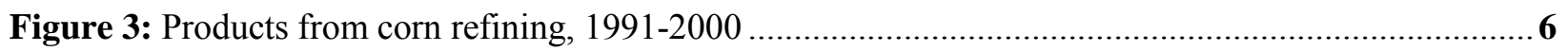

Figure 4: Overview of the processes and products of corn wet milling ............................................ 7

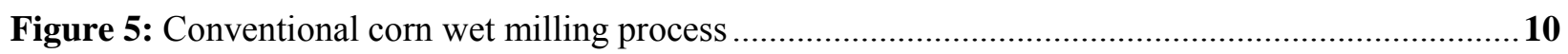

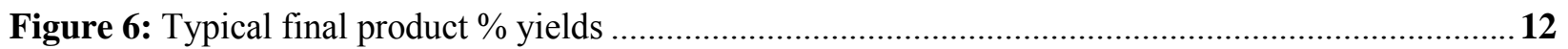

Figure 7: Corresponding current prices of products …................................................................... 12

Figure 8: Average energy expenditures for the corn wet milling industry from 1991 to 2000 ................ 13

Figure 9: Main corn wet milling process steps and their respective percentage of energy usage ............. 15

Figure 10: Main elements of a strategic energy management program ..............................................21

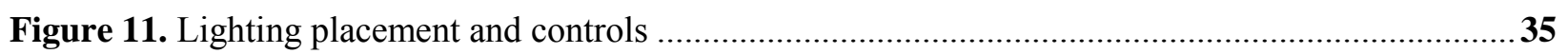




\section{Introduction}

As U.S. manufacturers face an increasingly competitive global business environment, they seek out opportunities to reduce production costs without negatively affecting product yield or quality. Uncertain energy prices in today's marketplace negatively affect predictable earnings, which are a concern, particularly for the publicly traded companies in the corn wet milling industry. For public and private companies alike, increasing energy prices are driving up costs and decreasing their value added. Successful, cost-effective investment into energy efficiency technologies and practices meets the challenge of maintaining the output of a high quality product despite reduced production costs. This is especially important, as energy-efficient technologies often include "additional" benefits, such as increasing the productivity of the company.

Energy efficiency is an important component of a company's environmental strategy. End-of-pipe solutions can be expensive and inefficient while energy efficiency can be an inexpensive opportunity to reduce criteria and other pollutant emissions. Energy efficiency can be an efficient and effective strategy to work towards the so-called "triple bottom line" that focuses on the social, economic, and environmental aspects of a business ${ }^{1}$. In short, energy efficiency investment is sound business strategy in today's manufacturing environment.

Voluntary government programs aim to assist industry to improve competitiveness through increased energy efficiency and reduced environmental impact. ENERGY STAR, a voluntary program managed by the U.S. Environmental Protection Agency (EPA), stresses the need for strong and strategic corporate energy management programs. ENERGY STAR provides energy management tools and strategies for successful corporate energy management programs. The current report describes research conducted to support ENERGY STAR and its work with the corn wet milling industry. This research provides information on potential energy efficiency opportunities for corn wet milling. ENERGY STAR can be contacted through www.energystar.gov for additional energy management tools that facilitate stronger energy management practices in U.S. industry.

In the following report, energy efficiency opportunities in the corn wet milling industry ${ }^{2}$ have been assessed. Almost $\$ 25$ billion value is created from corn crop production. Wet milling uses $15 \%$ of that corn to make starch, ethanol, sweeteners, feed products, vegetable oil and other byproducts. ${ }^{3}$ Within the food and kindred products group (SIC 20), corn wet milling is the most energy intensive industry, using $15 \%$ of the total energy in the food industry (EIA, 2001). In addition, energy costs are the largest operating cost in corn wet milling and a large percentage of the total costs in corn wet milling (Hohmann and Rendleman, 1993). For a typical plant processing 100,000 bushels per day, approximately $\$ 15$ to $\$ 25$ million per year are spent on energy, whereas $\$ 250$ to $\$ 300$ million are spent on capital costs (Singh, 2002a). In this report, ways are presented to decrease these costs and increase energy efficiency.

This report begins with a description of the trends, structure and production of the industry in the U.S. The main production processes and the energy use in corn wet milling plants along with its end-uses are then summarized. In the remainder of the report is an examination of energy efficiency opportunities in corn wet milling plants. Measures and technologies that have successfully been demonstrated in individual plants in the U.S. or abroad, but that may still be implemented in other U.S. plants, are presented. Although new technologies are developed continuously (see e.g. Martin et al., 2000a), The

1 The concept of the "triple bottom line" was introduced by the World Business Council on Sustainable Development (WBCSD). The three aspects of the "triple bottom line" are interconnected as society depends on the economy and the economy depends on the global ecosystem, whose health represents the ultimate bottom line.

${ }^{2}$ See Chapter 2 for a discussion of the classification of the corn wet milling industry that is used in this report.

${ }^{3}$ Based on 2001/02 marketing year (USDA, 2002) 
report is focused on practices that are proven and currently commercially available. Some of the technologies that may hold promise for the future but are still in the research and development phase are included in Section 5.8 .

This report aims to serve as a guide for energy managers and decision-makers to help them develop efficient and effective corporate and plant energy management programs through information on new or improved energy-efficient technologies. 


\section{The Corn Wet Milling Industry}

Corn wet milling is a relatively sophisticated process producing a variety of products for the paper, food, beverage and other industries. Table 1 gives an overview of the output from corn wet milling industries on a physical output basis and value basis for the last year information is available. ${ }^{4}$ Corn wet milling plants require a large capital investment and are bound by large economies of scale. Most plants in the U.S. process at least 100,000 bushels per day (bu/day, or 2,800 ton/day) and operate continuously for nearly 365 days per year, although approximately one quarter (ten) of the plants are smaller and have capacities less than 100,000 bu/day ${ }^{5}$. Capacities for U.S. plants are estimated in Appendix A.

Two major outputs of corn wet milling are corn sweeteners and ethanol. Both corn sweeteners and ethanol are made from the starch in the corn. Sweeteners fall into three major categories: corn syrup or glucose syrup, dextrose and high fructose corn syrup. Ethanol is an increasingly important component of the U.S. fuel supply. About $60 \%$ of the ethanol produced in the U.S. currently comes from corn wet milling ${ }^{6}$, generally produced in the refining factories along with starches and syrups. Corn starch is another important corn refining product, with both food and industrial applications, such as the paper and corrugating industries. Corn oil, produced from the germ component, is the other main high value product. Corn refining also produces many byproducts that are used in animal feed. Appendix B lists products by each corn wet milling company, along with a listing of their plant locations and company headquarters.

Corn refining has been the fastest growing market for U.S. agriculture over the past twenty years (CRA, 2002). Refiners currently use about $15 \%$ of the $\$ 25$ billion corn crop (USDA, 2002). Some other grains are wet-milled in the U.S. today, but corn far exceeds the combined total of all of them (Matz, 1991).

\footnotetext{
${ }^{4}$ The classification of corn wet milling, also referred to as corn refining, is SIC 2046 or NAICS 311221, which completely match between the two classification systems. However, when looking at data on corn wet milling, it is important to keep in mind the difference between industry groupings and product groupings. The complicating factor is that some products of the NAICS 311221 industries fall into a different classification. The chief product affected by this difference is ethanol, which falls into SIC 2869 (Industry Organic Chemicals, Not Elsewhere Classified) and NAICS 325193 (Ethyl Alcohol). Therefore, in the Economic Census for NAICS 311221, the Wet Corn Milling industry reports value of shipments at $\$ 8.5$ billion for 1997 (Table 1 in DOC, 1999), but under product statistics, the total shipments are $\$ 7.2$ billion (Table 6a in DOC, 1999). Looking at the Economic Census report for NAICS 325193, it reports that total $\$ 2.3$ billion in ethanol shipments, $\$ 1.4$ billion is manufactured by the wet milling process. We may assume that a majority of this ethanol output originates from industries in the corn wet milling classification. In addition, we note that SIC 2046 and NAICS 311221 include rice and sorghum wet millers in addition to wet corn millers. Data from the Corn Refiners Association do not include rice and sorghum millers, nor does it include alcohol in its shipment data. Although we use data from each of these sources, these discrepancies should be small enough or irrelevant so as not to affect our general conclusions.

${ }^{5} 1$ bushel $=56$ pounds $(25.4 \mathrm{~kg})$

${ }^{6}$ This percentage is based on value of output. The remaining amount is made mostly through "dry corn milling", a similar process, which produces ethanol and animal feed byproducts, but not the other high-value products that corn wet milling produces.
} 
Table 1: Corn wet milling product output

\begin{tabular}{|lcc|}
\hline & Million tons, 2001 $^{\mathrm{a}}$ & ${\text { \$Billion, } \mathbf{~ 1 9 9 7 ~}^{\mathrm{b}}}^{\mathrm{b}}$ \\
\hline Corn Sweeteners & 16.4 & $\$ 3.1$ \\
Starch Products & 2.9 & $\$ 1.5$ \\
Corn Oil & 0.6 & $\$ 1.0$ \\
Byproducts & 7.2 & $\$ 1.6$ \\
Ethanol & N/A & $\$ 1.4$ \\
\hline
\end{tabular}

${ }^{a}$ These values are from the Corn Refining Association (CRA, 2002), reporting on the output from its member companies. These data do not include rice and sorghum wet millers.

${ }^{\mathrm{b}}$ These values are from the Census and are reported based on product output, not industry output, and does not include alcohol output (see above for details). This coincides with the data from the CRA, which also does not include alcohol shipments in its data.

Figure 1 shows the output for the corn wet milling industry for two decades. Data are plotted for the total value of product shipments from the industry, as reported by the Bureau of Economic Analysis, and for the total tonnage of products, as reported by the Corn Refiners Association. Note that on a weight basis, output from the industry has grown steadily, at an overall average rate of 5.3\% per year, resulting in nearly a tripling of output from 1978 to 1998 . The value of shipments shows cycles of growth during this period, but overall growth averaged only $2.6 \%$ per annum. During this period, the value of shipments from the entire food processing industry grew only $0.5 \%$. The fact that the growth in value of products from this industry grew at only half the rate of physical output from this industry suggests the value added has been on the decline. A problem facing the industry in recent years has been sagging prices. In mid1997, after a year and a half of stable pricing at just over 13 cents per pound, the price of high fructose corn syrup on the spot market fell 35\% to 8.3 cents per pound (Bureau of Economic Analysis). Part of the reason for this collapse in prices is the over-expansion of production capacity in the mid-1980s. Figure 2 shows the prices of the main products of corn wet milling from 1981 to 2001. 
Figure 1: Product output from corn wet milling industries, 1978-1998

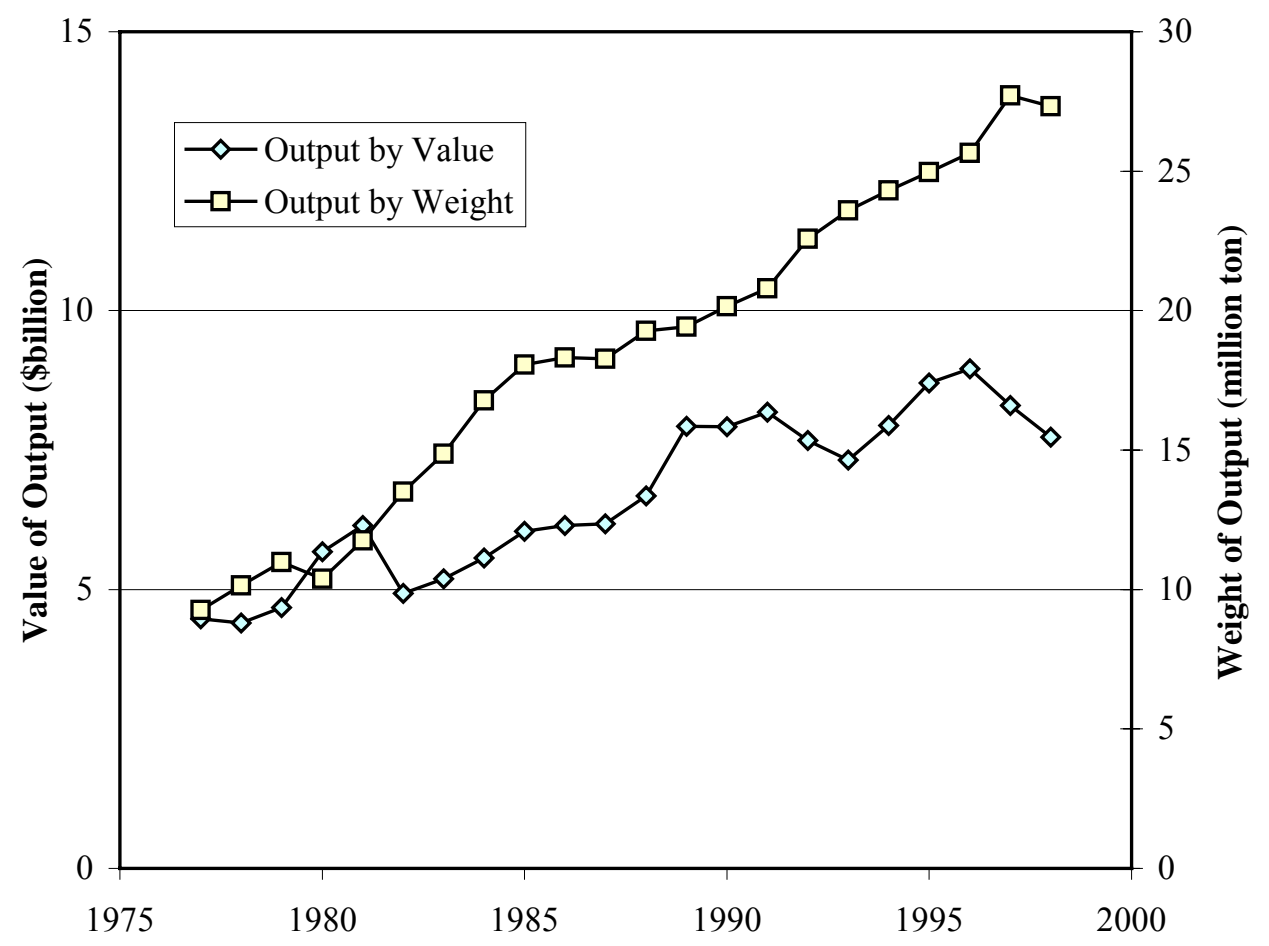

Source: Bureau of Economic Analysis, 2001; CRA, 2002, reporting on the output from its member companies, which exclude sorghum and rice wet millers as well as alcohol shipments.

Figure 2: Trend in prices for corn wet milling products, 1981-2001

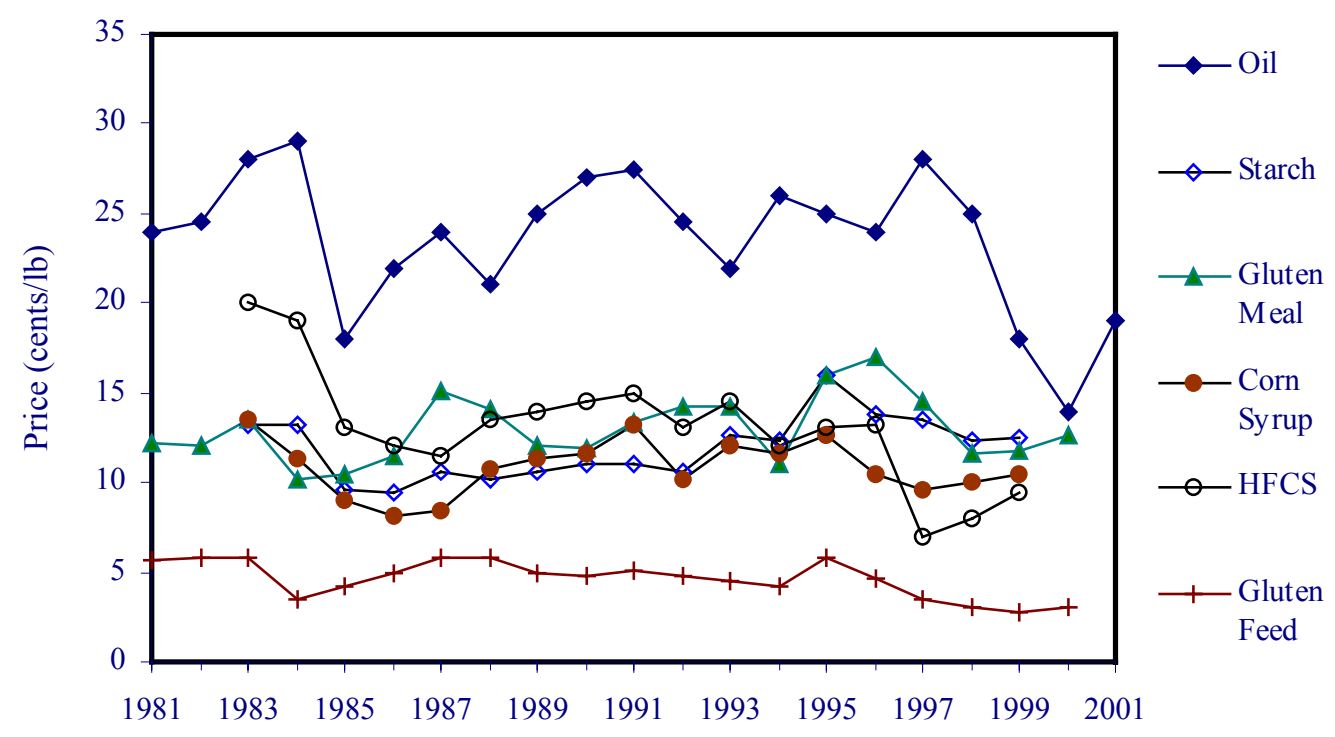

Source: Eckhoff (2002a); Rausch (2002a)

HFCS=high fructose corn syrups

The remarkable sustained growth in corn wet milling, despite the drop in prices, has resulted from the industry's continuous development of new products and expansion into new markets. Advances in food 
chemistry have developed ways to transform corn into a variety of products. Throughout the 1970s, the manufacture of sweeteners from corn developed quickly. In particular, high fructose corn syrup became the sweetener of choice in the soft drink industry by the mid-1980s. Another growth market for corn refiners was the production of ethanol. The energy crisis of the 1970s led to greater interest in ethanol as a possible fuel. Investment in ethanol led to improving technologies for the manufacture of ethanol from corn. During the 1960s and 1970s, corn refiners also began to take advantage of new enzyme technology to develop more diverse products such as organic acids, sugar alcohols and starch derivatives. Figure 3 gives a summary of the product trends from 1991 to 2000; it shows the annual production of high fructose corn syrup (HFCS), alcohol, starch and corn syrups during this period.

In the future, new product development is expected to continue, allowing for future growth in new markets. Some of the products under development are biodegradable packaging materials made by extruding corn starch derivatives, an organic acid derivative that can be made into plastic and corn-based clothing.

Figure 3: Products from corn refining, 1991-2000

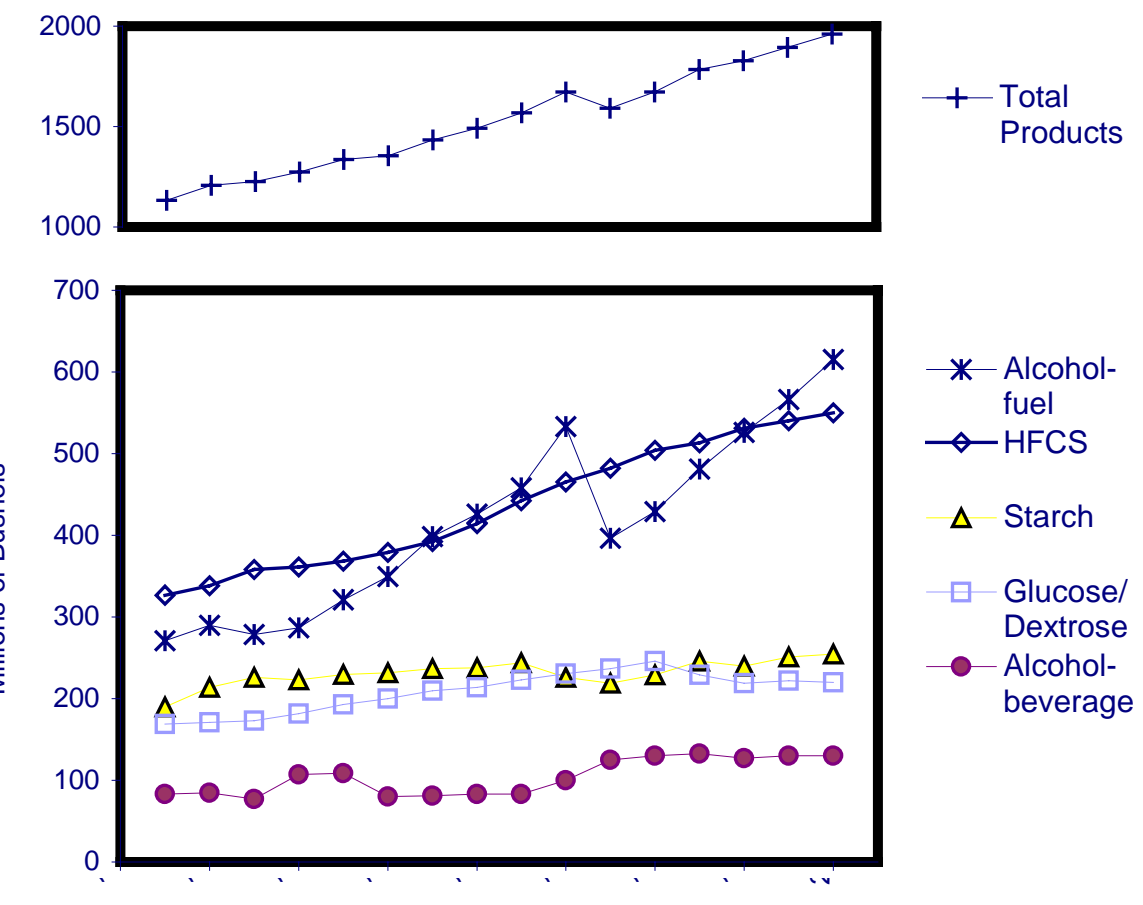

HFCS $=$ high fructose corn syrups

Source: CRA, 2001 (estimated from USDA sources) 


\section{Overview of Processes}

This section describes the main production processes and the products derived from corn wet milling. The flowchart depicted in Figure 4 provides a brief overview of the main processes. In the discussion below, more attention is given to the drying and dewatering steps because these are the main energy consumers in the milling process.

\section{Figure 4: Overview of the processes and products of corn wet milling}

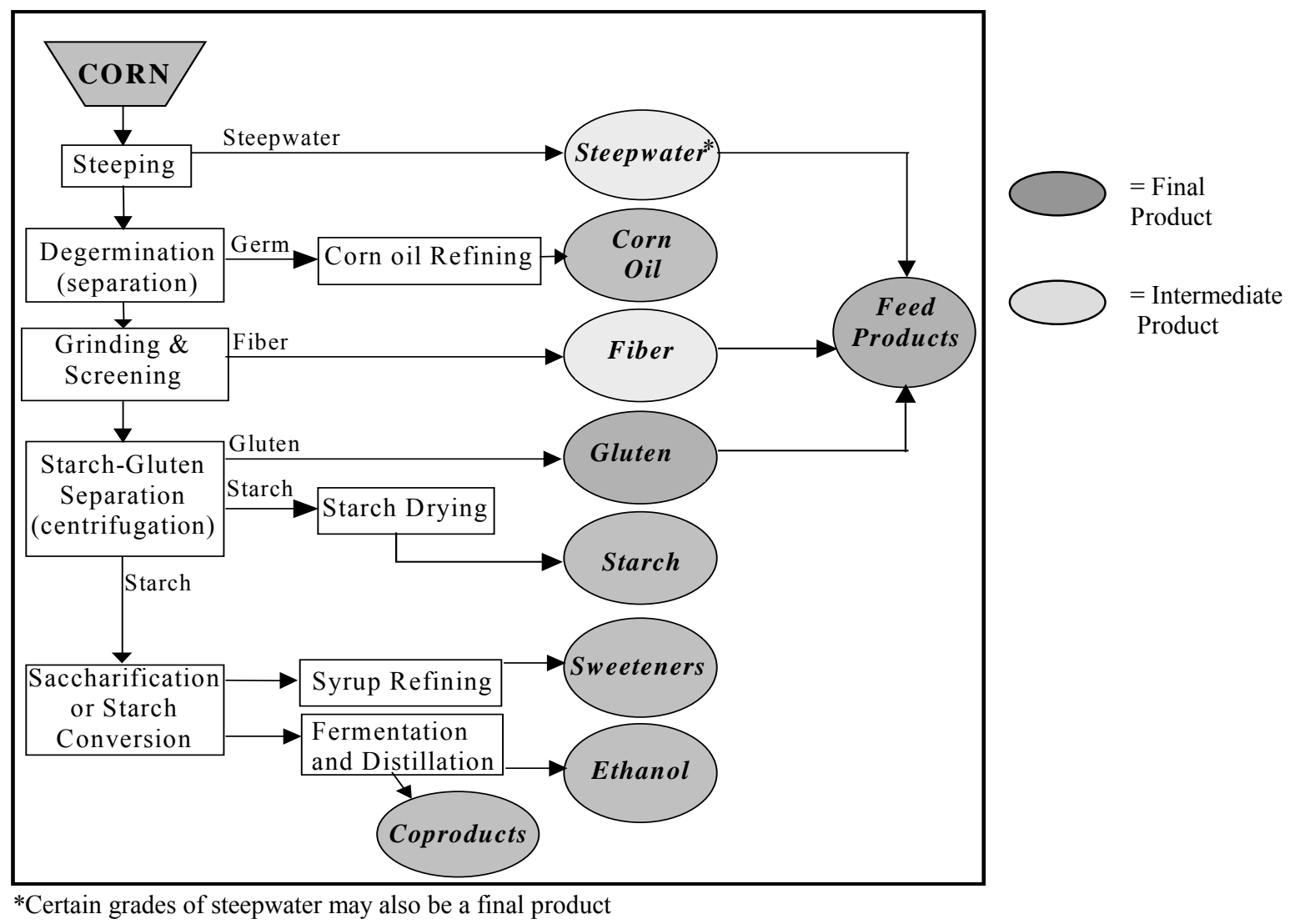

The goal of corn wet milling is to separate corn into its four main components - starch, germ, fiber and protein (gluten) - and then convert the components into useful products. The two main products, ethanol and sweeteners, are made by further processing starch. Corn starch is another main product, along with corn oil, made from the germ component. The fiber contains proteins and it, along with other byproducts, is generally used in animal feed.

The corn wet milling process begins with corn that has been removed from the cobs and cleared of all debris and foreign materials. The corn enters the steeping stage, where the kernels are soaked in large stainless steel tanks in mildly acidic water at about $120^{\circ} \mathrm{F}\left(50^{\circ} \mathrm{C}\right)$ normally for $20-36$ hours (Blanchard, 1992). There is a tradeoff between operating and capital costs in increasing steep times. Longer steep times require more capital and energy but less sulfur dioxide $\left(\mathrm{SO}_{2}\right)$ and later cleanup (scrubbing) of the $\mathrm{SO}_{2}$. In energy terms, small amounts of energy are lost due to thermal radiation and increased circulation pump power, because of increased steep times. However, these are traded for decreased power at the grind mills.

During steeping, the kernels absorb water and more than double in size. The gluten bonds in the corn loosen and starch is released. The corn is then coarsely ground to release the germ from the kernel. The 
water that the corn soaked in, referred to as steepwater, contains much of the soluble material from the corn, including a significant percentage of proteins and sugars.

In addition to most of the soluble matter from the corn, water drawn off from the steeping stage contains the products of lactic fermentation and bacterial cells. The solids content is in the range of $5-10 \%$ and must be evaporated to $45-50 \%$ solids (called "heavy steepwater" or "corn steep liquor") for commercial sale or for blending with corn fiber to produce corn gluten feed. According to Blanchard (1992), to maximize efficiency, steepwater evaporation has usually been done in multiple effect evaporators (3-5 effects), but mechanical vapor recompression (MVR) has been used as well since the early 1990s. For a more detailed discussion of the drying techniques, the reader is referred to Sections 5.5 and 5.6. Corn steep liquor is used for commercial purposes as an ingredient in animal feed or as a nutrient source in industrial fermentation.

The slurry generated by the coarse grinding that follows steeping subsequently undergoes degermination (separation) to separate the germ from the other components. The corn germ contains most of the oil present in the corn kernel and is separated to recover the oil on- or offsite. Since this fraction contains most of the corn's oil, it is less dense than water and can be efficiently separated using hydrocyclone separators. The hydrocyclones spin out the low-density germ from the remainder of the slurry. The germ is pumped into a series of screens to remove the loose gluten and starch and then washed repeatedly to recover and return all starch to the main process stream.

The germ is dewatered using a screw press, which has a conical screw revolving slowly within a cone of perforated mesh. It is squeezed and passes to the narrow end where it is discharged, while water passes out through the mesh. This results in germ with a water content of $50-60 \%$.

To achieve a moisture content of $2-4 \%$, the germ is then dried, typically using a rotary steam tube dryer. This dryer consists of a large rotating cylinder that has numerous tubes running inside it. These tubes are heated internally by steam. As the cylinder rotates, the moist germ is tumbled around and falls over the heated tubes. The internal walls of the rotating cylinder are designed to scoop the material and move it along from one end to the other. A countercurrent flow of air carries away the moisture. Blanchard (1992) reports that steam consumption is about $120 \%$ of the weight of water evaporated. Because of its regular shape and close particle size distribution, corn germ can also be dried using a fluidized bed dryer.

It is only economic to process the corn germ on a large scale, so there are a small number of centralized plants that purchase dried germ from many corn wet milling sites. Hence, smaller corn wet milling plants ship germ out to be processed offsite. After the germ is dried, corn oil is extracted through a combination of chemical and mechanical processes. The extracted oil then undergoes a series of steps to remove all impurities and to prepare the product for market and consumption.

The underflow from the hydrocyclones is the corn-water slurry that remains after recovering the oil in degermination. This slurry undergoes fine grinding and screening to liberate all starch and gluten from the fiber. A thorough grinding breaks up all the components in the kernel. A series of screens allows the gluten and starch to pass but retain the fiber. The fiber wash water is then used to recover as much starch and gluten to the main stream as possible.

Fiber is then dewatered in two steps. First, a screen centrifuge, which has a conical basket fitted with a perforated plate screen, is used to reduce the moisture to $65-75 \%$. Next, a screw press similar to that used for germ dewatering reduces moisture content by a further $10 \%$. Corn steep liquor is added to the moist fiber and the mixture is dried to yield corn gluten feed. This drying is done using various dryer designs. Commonly used is a rotary dryer consisting of a rotary drum through which the feed passes and is dried by a co-current hot air stream, usually generated by direct firing. In many areas it is now more economical 
to use steam tube dryers, also used for drying germ, although the economics strongly depend on the availability of fuels and the cost of steam (Blanchard, 1992, 2002).

The fiber becomes the major component of animal feed. It is combined with the corn steep liquor to make corn gluten feed for cattle and other animals. In most cases, the cattle feed is dried and exported. If local farms are present, this feed could be sold wet as a feed product to those farmers, thus avoiding longdistance shipping costs, drying costs and the energy of drying. The solution remaining after the fiber is separated and dewatered contains mostly starch and gluten.

This starch-gluten mixture undergoes starch gluten separation (centrifugation). Since the gluten has a lower density than the starch, centrifuges can be used to spin out the gluten from the solution. After removing the gluten slurry, the gluten is dewatered using filter or centrifuge technologies. The first option is a filter. The standard technique for dewatering gluten is the belt vacuum filter, which requires energy to maintain a vacuum using a pump (Blanchard, 2002). Another filtering option is the rotary drum filter, in which a rotating drum with a filtering surface and an internal vacuum passes through a stream of thickened gluten. A gluten "cake" forms on the drum and can be collected; it has a solids content of 40$43 \%$. The second option is a decanter centrifuge, which results in a gluten "mud" of $30-40 \%$ solids content. This works well when the material being dried has not been treated with sulfur dioxide (Blanchard, 2002). While the decanter centrifuge is a simpler installation for the plant, the filter system produces a dried intermediate product that reduces the cost of final drying.

After dewatering, the material is still too wet to be handled well by a dryer, so some previously dried material is blended in to bring the moisture content down to around 30\%. Then a number of dryer options exist. Rotary dryers are cheap and simple to operate, but can scorch the product. The typical dryer choice is a flash dryer (Blanchard, 1992). In this system, the moist material is dispersed in a stream of hot air, generally heated by direct firing of gas. The hot air stream conveys the material along a drying column with a residence time of a few seconds and delivers the product to cyclones to collect it. The flash dryer has a low thermal efficiency because $20-30 \%$ of the input heat is discharged with the spent air (Blanchard, 1992). Another option is the use of steam-tube dryers, as is used for germ drying (see above). The tube dryers are more efficient than the flash dryers that use large amounts of air, but since they use steam rather than direct firing, inefficiencies are introduced.

The byproduct made from the gluten, corn gluten meal, is also used as animal feed, commonly for poultry. The remaining starch solution is then diluted and spun many times to yield highly pure starch, typically more than $99.5 \%$ pure (CRA, 2002).

For starch that will be sold directly (instead of being converted into syrups and/or ethanol), the product (pearl starch) must be completely dried to a powder. The set of hydrocyclones or the filtering system is the final step used to separate the starch from the gluten. This results in raw starch slurry with a solids content of about 33 to $40 \%$ starch. (Chemical modification at this stage can lower concentrations due to the addition of chemicals and centrifuges can be used to raise those concentrations back to 33 to $37 \%$ solids.) Any higher concentration cannot be pumped, as the slurry becomes dilatant. Starch slurries cannot be held for too long because microorganisms begin to develop, affecting the color, odor and physical properties of the starch. The remaining starch slurry present after the final washing stage is then dewatered to $33-42 \%$ moisture content. The most commonly used dryer for this material is the flash dryer described above for gluten drying. Starch slurry can also be dried in a spray dryer or a film dryer. For small batch starches, other drying systems may be more appropriate, such as conveyer belt dryers, fluid bed dryers or drum dryers.

Starch can also be physically modified to produce a broad range of products with varying functionality. It can be modified in several ways to produce products for different applications. Processes used to 
physically modify starch include conveyor belt drying, drum drying, flash drying, thermal processing, compact granulation or jet cooking. Dried starch can also be chemically modified to produce starch with functional substituent groups.

The starch that is not dried and prepared for sale as various starch products goes on to the saccharification or starch conversion stage to convert the solution to sugar syrups. In starch conversion, the starch solution is treated with acid and/or enzymes to convert the starch into various sugars such as dextrose and maltose. These syrups are then refined or further processed to make a variety of final products, including high fructose corn syrup (HFCS).

Figure 5: Conventional corn wet milling process

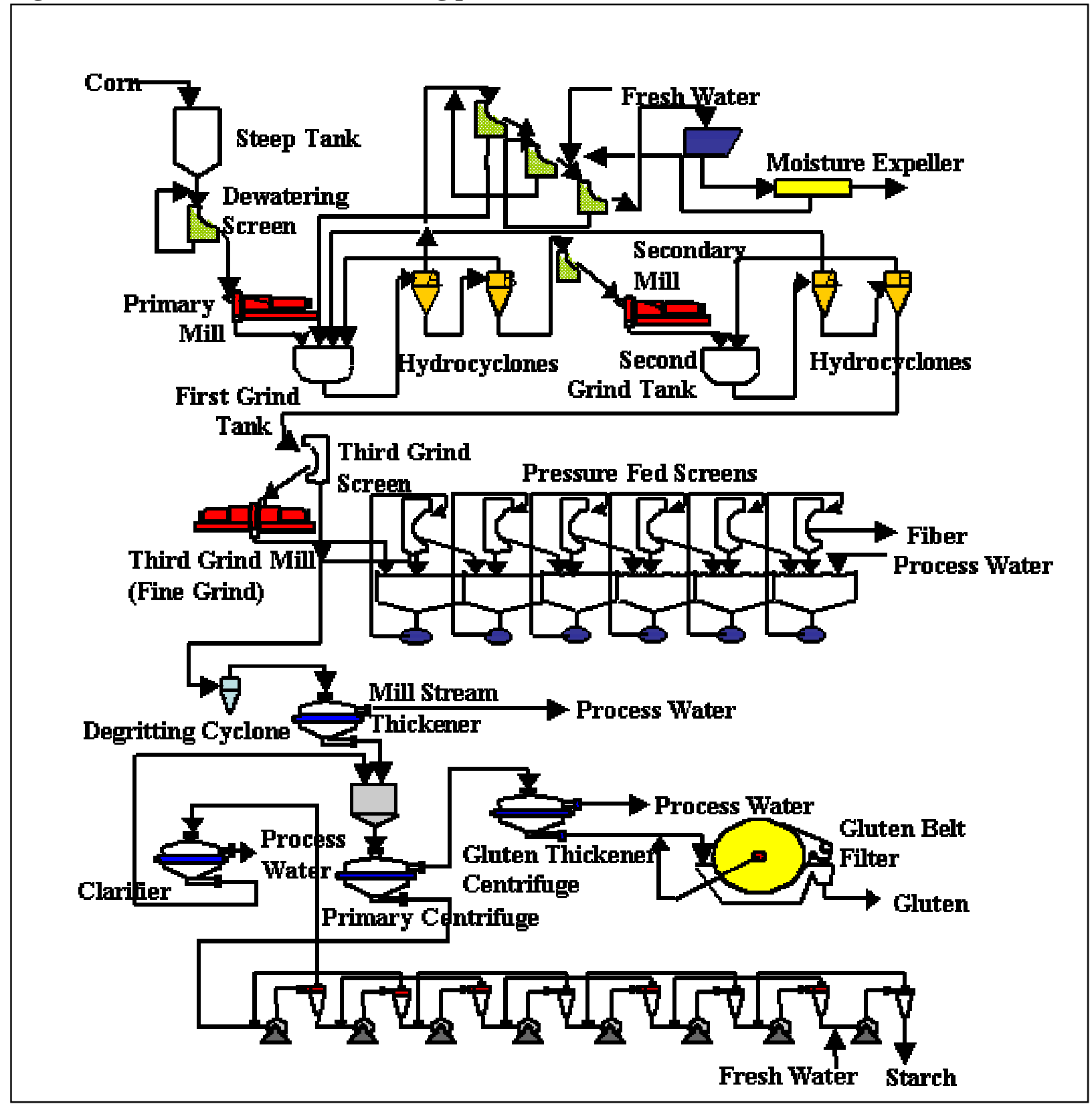

Source: Singh, 2002a 
Evaporation is a critical part of the syrup refining step. Much of the energy consumed in a syrupproducing corn wet mill is done in the syrup evaporation area. Some of the largest opportunities for energy saving appear in the syrup refinery through process integration - i.e. recovery of waste heat from jet conversion to be used in syrup evaporation, etc.

In many corn refineries, some of the dextrose solution generated will be piped to a fermentation facility to make ethanol, amino acids and other fermentation products. Fermentation can be conducted using yeast or bacteria, depending on the desired product. Distillation and dehydration or other separation techniques are used to isolate the final products. About two thirds of the U.S. ethanol production comes from corn wet milling, but most wet milling plants do not produce ethanol as their main product (Shapouri et al., 1995).

There are no absolute yields for the various products from corn wet milling because of the range of byproducts produced, the nature of the specific corn milled, and the equipment used (Blanchard, 1992). Typical yields from corn wet milling, however, are shown in Tables 2 and 3 and illustrated graphically in Figure 6. Figure 7 shows the approximate current (2002) prices for these corn products and coproducts (Eckhoff, 2002b).

Table 2: Typical yields of corn components. (Before combined and further processed to products in Table 3)

\begin{tabular}{|lc|}
\hline Product & Yield $(\mathbf{\%})$ \\
\hline Steep Liquor & 6.5 \\
Germ & 7.5 \\
Bran/Fiber & 12.0 \\
Gluten & 5.6 \\
Starch & 68.0 \\
Losses & 0.4 \\
\hline
\end{tabular}

Source: Blanchard, 1992; Matz, 1991.

Table 3: Typical final product yields for one bushel $^{1}$ of corn

\begin{tabular}{|ll|}
\hline Product & Yield (pounds or gallons) \\
\hline Starch & $31-32$ pounds \\
Ethanol $^{2}$ & $(2-3$ gallons) \\
Sweeteners $^{2}$ & $(33$ pounds) \\
Corn gluten feed & $11-14$ pounds \\
Corn gluten meal & $2-3$ pounds \\
Corn oil & $1-2$ pounds \\
\hline 1 bushel = 56 pounds $(25.4 \mathrm{~kg})$ & \\
${ }^{2}$ Ethanol and sweeteners are produced from final starch product \\
Sources: Shapouri et al., 1995; NCGA, 2002; CRA, 2002.
\end{tabular}


Figure 6: Typical final product \% yields

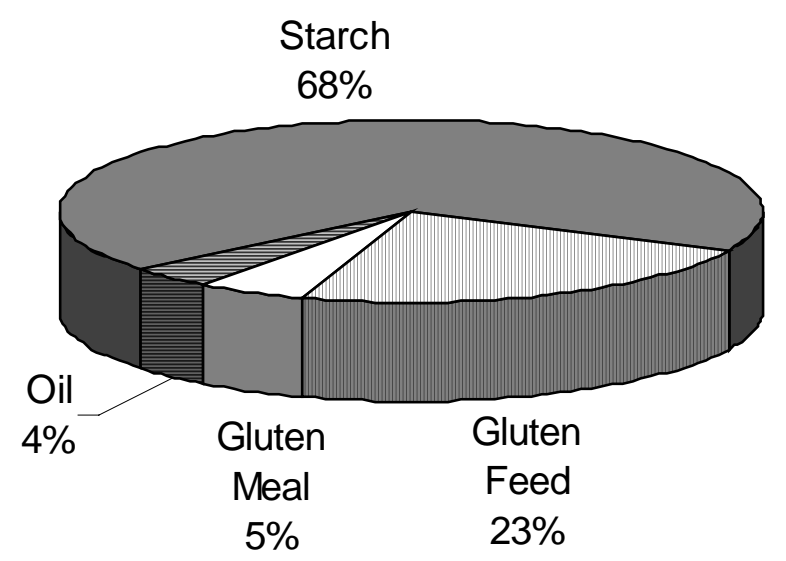

Figure 7: Corresponding current prices of products

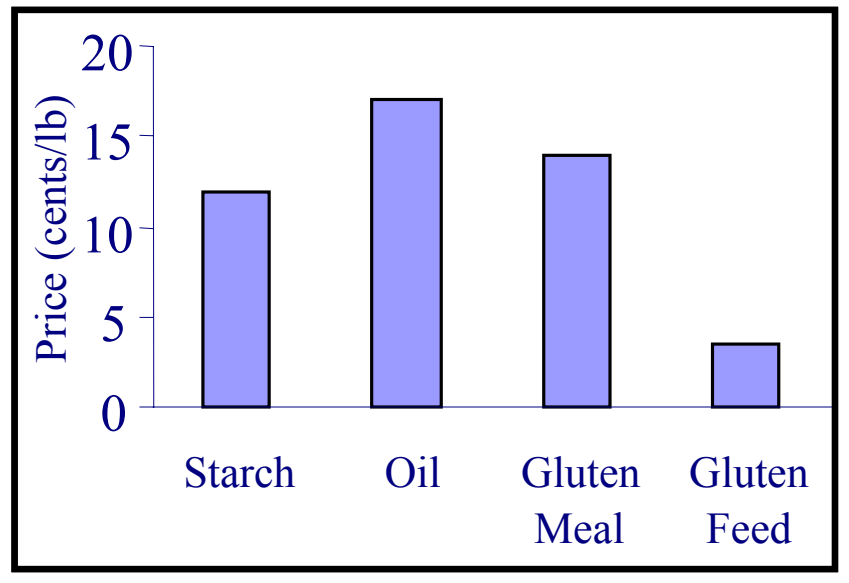

Source: Eckhoff, 2002b 


\section{Energy Trends}

Energy is an important part of a corn wet miller's variable cost. The Annual Survey of Manufacturers reports annually on energy expenditures by industry; Figure 8 shows energy expenditures for the corn wet milling industry from 1991 to 2000. Although there was a drop in energy expenditures from 1997 to 1999 , overall energy expenditures have risen from about $\$ 450$ million in 1991 to $\$ 640$ million in 2000 (normalized to \$1996).

Figure 8: Average energy expenditures for the corn wet milling industry from 1991 to 2000 (in \$millions, normalized to $\$ 1996$ )

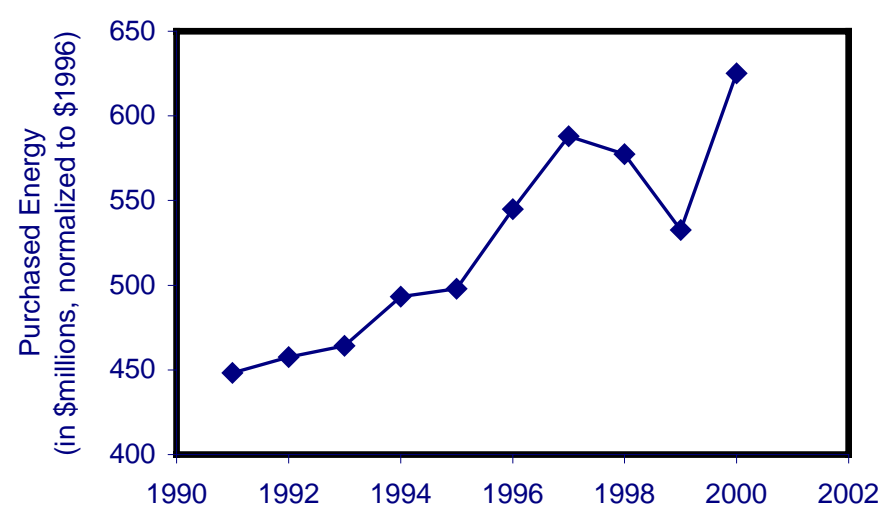

Energy expenditures are influenced both by the amount of energy that is purchased and the purchase price of electricity and fuels. It is clear that prices have fluctuated in the last decade. However, energy consumption in corn wet milling has also risen. Table 4 shows data from the Manufacturing Energy Consumption Survey for 1991, 1994 and 1998 for energy consumption. The data suggest that energy consumption in the corn wet milling industry has grown over the past decade. However, energy consumption increased more quickly from 1991 to 1994 - on average roughly $8 \%$ per annum, whereas from 1994 to 1998, energy consumption increased about 1\% per year.

Table 4: Total energy consumption summary

\begin{tabular}{|lcccc|}
\hline Fuel & Units* & $\begin{array}{c}\text { 1991 } \\
\text { Consumption }\end{array}$ & $\begin{array}{c}\mathbf{1 9 9 4} \\
\text { Consumption }\end{array}$ & $\begin{array}{c}1998 \\
\text { Consumption }\end{array}$ \\
\hline Electricity & TWh & 4.1 & 5.7 & 7 \\
Natural Gas & TBtu & 52 & 68 & 77 \\
Coal & TBtu & 68 & 78 & 65 \\
Other & TBtu & 6 & 8 & 7 \\
\hline Total Primary & TBtu & $\mathbf{1 6 8}$ & $\mathbf{2 1 2}$ & $\mathbf{2 2 1}$ \\
\hline
\end{tabular}

Source: EIA, 1994; EIA, 1997; EIA, 2001

* To convert from TWh to GJ, multiply by $3.6 * 10^{6} \mathrm{GJ} / \mathrm{TWh}$. To convert from TBtu to GJ, multiply by $1.055^{*} 10^{6} \mathrm{GJ} / \mathrm{TBtu}$.

To determine energy intensity (see page 5), an indicator must be carefully chosen to accurately represent industry trends. For example, Figure 1 shows trends in output value and product weight from 1978 to 
1998. Product weight increased on average about 5\% per year while output value only increased on average approximately $2 \%$ per year. If either of these indicators were used, energy intensity would be shown to have increased from 1991 to 1994 but decreased slightly from 1994 to 1998.

Due to the mix of different products with varying energy intensities, shifts in the product mix, prices and value added, we do not suggest a single indicator for determining energy intensity in this report. Instead, we assume that energy costs are an important variable cost and that a decrease in actual energy consumption will improve companies' bottom line and increase profitability, especially during times of dynamic energy prices.

\subsection{Manufacturing Processes and Energy Use}

Corn wet milling is an energy-intensive industry because it is a wet process that produces dry products. In the first step, corn is soaked in water to loosen the corn's component materials - protein, gluten and fiber - and throughout the process, water is used as a medium for separating these components. For many of the products, dewatering, evaporating and drying are required, and these often entail the use of large amounts of energy. In addition, significant amounts of energy are required to power the large motors for grinding after degermination, as well as the blowers and pumps for those facilities that have biological waste treatment. Table 5 summarizes the electricity, steam and fuel used in corn wet milling for each process step.

Table 5: Estimated energy consumption for processes in corn wet milling operations, based on a 100,000 bushel/day facility. ${ }^{1}$

\begin{tabular}{|c|c|c|c|c|c|c|c|}
\hline Process & $(\mathbf{H P})^{5}$ & $\begin{array}{l}\text { Electricit } \\
(\mathrm{kWh})^{5}\end{array}$ & $(B t u / b u)^{5}$ & $\begin{array}{r}\mathrm{St} \\
(\mathbf{L b} / \mathbf{b u})^{5}\end{array}$ & $\begin{array}{l}\text { eam } \\
(B t u / b u)^{5}\end{array}$ & $\begin{array}{c}\text { Fuel } \\
(\text { Btu/bu) }\end{array}$ & $\begin{array}{c}\text { Primary } \\
\text { Energy }^{2} \\
(\mathrm{Btu} / \mathrm{bu})^{5}\end{array}$ \\
\hline Corn receiving & 695 & 12443 & 425 & & & & 1,308 \\
\hline Steeping & 350 & 6266 & 214 & 2.52 & 3,150 & & 3,809 \\
\hline Steepwater evaporation & 860 & 15397 & 525 & 15.61 & 19,513 & & 21,131 \\
\hline Germ recovery $\left(1^{\text {st }}\right.$ grind $)$ & 1,115 & 19963 & 681 & & & & 2,098 \\
\hline Germ recovery ( $2^{\text {nd }}$ grind $)$ & 570 & 10205 & 348 & & & & 1,072 \\
\hline Germ recovery (germ washing) & 40 & 716 & 24 & & & & 75 \\
\hline Germ dewatering and drying & 720 & 12891 & 440 & 2.74 & 3,425 & 3,355 & 8,135 \\
\hline Fiber recovery ${ }^{3}$ & 3,530 & 63201 & 2156 & & & & 6,642 \\
\hline Fiber dewatering & 620 & 11100 & 379 & & & & 1,167 \\
\hline Protein (gluten) recovery ${ }^{4}$ & 1,635 & 29273 & 999 & & & & 3,076 \\
\hline Gluten thickening and drying & 840 & 15039 & 513 & & & 3,557 & 5,137 \\
\hline Starch washing & 785 & 14055 & 480 & & & & 1,477 \\
\hline Starch dewatering and drying & 4,375 & 78330 & 2673 & & & 27,000 & 35,232 \\
\hline Gluten feed dryer & 1,595 & 28557 & 974 & & & 22,418 & 25,419 \\
\hline Total & 17,730 & $\mathbf{3 1 7 , 4 3 8}$ & 10,831 & 20.87 & 26,088 & 56,330 & 115,777 \\
\hline
\end{tabular}

${ }^{1}$ Data is estimated based on the following assumptions: capacity of 100,000 bushel/day; modern plant; operating 24 hours per day; feed house integrated to maximize energy efficiency; incoming fresh water to starch washing heated with waste heat; compressed air demands for pneumatic controls (approx. $2000 \mathrm{ft}^{3} / \mathrm{hr}$ or $15 \mathrm{HP}$ ) not included in analysis

${ }^{2}$ Primary energy accounts for steam, fuel and electricity use, as well as electricity transmission and distribution losses. We use a conversion factor of 3.08 to convert from final to primary electricity use based on average US power plant heat rates. To convert $\mathrm{HP}$ to $\mathrm{kWh}$ use the conversion factor $17.9 \mathrm{kWh} / \mathrm{HP}$. To convert from $\mathrm{kWh}$ to Btu/bu use the conversion factor $0.034 \mathrm{Btu} / \mathrm{bu} / \mathrm{kWh}$ (based on a 100,000 bushel/day plant). To convert from lb-steam/bu to Btu/bu use the conversion factor 1,250 Btu/lb steam.

${ }^{3}$ Fiber recovery includes mills, screens, tanks and pumps for separation of the fiber

${ }^{4}$ Protein (gluten) recovery includes cyclones, centrifuges, tanks and pumps for separation of the gluten from starch Source: Blanchard (1992); Wideman (2000); Eckhoff (2002c)

${ }^{5}$ To convert from $\mathrm{kWh}$ to GJ, multiply by $3.6^{*} 10^{-3} \mathrm{GJ} / \mathrm{kWh}$. To convert from Btu/bu to $\mathrm{GJ} / \mathrm{kg}$, first multiply by $1.055^{*} 10^{-6} \mathrm{GJ} / \mathrm{Btu}$, then divide by $25.4 \mathrm{~kg} / \mathrm{bu}$. 
The relative importance of electricity, in addition to the high steam demand in the sector has prompted investment into the co-generation of onsite electricity and steam at various manufacturing facilities. In fact, most corn milling plants generate both electrical and thermal energy burning coal, in boilers using steam turbines. A few generate only steam and purchase all electricity. Cogenerated electricity (the production of both heat and power, also called combined heat and power or CHP) in 1998 was 1,871 million kWh (EIA, 2001). Accounting for all of the electricity uses (net demand), cogenerated electricity accounts for $21 \%$ of the total electricity used onsite ${ }^{7}$. Although this share of cogenerated electricity is lower than it was in 1994 (23\%), it is still relatively high compared to other industries in the U.S.

Electricity is mostly used for pumping, grinding, separating and drying the corn products. Fuel is used either to make steam or for direct drying. Steam is used for evaporation, drying and maintaining process temperatures, as well as fermentation, extraction, ethanol recovery and for jetting or jet conversion of starch in refineries. Flue gas is used for drying and stillage processing (Shapouri et al., 1995; Drescher, 1997). Figure 9 lists some of the key process steps and their relative values for energy consumption, from steeping through starch drying.

\section{Figure 9: Main corn wet milling process steps and their respective percentage of energy usage}

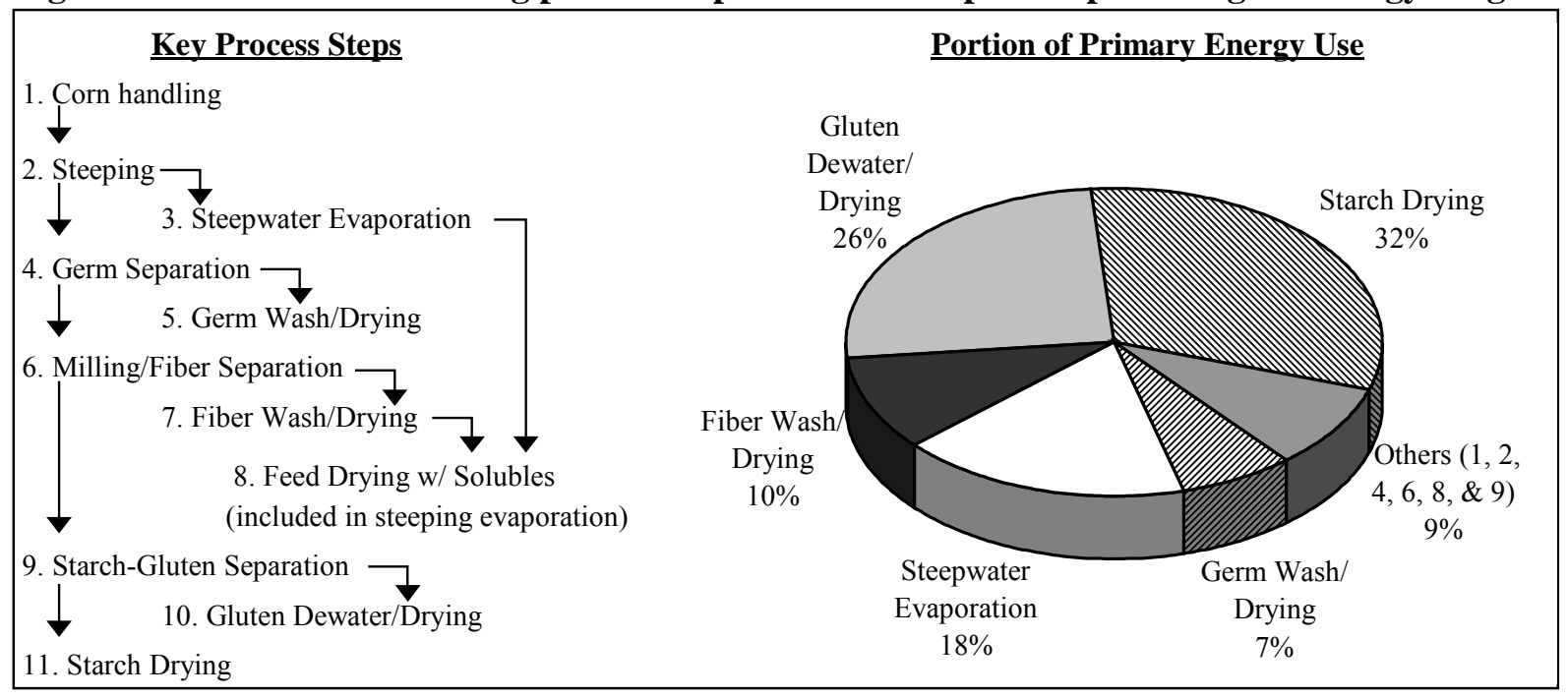

Source: Eckhoff (2001); Blanchard (1992); Wideman (2000); Eckhoff (2002c)

From Figure 9 it is clear that processes for dewatering, drying and evaporation are key to the energy use patterns for the industry. To help reduce energy consumption, and also to improve product yields, it is desirable for the industry to use as little water as possible throughout the production process. To accomplish this, the industry relies on the countercurrent concept. In this approach fresh water is introduced to the system at only one place, i.e. the last step, starch washing. The water recovered from starch washing is used in the previous step, and so on, so that the water in which corn steeps is the same water that was introduced during starch washing. In this way, the plants minimize water usage and energy required for evaporation and drying.

The countercurrent concept is used with the various process steps as well. For example, the most common arrangement for starch washing uses 9 to 15 stages of hydrocyclones. Fresh water is added to the last stage, and the overflow from that stage is added to the second last stage, and so on. Similarly, steeping of

\footnotetext{
${ }^{7}$ Net demand accounts for the total uses of electricity onsite and reflects the fact that some of the purchased fuels are used to produce electricity for internal consumption. In 1998, net electricity use (purchases) was 24 TBtu (7,032 million $\mathrm{kWh}$ ) while net demand was $30 \mathrm{TBtu}(8,954$ million $\mathrm{kWh})$.
} 
corn takes place in a series of stainless steel tanks. The "freshest" water, which will be water discarded from steps further along in the process, is introduced to a tank where corn has been soaking for nearly its entire steeping period. The water that this had been steeping in is passed to the tank where corn has been steeping the second longest, and so on, ensuring that the water that has been in the system the longest and has steeped with every tank of corn - is added to the tank where fresh corn is introduced and begins the process. After steeping the freshest corn for a period, this water, which has been in the production process for the longest, is evaporated so that all the soluble materials it picked up along the way are recovered in this steep corn liquor.

This countercurrent system reduces the total amount of water used, and thereby reduces the amount of dewatering and evaporation that will be needed to attain the highest product yield. 


\section{Energy Efficiency Options in Corn Wet Milling}

Opportunities exist within U.S. corn wet milling plants to improve energy efficiency while maintaining or enhancing productivity. Improving energy efficiency at a corn wet milling plant should be approached from several directions. First, corn wet milling uses energy for equipment such as motors, pumps, and compressors. These important components require regular maintenance, good operation and replacement, when necessary. Thus, a critical element of plant energy management involves the efficient control of cross-cutting equipment that powers the production process of a plant. A second and equally important area is the proper and efficient operation of the processes. Process optimization and ensuring the most productive technology is in place are key to realizing energy savings in a plant's operation. Finally, throughout a corn wet milling plant, there are many processes in operation at the same time. Coordinating their efficiency and operation is necessary to ensure energy savings are realized. If a corporation operates more than one mill, energy management can be more complex than just considering the needs of a single plant. Whether for a single plant for an entire corporation, establishing a strong organizational energy management framework is important to ensure that energy efficiency measures are implemented effectively.

The sections below categorize energy efficiency measures by their utility systems (general, motors, compressed air, heat and steam distribution, lighting, HVAC, material handling) or by process (feed streams, steeping, fermentation, dewatering, drying and evaporation and membranes (alternative to drying)). Case studies for U.S. corn wet milling plants with specific energy and cost savings data are included where available. For other measures, comparable data from similar facilities, such as in other food processing industries, or for corn wet milling facilities around the world, are provided. This analysis excludes opportunity costs (such as down time for equipment replacement) and the cost associated with the replacement of non-depreciated equipment because these numbers vary among individual plants and may be as low as zero for some. When available data exists, simple payback period as a first measure of profitability was calculated. Better methods exist for determining profitability, such as return on investment or life cycle analysis. However, these methods often require much more data than are available through our research. It is expected that the reader will use the payback period as a first criterion to determine whether or not to pursue further research on profitability of the measure.

For corn wet milling plants in the U.S., actual payback and savings for the measures will vary, depending on plant configuration and size, manufactured products, operating characteristics and location. The values presented in this review are offered as guidelines since only a detailed study of a specific location can produce reliable estimates for that plant. Wherever possible, a range of savings and paybacks found under varying conditions is provided. Table 6 lists energy efficiency measures that are process-specific, characterized by the process to which they apply. Table 7 similarly lists energy efficiency measures that are general utility or cross-cutting measures, characterized by the system to which they apply.

Although technological changes in equipment can help to reduce energy use, changes in staff behavior and attitude may have a greater impact. Staff should be trained in both skills and the company's general approach to energy efficiency in their day-to-day practices. Personnel at all levels should be aware of energy use and objectives for energy efficiency improvement. Often this information is acquired by lower level managers but not passed to upper management or down to staff (Caffal, 1995). Programs with regular feedback on staff behavior, such as reward systems, have had the best results. Though changes in staff behavior, such as switching off lights or closing windows and doors, often save only small amounts of energy at one time, taken continuously over longer periods they may have a much greater effect than more costly technological improvements. Most importantly, companies need to institute strong energy management programs that oversee energy efficiency improvement across the corporation. An energy management program will see to it that all employees actively contribute to energy efficiency 
improvements. Further details for these programs can be found in Section 5.1 under "Energy Management and General Equipment/Utilities Approaches."

Participation in voluntary programs like the EPA ENERGY STAR program, or implementing an environmental management system such as ISO 14001 can help companies track energy and implement energy efficiency measures. One ENERGY STAR partner noted that combining the energy management programs with the ISO 14001 program has had the largest effect on saving energy at their plants. 
Table 6: Cross-cutting (utilities) energy efficiency measures for the corn wet milling industry.

\begin{tabular}{|lc|}
\hline \multicolumn{2}{|c|}{ General Equipment/Utility Approaches } \\
\hline $\begin{array}{l}\text { Energy management systems and programs } \\
\text { Combined heat and power }\end{array}$ & Alternative fuels \\
& Anaerobic wastewater treatment \\
\hline Sizing & Motors \\
Higher efficiency motors & Adjustable speed drives \\
Switched reluctance drives & Variable voltage controls \\
\hline & \\
\hline Operations and Maintenance & Pumps \\
Monitoring & Adjustable Speed Drives \\
Reduce need & Avoid throttling valves \\
More efficient pump & Correct sizing of pipes \\
Correct sizing of pump(s) & Replace belt drives \\
Use multiple pumps & Precision castings, surface coatings or polishing \\
Trimming impeller (or shaving sheaves) & Sealings \\
Controls & Curtailing leakage through clearance reduction
\end{tabular}

Controls

\begin{tabular}{|c|c|}
\hline \multicolumn{2}{|c|}{ Compressed air } \\
\hline Maintenance & Properly size regulators \\
\hline Monitoring & Pipe diameter sizing \\
\hline Leak reduction & Heat recovery \\
\hline Inlet air temperature reduction & Natural gas engine-driven air compressors \\
\hline Pressure dew point maximization (air intake) & System improvements \\
\hline \multicolumn{2}{|c|}{ Compressor motors } \\
\hline Adjustable speed drives & Higher efficiency motors \\
\hline \multicolumn{2}{|c|}{ Lighting } \\
\hline Controls & Replace metal halide HID with high-intensity \\
\hline Daylighting & fluorescents \\
\hline Replace incandescent with fluorescent or CFL & Replace magnetic with electronic ballasts \\
\hline Replace T-12 with T-8 or metal halides & Reflectors \\
\hline $\begin{array}{l}\text { Replace mercury with metal halide or high } \\
\text { pressure sodium }\end{array}$ & $\begin{array}{l}\text { Light emitting diodes (LEDs) or radium strips } \\
\text { System improvements }\end{array}$ \\
\hline \multicolumn{2}{|c|}{ Materials handling/tools } \\
\hline \multicolumn{2}{|l|}{ High efficiency belts } \\
\hline \multicolumn{2}{|c|}{ HVAC } \\
\hline $\begin{array}{l}\text { Electronic controls } \\
\text { Non-production hours setback temperatures }\end{array}$ & Ventilation and cooling design improvements \\
\hline \multicolumn{2}{|c|}{ Heat and steam distribution-Boilers } \\
\hline Improve process control & Recover heat from flue gas \\
\hline Reduce flue gas & Return condensate \\
\hline Reduce excess air & Recover steam from blowdown \\
\hline Correct sizing in design & Replace obsolete burners by new optimized \\
\hline Improve insulation & boilers \\
\hline Boiler maintenance & \\
\hline \multicolumn{2}{|c|}{ Heat and steam distribution-Distribution } \\
\hline Improve insulation & Monitor steam traps automatically \\
\hline Maintain insulation & Repair leaks \\
\hline Improve steam traps & Recover flash steam \\
\hline Maintain steam traps & \\
\hline
\end{tabular}

Included in Future technologies, Section 5.8. 
Table 7: Process-related energy efficiency measures for the corn wet milling industry.

\begin{tabular}{|c|c|}
\hline \multicolumn{2}{|c|}{ Feed Streams } \\
\hline Corn hybrids & \\
\hline \multicolumn{2}{|c|}{ Steeping } \\
\hline $\begin{array}{l}\text { Intermittent milling and dynamic steeping } \\
\text { Use of gaseous sulfur dioxide }^{1}\end{array}$ & $\begin{array}{l}\text { Alkali steeping }^{1} \\
\text { Use enzymes during steeping to reduce time }^{1}\end{array}$ \\
\hline \multicolumn{2}{|c|}{ Fermentation and Ethanol Production } \\
\hline $\begin{array}{l}\text { Improving yeast fermentation } \\
\text { Bacterial fermentation }\end{array}$ & $\begin{array}{l}\text { Molecular sieves } \\
\text { Enzymes used for hydrolysis }{ }^{1}\end{array}$ \\
\hline \multicolumn{2}{|c|}{ Mechanical dewatering } \\
\hline $\begin{array}{l}\text { Germ dewatering } \\
\text { Starch dewatering filters }\end{array}$ & Fiber dewatering \\
\hline \multicolumn{2}{|c|}{ Drying Technology } \\
\hline $\begin{array}{l}\text { Process integration/pinch technology } \\
\text { Controls on heaters between steps } \\
\text { Reusing waste heat } \\
\text { Replacing dryer with more efficient one } \\
\text { Regenerative thermal oxidizers } \\
\text { Direct use of gas turbine offgases for drying }\end{array}$ & $\begin{array}{l}\text { Multiple effect evaporators } \\
\text { Thermal and mechanical vapor recompression } \\
\text { Operations and maintenance } \\
\text { Improve process control } \\
\text { Reduction in air supply rate } \\
\text { Challenging customer requirements }\end{array}$ \\
\hline \multicolumn{2}{|c|}{ Membranes } \\
\hline $\begin{array}{l}\text { Reverse osmosis }(\mathrm{RO}) \text { for steepwater } \\
\text { concentration } \\
\text { Microfiltration }(\mathrm{MF}) \text { for steepwater } \\
\text { concentration }\end{array}$ & $\begin{array}{l}\text { RO or other membrane to concentrate syrups } \\
\text { Membranes to purify syrups } \\
\text { Membrane filtration or RO to recycle starch } \\
\text { wash water or reduce water in steeping }\end{array}$ \\
\hline
\end{tabular}

\subsection{Energy Management and General Equipment/Utilities Approaches.}

Improving energy efficiency in corn wet milling should be approached from several directions. A strong, corporate-wide energy management program is essential. Cross-cutting equipment and technologies such as compressed air and motors, common to most plants and manufacturing industries including corn wet milling, present well-documented opportunities for improvement. Equally important, the production process can be fine-tuned to produce additional savings. Below are some measures concerning these and other general cross-cutting utilities that apply to the corn wet milling industry.

Energy management programs. Changing how energy is managed by implementing an organizationwide energy management program is one of the most successful and cost-effective ways to bring about energy efficiency improvements.

An energy management program creates a foundation for improvement and provides guidance for managing energy throughout an organization. In companies without a clear program in place, opportunities for improvement may be known but may not be promoted or implemented because of organizational barriers. These barriers may include a lack of communication among plants, a poor understanding of how to create support for an energy efficiency project, limited finances, poor accountability for measures or perceived change from the status quo. Even when energy is a significant cost for an industry, many companies still lack a strong commitment to improve energy management.

EPA, through ENERGY STAR, has worked with many of the leading industrial manufacturers to identify the basic aspects of an effective energy management program. ${ }^{8}$ The major elements are depicted in Figure 10 .

\footnotetext{
${ }^{8}$ Read about strategic energy management at www.energystar.gov.
} 


\section{Figure 10: Main elements of a strategic energy management program}

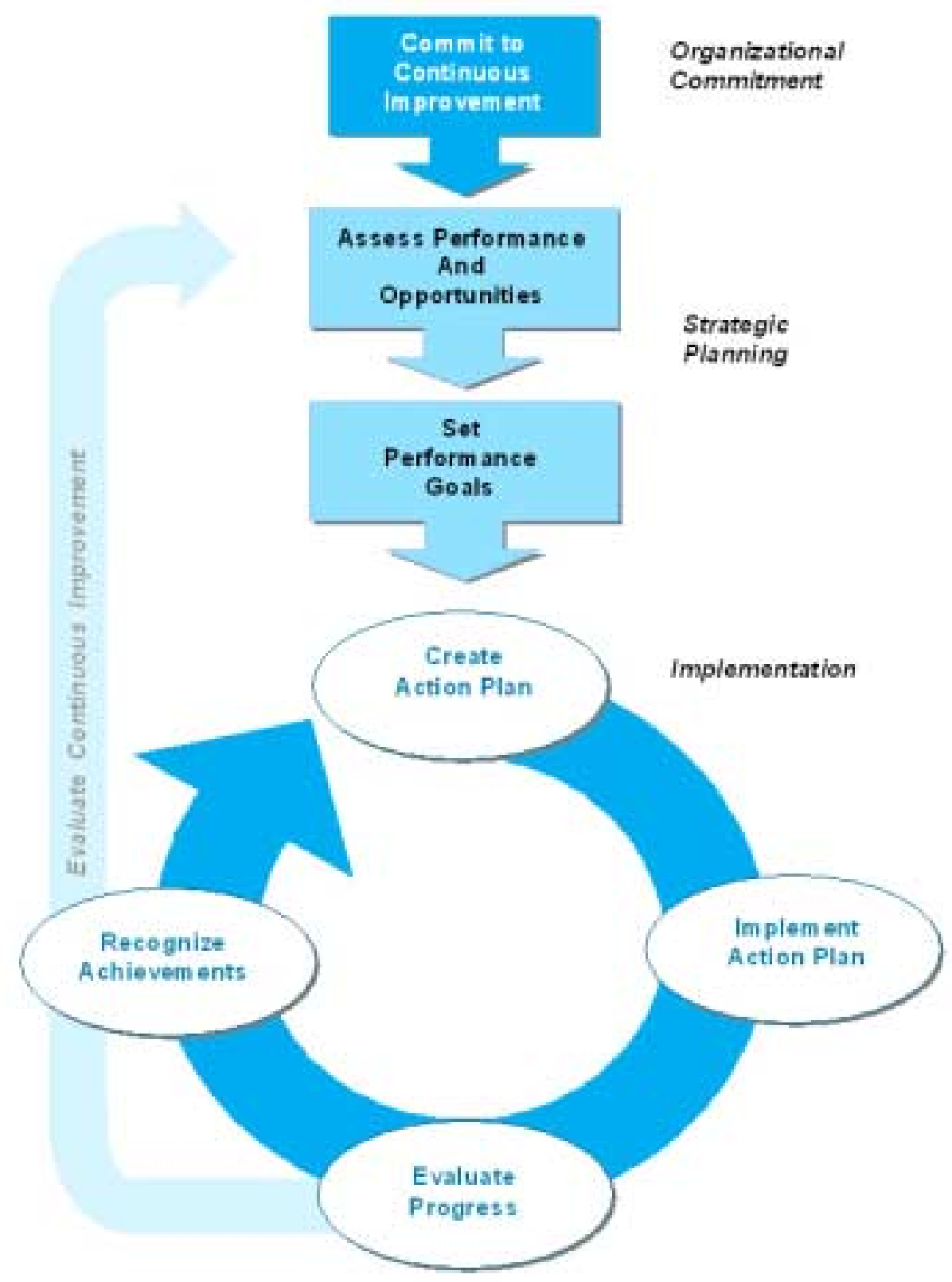

A successful program in energy management begins with a strong commitment to continuous improvement of energy efficiency. This typically involves assigning oversight and management duties to an energy director, establishing an energy policy, and creating a cross-functional energy team. Steps and procedures are then put in place to assess performance, through regular reviews of energy data, technical assessments and benchmarking. From this assessment, an organization is then able to develop a baseline of performance and set goals for improvement.

Performance goals help to shape the development and implementation of an action plan. An important aspect for ensuring the successes of the action plan is involving personnel throughout the organization. 
Personnel at all levels should be aware of energy use and goals for efficiency. Staff should be trained in both skills and general approaches to energy efficiency in day-to-day practices. In addition, performance results should be regularly evaluated and communicated to all personnel, recognizing high performers. Some examples of simple tasks employees can do are outlined in Appendix C.

Evaluating performance involves the regular review of both energy use data and the activities carried out as part of the action plan. Information gathered during the formal review process helps in setting new performance goals and action plans and in revealing best practices. Establishing a strong communications program and seeking recognition for accomplishments are also critical steps. Strong communication and receiving recognition help to build support and momentum for future activities.

A quick assessment of an organization's efforts to manage energy can be made by comparing the current program against the table contained in Appendix D.

Energy monitoring systems. The use of energy monitoring and process control systems can play an important role in energy management and in reducing energy use. These may include sub-metering, monitoring and control systems. They can reduce the time required to perform complex tasks, often improve product and data quality and consistency and optimize process operations. Typically, energy and cost savings are around 5\% or more for many industrial applications of process control systems. These savings apply to plants without updated process control systems; many U.S. plants may already have modern process control systems in place to improve energy efficiency.

Amylum Nederland BV (Koog aan de Zaan, the Netherlands) installed a computerized process control system in their corn wet milling plant in 1994. The system measures and provides information on energy flows on a real-time basis, as well as over time for all major process units. This is integrated with a monitoring and targeting system. Installation of the control system has resulted in overall energy savings of $10 \%$ for the total plant within a period of six months (NOVEM, 1996). The actual savings exceeded the expected savings of 5\% (NOVEM, 1993). The payback period under the conditions in the Netherlands was 3.5 years for an investment of $\$ 750,000$ (1994). Under current U.S. conditions, this is likely to result in a slightly longer payback period for similarly-sized plants due to lower fuel costs. For large plants, the payback period may be shorter.

Specific energy savings and payback periods for overall adoption of an energy monitoring system vary greatly from plant to plant and company to company.

Support for a business energy management program can come from outside sources as well. Some utility companies work with industrial clients to achieve energy savings. In these cases, utility personnel work directly with managers onsite to better identify and implement programs that are more effective energy management programs and measures for the particular situation of the facility.

Combined heat and power (CHP). For industries like corn wet milling that have process heat and steam and electricity requirements, the use of combined heat and power systems may be able to save energy and reduce pollution. Cogeneration plants are significantly more efficient than standard power plants because they take advantage of what are losses in standard plants by utilizing waste heat. In addition, transportation losses are minimized when CHP systems are located at or near the plant. Many corn wet milling plants have already installed CHP systems. About $21 \%$ of the electricity used at corn wet milling plants is cogenerated onsite.

Often, utility companies will work with a company to develop CHP for their plants. In this scenario, the utility company owns and operates the system for the mill; therefore, the company avoids the capital 
expenditures associated with CHP projects, but gains the benefits of a more energy efficient system of heat and electricity.

In the corn wet milling industry, hot water and thermal energy are used throughout the process beginning at the steeping stage all the way through until the starch is dried, while electricity is used for pumping, grinding, separating and drying the corn. In addition to the energy savings, CHP also has comparable or better availability of service than utility generation. In the automobile industry, for example, typical CHP units are reported to function successfully for 95 to $98 \%$ of planned operating hours (Price and Ross, 1989). For installations where initial investment is large, potential multiple small-scale CHP units distributed to points of need could be used cost effectively.

The difficulty with CHP is maintaining the proper balance. Often electricity is purchased to supplement CHP generated power. For a new plant or a major rebuild, however, gas-turbine generation, which uses turbine discharge gases to generate process steam, or high-pressure turbines can be used. Innovative gas turbine technologies may make CHP more attractive for sites with large variations in heat demand. A pinch technology study should be used to find the optimal arrangement (see process integration/pinch technology section).

Currently, most large-scale mills use steam turbine systems. Switching to natural gas-based systems will improve the power-output and efficiency of the CHP system, due to the increased power production capability. Although the overall system efficiency of a steam turbine based system $(80 \%$, HHV) is higher than that of a gas turbine-based system $(74 \%, \mathrm{HHV})$, the electrical efficiency of a gas turbine-based system is much higher (27 to $37 \%$ for typical industrial scale gas turbines) (Energy Nexus Group, $2002 \mathrm{a}, \mathrm{b}){ }^{9}$ The power-to-heat ratio of a steam turbine based system is very low (limited to about 0.2 ), limiting the output of electricity. The power-to-heat ratio of a gas turbine-based system is much higher (between 0.5 and 1.0), producing more power for the same amount of fuel. This may improve the profitability of a natural gas-based CHP unit, depending on the price of power to the plant. Modern gasbased CHP systems have low maintenance costs, and will reduce the nitrous oxides $\left(\mathrm{NO}_{\mathrm{x}}\right), \mathrm{SO}_{2}$, carbon dioxide $\left(\mathrm{CO}_{2}\right)$ and particulate matter (PM) emissions from the power plant considerably, especially when replacing a coal-fired boiler (Energy Nexus Group, 2002a,b).

Combined cycles (combining a gas turbine and a back-pressure steam turbine) offer flexibility for power and steam production at larger sites, and potentially at smaller sites as well. Steam-injected gas turbines (STIG, or Cheng cycle) can absorb excess steam, e.g. due to seasonal reduced heating needs, to boost power production by injecting the steam in the turbine. The size of typical STIGs starts around 5 MWe. STIGs are found in various industries and applications, especially in Japan and Europe, as well as in the U.S. International Power Technology (CA), for example, installed STIGs at Sunkist Growers in Ontario (CA) in 1985. By the early to mid-1980s in the Netherlands, four starch plants had installed CHP units with gas turbines: Avebe at Foxhol (potatoes); CPC's Sas van Gent (corn); ZBB's Bijenkorf - Zaandam (corn) and Cargill's Bergen op Zoom (corn). They varied in size from 3.6 MWe to $16 \mathrm{MWe}$. The use of gas turbines for drying and power generation is discussed in more detail in Section 5.6.

Generally, the energy savings of replacing a traditional system of a boiler for steam generation, and power production in a stand-alone power plant, by a standard gas turbine-based CHP-unit is estimated at 20$30 \%$. The efficiency gain will be higher when replacing older or less maintained boilers.

\footnotetext{
${ }^{9}$ In the U.S., efficiencies are generally expressed using the Higher Heating Value (HHV), while internationally Lower Heating Value (LHV) is used. Gas turbine manufacturers generally also use the LHV-value to express efficiency. HHV includes the condensation heat contained in the hot water, while LHV excludes this. Due to the higher hydrogen content of natural gas, the difference between efficiencies expressed in HHV and LHV is higher than for coal. When expressed in LHV, the overall system efficiencies for both systems would be comparable.
} 
Shapouri et al. (1995), estimate CHP is economically justified for corn wet milling plants that have a production capacity of 30 million gallons of ethanol per year or greater. Assuming a typical product yield of 2 to 3 gallons of ethanol per bushel of corn, this translates to a plant capacity of 10 to 15 million bushels of corn per year or 30,000 to 40,000 bushels per day, which account for most plants in the U.S. today (see Appendix A).

Use alternative fuels. Some industrial processes produce waste products that can be incinerated exothermically and thus provide an ideal fuel for the boiler. The energy saved by using some of these waste streams (particularly chemical waste streams) must be balanced against the potential release of environmental toxins into the atmosphere (Ganapathy, 1995).

If a landfill is nearby, landfill gas could also be burned in the boilers. Landfill gas consists mostly of methane $\left(\mathrm{CH}_{4}\right)$ and $\mathrm{CO}_{2}$. The EPA estimates that more than 700 landfills across the U.S. could install economically viable energy recovery systems. Plants must be located near viable landfills to implement this measure in a cost-effective manner.

The Cargill Company of Bergen op Zoom (the Netherlands), a corn and wheat processing company, uses biogas in its afterburners (Caddet, 1995). The biogas is produced by their on-site wastewater treatment unit through anaerobic digestion of organic material in the water (see also, Anaerobic wastewater treatment section below). Afterburners are used to remove odorous vapors produced during the drying of semi-finished products. Previously, the vapors were removed by a natural gas-fired afterburner. The new system uses biogas produced by anaerobic digestion of organic material in the water at an on-site wastewater treatment unit. Preheating the biogas and reducing relative humidity to below $60 \%$ in the afterburner, a point where acid formation is no longer a problem, avoids the formation of sulfuric acid. The project saves $1,000,000 \mathrm{Nm}^{3}$ of natural gas annually (equivalent to $33 \mathrm{TBtu} /$ year), with a payback period of 1.7 years. Kröner-Stärke, an organic wheat processing plant, also uses the methane from its wastewater treatment plant in its production process, saving primary energy (Kröner, 2002).

Anaerobic wastewater treatment. Industrial wastewater is typically treated by aerobic systems that remove contaminants prior to discharging the water. Use of aerobic systems may be disadvantageous because of their relatively high electricity use, large amounts of sludge produced and the reduction of dissolved oxygen in the water. Anaerobic wastewater treatment is an alternative method for cleaning industrial wastewater that converts organic compounds in the wastewater into a biogas (methane) that can be used on site. Anaerobic organisms produce trace amounts of hydrogen sulfide $\left(\mathrm{H}_{2} \mathrm{~S}\right)$ that must be removed by scrubbing.

Biothane Corporation currently sells an upflow anaerobic sludge blanket (UASB) that was developed in the late 1960s and is currently used in the starch industry worldwide (le Roux and Kehl, 1999). They claim typical purification efficiencies of 80 to $95 \%$ for biochemical oxygen demand (BOD), producing about $10 \%$ of the sludge normally produced by aerobic systems. In addition to the benefits described above, Biothane claims their systems are smaller and save in capital costs. Volumetric loading rates vary depending on the system, between 10 and $40 \mathrm{~kg} \mathrm{COD} / \mathrm{m}^{3} /$ day.

Ogilvie flour mills use an anaerobic treatment system in their plant in Candic, Quebec (Canada). Wastewater is treated in the system and biogas is produced and then fed to boilers to heat the building and preheat the intake air for the dryers. The biogas generates $300 \mathrm{GJ} /$ day $(280 \mathrm{MBtu} /$ day $)$ of energy, saving the equivalent in natural gas formerly used (see also, Use alternative fuels section). This corresponds to \$327,000 1990 U.S./year (CADDET, 1991). The complete system was installed for \$770,000 1990 U.S., yielding a payback of 2.3 years. An anaerobic system was installed during an expansion of a midwestern corn wet milling plant in the U.S. (Grant et al., 1997). Although energy savings are not available, effluent limits have been met and overall COD and BOD removal averages were 98 and 99\%, respectively. The 
system also generates no sludge. Other examples of applications of this technology can be found in Martin et al. (2000a).

In a more recent development in beer brewing wastewater treatment, Ince et al. (2001) report on piloting the use of a crossflow ultrafiltration membrane in anaerobic digester systems, also known as the anaerobic digestion ultrafiltration process (ADUF). This system may have several advantages to traditional anaerobic systems, including reduced equipment (no sedimentation tank), minimized required reactor volume and improved control. However, only pilot data are currently available (Ince et al. 2001).

\subsubsection{Motors}

Motors are used in the milling and grinding processes in a corn wet milling plant. The following section applies to these systems or any other systems that use motors. When available, we listed specific examples detailing the corn wet milling process to which the measure has been applied and to what success.

Using a "systems approach" that looks at the entire motor system (pumps, compressors, motors, and fans) to optimize supply and demand of energy services often yields the most savings. For example, in pumping, a systems approach analyzes both the supply and demand sides and how they interact, shifting the focus of the analysis from individual components to total system performance. The measures we identify below reflect aspects of this system approach including matching speed and load (variable speed drives), sizing the system correctly, as well as upgrading system components. However, for optimal savings and performance, we recommend the systems approach. Pumps and compressors are both discussed in more detail in sections 5.1.2 and 5.1.3.

Sizing of motors. Motors and pumps that are sized inappropriately result in unnecessary energy losses. Where peak loads can be reduced, motor size can also be reduced. Correcting for motor oversizing saves $1.2 \%$ of their electricity consumption (on average for the U.S. industry), and even larger percentages for smaller motors (Xenergy, 1998).

Higher efficiency motors. High efficiency motors reduce energy losses through improved design, better materials, tighter tolerances and improved manufacturing techniques. With proper installation, energyefficient motors run cooler and consequently have higher service factors, longer bearing and insulation life and less vibration. Yet, despite these advantages, less than $8 \%$ of U.S. industrial facilities address motor efficiency in specifications when purchasing a motor (Tutterow, 1999).

Typically, high efficiency motors are economically justified when exchanging a motor that needs replacement, but are not economically feasible when replacing a motor that is still working (CADDET, 1994). Sometimes though, according to a case study by the Copper Development Association (CDA, 2000), even working motor replacements may be beneficial. The payback for individual motors varies based on size, load factor and running time. The best savings are achieved on motors running for long hours at high loads. When replacing retiring motors, paybacks are typically less than one year from energy savings alone (LBNL et al., 1998).

To be considered energy efficient in the U.S., a motor must meet performance criteria published by the National Electrical Manufacturers Association (NEMA). However, most manufacturers offer lines of motors that significantly exceed the NEMA-defined criteria, even those defined by NEMA as energyefficient (DOE, 2001b). NEMA and other organizations have created the "Motor Decisions Matter" campaign to market NEMA approved premium efficient motors to industry (NEMA, 2001).

Even these premium efficiency motors may have low a payback period. According to data from the CDA, the upgrade to high efficiency motors, as compared to motors that achieve the minimum efficiency as specified by the Energy Policy Act, have paybacks of less than 15 months for $50 \mathrm{hp}$ motors (CDA, 2001). 
Because of the fast payback, it usually makes sense not only to buy an energy-efficient motor but also to buy the most efficient motor available (LBNL, 1998).

Replacing a motor with a high efficiency motor is often a better choice than rewinding a motor. The practice of rewinding motors currently has no quality or efficiency standards. To avoid uncertainties in performance of the motor, a new high efficiency motor can be purchased instead of rewinding one.

One case study in the corn wet milling industry (U.S.) indicated using electric motors that are more efficient would result in about 1\% annual electricity savings and a payback period of about 2.9 years (IAC, 2001). ${ }^{10}$ Another similar case study indicated a payback of 5.1 years, but with greater annual electric savings of about $1.5 \%$.

Adjustable speed drives (ASDs)/ variable speed drives (VSDs). ASDs better match speed to load requirements for motor operations. Energy use on many centrifugal systems like pumps, fans and compressors is approximately proportional to the cube of the flow rate. Hence, small reductions in flow that are proportional to motor speed can sometimes yield large energy savings. Although they are unlikely to be retrofitted economically, paybacks for installing new ASD motors in new systems or plants can be as low as 1.1 years (Martin et al., 2000a). The installation of ASDs improves overall productivity, control and product quality, and reduces wear on equipment, thereby reducing future maintenance costs.

ASDs were added to a large extract fan motor at the Trafford Flour Mill in Manchester (UK). The investment cost was 12,900 GBP (\$23,700 1992 US), and the savings expected were 114,342 kWh of electricity annually when using automatic speed control, equaling 4,900 GBP per year (\$9,000 1992 US) (Best Practice Programme, 2002a). Some operators had overridden the automatic speed control, so total actual savings were less $(82,320 \mathrm{kWh})$, leading to a payback of 3.6 years, instead of the anticipated 2.6 years.

Variable voltage controls (VVCs). In contrast to ASDs, which have variable flow requirements, VVCs are applicable to variable loads requiring constant speed. The principle of matching supply with demand, however, is the same as for ASDs.

\subsubsection{Pumps}

Pumping systems account for nearly $20 \%$ of the world's electrical energy demand (Hydraulic Institute and Europump, 2001; Xenergy, 1998). In the U.S., pumping systems account for about $24.8 \%$ of the electricity used in manufacturing, and $16.4 \%$ in the Food and Kindred Products (SIC 20) sector (Xenergy, 1998). The Food and Kindred Products sector alone has a potential energy savings of approximately 1,250 GWh per year for pump system improvements (Hydraulic Institute and Europump, 2001; Xenergy, 1998).

In the corn wet milling industry, about $9 \%$ of the electrical energy is used by pump systems (Wideman, 2000; Eckhoff, 2002c). Pumps are used throughout the entire corn wet milling plant to generate a pressure and move liquids. Studies have shown that over $20 \%$ of the energy consumed by these systems could be saved through equipment or control system changes (Xenergy, 1998).

\footnotetext{
${ }^{10}$ The Industrial Assessment Center (IAC) database shows a series of case studies where a particular technology was used. It gives a wide variety of information, including implementation costs and savings for each case. Using this information, we calculated a simple payback for each case. For applications with multiple case studies, we calculated an overall payback for that particular technology by averaging all the individual cases. We sampled only SIC code 2046.
} 
It is important to note that initial costs are only a fraction of the life cycle costs of a pump system. Energy costs, and sometimes operations and maintenance costs, are much more important in the lifetime costs of a pump system. In general, for a pump system with a lifetime of 20 years, the initial capital costs of the pump and motor make up merely $2.5 \%$ of the total costs (Best Practice Programme, 1998). Energy costs, however, make up about $95 \%$ of the lifetime costs of the pump. Maintenance costs compose the remaining $2.5 \%$. Hence, the initial choice of a pump system should be highly dependent on energy cost considerations rather than on initial costs.

Pumping systems consist of a pump, a driver, pipe installation and controls (such as adjustable speed drives or throttles) and are a part of the overall motor system, discussed in Section 5.1.1. The following section applies to all areas that use pumps. When available, specific case studies to which the measure has been applied and the level of success are described. Using a "systems approach" on the entire motor system (pumps, compressors, motors and fans) was also discussed in section 5.1.1. For example, higher efficiency motors also increase the efficiency of the associated pump by 2 to $5 \%$. In this section, the pumping systems are addressed; for optimal savings and performance, it is recommended that the systems approach incorporating pumps, compressors, motors and fans be used.

There are two main ways to increase pump efficiency, aside from reducing use. These are reducing the friction in dynamic pump systems, (not applicable to static or "lifting" systems) or adjusting the system so that it draws closer to the best efficiency point (BEP) on the pump curve (Hovstadius, 2002). Correct sizing of pipes, surface coatings or polishings and adjustable speed drives, for example, may reduce the friction loss, increasing energy efficiency. Correctly sizing the pump and choosing the most efficient pump for the applicable system will push the system closer to the best efficiency point on the pump curve.

Operations and maintenance. Inadequate maintenance at times lowers pump system efficiency, causes pumps to wear out more quickly and increases costs. Better maintenance will reduce these problems and save energy. Proper maintenance includes the following (Hydraulic Institute, 1994; LBNL et al., 1999):

- Replacement of worn impellers, especially in caustic or semi-solid applications.

- Bearing inspection and repair.

- Bearing lubrication replacement, once annually or semiannually.

- Inspection and replacement of packing seals. Allowable leakage from packing seals is usually between two and sixty drops per minute.

- Inspection and replacement of mechanical seals. Allowable leakage is typically one to four drops per minute.

- Wear ring and impeller replacement. Pump efficiency degrades from 1 to 6 points for impellers less than the maximum diameter and with increased wear ring clearances (Hydraulic Institute, 1994).

- $\quad$ Pump/motor alignment check.

Although energy savings for operations and maintenance are less than for other measures, estimated to be between 2 and $7 \%$ of pumping electricity (for the U.S. industry), paybacks are usually immediate to one year (Xenergy, 1998; OIT, 2002a).

Monitoring. Monitoring in conjunction with operations and maintenance can be used to detect problems and determine solutions to create a more efficient system. Monitoring can determine clearances that need be adjusted, indicate blockage, impeller damage, inadequate suction, operation outside preferences, clogged or gas-filled pumps or pipes, or worn out pumps. Monitoring should include:

- Wear monitoring 
- Vibration analyses

- Pressure and flow monitoring

- Current or power monitoring

- Differential head and temperature rise across the pump (also known as thermodynamic monitoring)

- Distribution system inspection for scaling or contaminant build-up

Reduce need. Holding tanks can be used to equalize the flow over the production cycle, enhancing energy efficiency and potentially reducing the need to add pump capacity. In addition, bypass loops and other unnecessary flows should be eliminated. Each of these steps saves 5 to $10 \%$ of pump system electricity consumption, on average for the U.S. industry (Easton Consultants, 1995). Total head requirements can also be reduced by lowering process static pressure, minimizing elevation rise from suction tank to discharge tank, reducing static elevation change by use of siphons and lowering spray nozzle velocities.

\subsubsection{Pump changes.}

More efficient pumps. According to inventory data, 16\% of pumps are more than 20 years old. Pump efficiency may degrade 10 to $25 \%$ in its lifetime (Easton Consultants, 1995). Newer pumps are 2 to $5 \%$ more efficient. However, industry experts claim the problem is not necessarily the age of the pump but that the process has changed and the pump does not match the operation. Replacing a pump with a new efficient one saves between 2 to $10 \%$ of its energy consumption (ACEEE, 1994). Higher efficiency motors have also been shown to increase the efficiency of the pump system 2 to $5 \%$ (Tutterow, 1999). See section 5.1.1 for more detail.

A number of pumps are available for specific pressure head and flow rate capacity requirements. Choosing the right pump often saves both in operating costs and in capital costs (of purchasing another pump). For a given duty, selecting a pump that runs at the highest speed suitable for the application will generally result in a more efficient selection as well as the lowest initial cost (Hydraulic Institute and Europump, 2001). Exceptions to this include slurry handling pumps, high specified speed pumps or where the pump would need a very low minimum net positive suction head at the pump inlet.

Correct sizing of pump(s) (matching pump to intended duty). Pumps that are sized inappropriately result in unnecessary losses. Where peak loads can be reduced, pump size can also be reduced. Correcting for pump oversizing saves 15 to $25 \%$ of electricity consumption for pumping (on average for the U.S. industry) (Easton Consultants, 1995). In addition, pump load may be reduced with alternative pump configurations and improved O\&M practices.

Where pumps are dramatically oversized, speed can be reduced with gear or belt drives or a slower speed motor. Paybacks for implementing these solutions are less than one year (OIT, 2002a).

The Welches Point Pump Station, a medium sized water treatment plant located in Milford (CT), as a participant in the Department of Energy's Motor Challenge Program, decided to replace one of their system's four identical pumps with one smaller model (Flygt, 2002). They found that the smaller pump could more efficiently handle typical system flows and the remaining three larger pumps could be reserved for peak flows. While the smaller pump needed to run longer to handle the same total volume, its slower pace and reduced pressure resulted in less friction-related losses and less wear and tear. Substituting the smaller pump has a projected savings of $36,096 \mathrm{~kW}$, more than $20 \%$ of the pump system's annual electrical energy consumption. Using this system at each of the city's 36 stations would result in energy savings of over $\$ 100,000$. In addition to the energy savings projected, less wear on the 
system results in less maintenance, less downtime and longer life of the equipment. The station noise is significantly reduced with the smaller pump.

Use multiple pumps. Often using multiple pumps is the most cost-effective and most energy-efficient solution for varying loads, particularly in a static head-dominated system. Installing parallel systems for highly variable loads saves 10 to $50 \%$ of the electricity consumption for pumping (on average for the U.S. industry) (Easton Consultants, 1995). Variable speed controls should also be considered for dynamic systems (see below). Parallel pumps also offer redundancy and increased reliability. One case study of a Finnish pulp and paper plant indicated that installing an additional small pump (a "pony pump"), running in parallel to the existing pump used to circulate water from the paper machine into two tanks, reduced the load in the larger pump in all cases except for startup. The energy savings were estimated at $\$ 36,500$ (or $486 \mathrm{MWh}, 58 \%$ ) per year giving a payback of 0.5 years (Hydraulic Institute and Europump, 2001).

Trimming impeller (or shaving sheaves). If a large differential pressure exists at the operating rate of flow (indicating excessive flow), the impeller (diameter) can be trimmed so that the pump does not develop as much head. In the food processing, paper and petrochemical industries, trimming impellers or lowering gear ratios is estimated to save as much as $75 \%$ of the electricity consumption for that pump (Xenergy, 1998).

In one case study in the chemical processing industry, the impeller was reduced from $320 \mathrm{~mm}$ to $280 \mathrm{~mm}$, which reduced the power demand by more than 25\% (Hydraulic Institute and Europump, 2001). Annual energy demand was reduced by 83 MWh (26\%). With an investment cost of $\$ 390$ (US), the payback on energy savings alone was 23 days. In addition to energy savings, maintenance costs were reduced, system stability was improved, cavitation reduced and excessive vibration and noise were eliminated.

In another similar case study, Salt Union Ltd., the largest salt producer in the UK, trimmed the diameter of the pump impeller at its plant from $320 \mathrm{~mm}$ to $280 \mathrm{~mm}$ (13 to 11 inches) (Best Practice Programme, 1996b). After trimming the impeller, they found significant power reductions of $30 \%$, or $197,000 \mathrm{kWh}$ per year (710 GJ/year), totaling 8,900 GBP (\$14,000 1994 US). With an investment cost of 260 GBP (\$400 1993 US), and maintenance savings of an additional 3,000 GBP (\$4,600 1994 US), this resulted in a payback of 8 days (11 days from energy savings alone). In addition to energy and maintenance savings, like the chemical processing plant, cavitation was reduced and excessive vibration and noise were eliminated. With the large decrease in power consumption, the $110 \mathrm{~kW}$ motor could be replaced with a $75 \mathrm{~kW}$ motor, with additional energy savings of 58GJ (about 16,000 kWh) per year.

Controls. The objective of any control strategy is to shut off unneeded pumps or reduce load until needed. Remote controls enable pumping systems to be started and stopped more quickly and accurately when needed, and reduce the required labor. In 2000, Cisco Systems (CA) upgraded the controls on its fountain pumps that turn off the pumps during peak hours (CEC and OIT, 2002). The wireless control system was able to control all pumps simultaneously from one location. The project saved $\$ 32,000$ and $400,000 \mathrm{kWh}$ annually, representing a savings of $61.5 \%$ of the fountain pumps' total energy consumption. With a total cost of $\$ 29,000$, the simple payback was 11 months. In addition to energy savings, the project reduced maintenance costs and increased the pumping system's equipment life. 


\subsubsection{Motor changes.}

Adjustable speed drives (ASDs). ASDs better match speed to load requirements for pumps where, as for motors, energy use is approximately proportional to the cube of the flow rate ${ }^{11}$. Hence, small reductions in flow that are proportional to pump speed may yield large energy savings. Although they are unlikely to be retrofitted economically, new installations may result in short payback periods. In addition, the installation of ASDs improves overall productivity, control and product quality, and reduces wear on equipment, thereby reducing future maintenance costs.

According to inventory data collected by Xenergy (1998), 82\% of pumps in U.S. industry have no load modulation feature (or ASD). Similar to being able to adjust load in motor systems, including modulation features with pumps is estimated to save between 20 and 50\% of pump energy consumption, at relatively short payback periods, depending on pump size, load and load variation (Xenergy, 1998; Best Practice Programme, 1996a). As a general rule of thumb, unless the pump curves are exceptionally flat, a $10 \%$ regulation in flow should produce pump savings of $20 \%$ and $20 \%$ regulation should produce savings of 40\% (Best Practice Programme, 1996a).

Daishowa America Paper Mill (WA) installed ASDs on two of the pumps in its milling system to replace bypass and throttling valves, and rebuilt the pumps (OIT, 2002b). The project saved $\$ 32,000$ and 700,000 kWh (44\%) annually. With a partial grant from the Northwest Energy Efficiency Alliance (NEEA), the project cost $\$ 60,000$. Hence, the payback from energy savings alone was less than 2 years. In addition, the implementation of the project reduced cavitation and vibration, eliminated water surges and pipe hammer (lessening system stress and prolonging equipment life) and reduced maintenance, saving the plant $\$ 10,000$ annually.

In a similar case study, Teichert Aggregates, Inc. (CA), with the help of its local utility company, Sacramento Municipal Utility District (SMUD), added a magnetic induction ASD to their pumping system. They found annual energy savings of $233,000 \mathrm{kWh}$ or $\$ 17,000$, representing $24 \%$ of the pumping systems' power costs (CEC and OIT, 2001). The total project cost was $\$ 34,000$. With a grant from SMUD of $\$ 15,000$, the project had a payback of 13 months. Without the grant, payback would have amounted to approximately 2 years. In addition to the energy savings, the project also reduced maintenance costs, increased pump bearing life and improved the plant's process control.

Avoid throttling valves. Throttling valves should always be avoided. Extensive use of throttling valves or bypass loops may be an indication of an oversized pump (Tutterow et al., 2000). Variable speed drives or on off regulated systems always save energy compared to throttling valves (Hovstadius, 2002).

\subsubsection{System changes.}

Correct sizing of pipes. Similar to pumps, undersized pipes also result in unnecessary losses. The pipework diameter is selected based on the economy of the whole installation, the required lowest flow velocity, the minimum internal diameter for the application, the maximum flow velocity to minimize erosion in piping and fittings and plant standard pipe diameters. Increasing the pipe diameter may save energy but must be balanced with costs for pump system components. Easton Consultants (1995) and others in the pulp and paper industry (Xenergy, 1998) estimate retrofitting pipe diameters saves 5 to $20 \%$

\footnotetext{
${ }^{11}$ This equation applies to dynamic systems only. Systems that solely consist of lifting (static head systems) will accrue no benefits from (but will often actually become more inefficient) ASDs because they are independent of flow rate. Similarly, systems with more static head will accrue fewer benefits than systems that are largely dynamic (friction) systems. More careful calculations must be performed to determine actual benefits, if any, for these systems.
} 
of their energy consumption, on average for the U.S. industry. Correct sizing of pipes should be done at the design or system retrofit stages where costs may not be restrictive.

Replace belt drives. Inventory data suggests $4 \%$ of pumps have V-belt drives, many of which can be replaced with direct couplings to save energy (Xenergy, 1998). Savings are estimated at 1\% (on average for the U.S. industry) (Xenergy, 1998).

Precision castings, surface coatings or polishing. The use of castings, coatings or polishing reduces surface roughness that in turn, increases energy efficiency. It may also help maintain efficiency over time. This measure is more effective on smaller pumps. One case study in the steel industry analyzed the investment in surface coating on the mill supply pumps $(350 \mathrm{~kW}$ pumps). They determined that the additional cost of coating, $\$ 1200$ (US), would be paid back in 5 months by energy savings of $\$ 2700$ (US) (or $36 \mathrm{MWh}, 2 \%$ ) per year (Hydraulic Institute and Europump, 2001). Energy savings for coating pump surfaces are estimated to be 2 to 3\% over uncoated pumps (Best Practice Programme, 1998).

Sealings. Seal failure accounts for up to $70 \%$ of pump failures in many applications (Hydraulic Institute and Europump, 2001). The sealing arrangements on pumps will contribute to the power absorbed. Often the use of gas barrier seals, balanced seals, and no-contacting labyrinth seals optimize pump efficiency.

Curtailing leakage through clearance reduction. Internal leakage losses are a result of differential pressure across the clearance between the impeller and the pump casing. The larger the clearance, the greater is the internal leakage causing inefficiencies. The normal clearance in new pumps ranges from 0.35 to $1.0 \mathrm{~mm}$ (0.014 to $0.04 \mathrm{in}$.) (Hydraulic Institute and Europump, 2001). With wider clearances, the leakage increases almost linearly with the clearance. For example, a clearance of $5 \mathrm{~mm}(0.2 \mathrm{in}$.) decreases the efficiency by 7 to $15 \%$ in closed impellers and by 10 to $22 \%$ in semi-open impellers. Abrasive liquids and slurries, even rainwater, can affect the pump efficiency. Using very hard construction materials (such as stainless steel) can reduce the wear rate.

\subsubsection{Compressed Air}

The major uses of compressed air in corn wet milling are pneumatic valves, packing lines and dust collectors. Compressed air is probably the most expensive form of energy available in an industrial plant because of its poor efficiency. Typically, efficiency from start to end-use is around $10 \%$ for compressed air systems (LBNL et al., 1998). In addition, the annual energy cost required to operate compressed air systems is greater than their initial cost. Because of this inefficiency and the sizeable operating costs, if compressed air is used, it should be of minimum quantity for the shortest possible time, constantly monitored and reweighed against alternatives. Because of its limited use in corn wet milling (but still an inefficient source of energy), the main compressed air measures found in other industries are highlighted. Many opportunities to reduce energy in compressed air systems are not prohibitively expensive; payback periods for some options are extremely short - less than one year.

Maintenance. Inadequate maintenance can sometimes lower compression efficiency, increase air leakage or pressure variability and lead to increased operating temperatures, poor moisture control and excessive contamination. Better maintenance will reduce these problems and save energy.

Proper maintenance includes the following (LBNL et al., 1998, unless otherwise noted):

- Blocked pipeline filters increase pressure drop. Keep the compressor and intercooling surfaces clean and foul-free by inspecting and periodically cleaning filters. Seek filters with just a 1 psi pressure drop. Payback for filter cleaning is usually under 2 years (Ingersoll-Rand, 2001). Fixing improperly operating filters will also prevent contaminants from entering into equipment and causing them to wear out prematurely. Generally, when pressure drop exceeds 2 to 3 psig replace 
the particulate and lubricant removal elements. Inspect all elements at least annually. Also, consider adding filters in parallel to decrease air velocity and, therefore, decrease pressure drop. A $2 \%$ reduction of annual energy consumption in compressed air systems is projected for more frequent filter changing (Radgen and Blaustein, 2001). However, one must be careful when using coalescing filters; efficiency drops below $30 \%$ of design flow (Scales, 2002).

- Poor motor cooling can increase motor temperature and winding resistance, shortening motor life, in addition to increasing energy consumption. Keep motors and compressors properly lubricated and cleaned. Compressor lubricant should be sampled and analyzed every 1000 hours and checked to make sure it is at the proper level. In addition to energy savings, this can help avoid corrosion and degradation of the system.

- Inspect fans and water pumps for peak performance.

- Inspect drain traps periodically to ensure they are not stuck in either the open or closed position and are clean. Some users leave automatic condensate traps partially open at all times to allow for constant draining. This practice wastes substantial amounts of energy and should never be undertaken. Instead, install simple pressure driven valves. Malfunctioning traps should be cleaned and repaired instead of left open. Some automatic drains do not waste air, such as those that open when condensate is present. According to vendors, inspecting and maintaining drains typically has a payback of less than 2 years (Ingersoll-Rand, 2001).

- Maintain the coolers on the compressor to ensure that the dryer gets the lowest possible inlet temperature (Ingersoll-Rand, 2001).

- Check belts for wear and adjust them. A good rule of thumb is to adjust them every 400 hours of operation.

- Check water cooling systems for water quality ( $\mathrm{pH}$ and total dissolved solids), flow and temperature. Clean and replace filters and heat exchangers per manufacturer's specifications.

- Minimize leaks (see also Reduce leaks section, below).

- Specify regulators that close when failed.

- Applications requiring compressed air should be checked for excessive pressure, duration or volume. They should be regulated, either by production line sectioning or by pressure regulators on the equipment itself. Equipment not required to operate at maximum system pressure should use a quality pressure regulator. Poor quality regulators tend to drift and lose more air. Otherwise, the unregulated equipment operates at maximum system pressure at all times and wastes the excess energy. System pressures operating too high also result in shorter equipment life and higher maintenance costs.

Monitoring. Proper monitoring (and maintenance) can save a lot of energy and money in compressed air systems. Proper monitoring includes the following (CADDET, 1997):

- Pressure gauges on each receiver or main branch line and differential gauges across dryers, filters, etc.

- Temperature gauges across the compressor and its cooling system to detect fouling and blockages

- Flow meters to measure the quantity of air used

- Dew point temperature gauges to monitor the effectiveness of air dryers

- $\quad \mathrm{kWh}$ meters and hours run meters on the compressor drive

- Compressed air distribution systems should be checked when equipment has been reconfigured to be sure no air is flowing to unused equipment or obsolete parts of the compressed air distribution system.

- Check for flow restrictions of any type in a system, such as an obstruction or roughness. These require higher operating pressures than are needed. Pressure rise resulting from resistance to flow increases the drive energy on the compressor by $1 \%$ of connected power for every 2 psi of differential (LBNL et al., 1998; Ingersoll-Rand, 2001). Highest pressure drops are usually found at the points of use, including undersized or leaking hoses, tubes, disconnects, filters, regulators, 
valves, nozzles and lubricators (demand side), as well as air/lubricant separators, aftercoolers, moisture separators, dryers and filters.

Reduce leaks (in pipes and equipment). Leaks can be a significant source of wasted energy. A typical plant that has not been well maintained could have a leak rate between 20 to $50 \%$ of total compressed air production capacity (Ingersoll Rand, 2001). Leak repair and maintenance can sometimes reduce this number to less than $10 \%$. Overall, a $20 \%$ reduction of annual energy consumption in compressed air systems is projected for fixing leaks (Radgen and Blaustein, 2001).

The magnitude of a leak varies with the size of the hole in the pipes or equipment. A compressor operating 2,500 hours per year at 6 bar $(87 \mathrm{psi})$ with a leak diameter of 0.02 inches $(1 / 2 \mathrm{~mm})$ is estimated to lose $250 \mathrm{kWh} /$ year; $0.04 \mathrm{in}$. $(1 \mathrm{~mm})$ to lose $1100 \mathrm{kWh} /$ year; $0.08 \mathrm{in}$. $(2 \mathrm{~mm})$ to lose $4,500 \mathrm{kWh} /$ year; and 0.16 in. (4 mm) to lose $11,250 \mathrm{kWh} /$ year (CADDET, 1997).

In addition to increased energy consumption, leaks can make pneumatic systems/equipment less efficient and adversely affect production, shorten the life of equipment, lead to additional maintenance requirements and increased unscheduled downtime. Leaks cause an increase in compressor energy and maintenance costs.

The most common areas for leaks are couplings, hoses, tubes, fittings, pressure regulators, open condensate traps and shut-off valves, pipe joints, disconnects and thread sealands. Quick connect fittings always leak and should be avoided. A simple way to detect large leaks is to apply soapy water to suspect areas. The best way to detect leaks is to use an ultrasonic acoustic detector, which can recognize the high frequency hissing sounds associated with air leaks. After identification, leaks should be tracked, repaired and verified. Leak detection and correction programs should be ongoing efforts.

Reducing the Inlet Air Temperature. Reducing the inlet air temperature reduces energy used by the compressor. In many plants, it is possible to reduce inlet air temperature to the compressor by taking suction from outside the building. Importing fresh air has paybacks of 2 to 5 years (CADDET, 1997b). As a rule of thumb, each $5^{\circ} \mathrm{F}\left(3^{\circ} \mathrm{C}\right)$ will save $1 \%$ compressor energy use (CADDET, 1997b; Parekh, 2000). Three case studies in the corn wet milling industry taken from the database of energy audits performed by the Industrial Assessment Centers (IAC) throughout the U.S. estimate implementation costs for this measure ranging from $\$ 300$ to $\$ 480$, and annual savings of $\$ 1,580$ to $\$ 2,349(0.1$ to $0.6 \%)$ in electricity (IAC, 2001). ${ }^{10}$ Only one of these plants had implemented the measure, and they found a payback of about 2 months. The others estimated a payback between 2 and 4 months.

Maximize Allowable Pressure Dew Point at Air Intake. Choose the dryer that has the maximum allowable pressure dew point, and best efficiency. A rule of thumb is that desiccant dryers consume 7 to $14 \%$ of the total energy of the compressor, whereas refrigerated dryers consume 1 to $2 \%$ as much energy as the compressor (Ingersoll Rand, 2001). Consider using a dryer with a floating dew point. Note that where pneumatic lines are exposed to freezing conditions, refrigerated dryers are not an option.

Controls. Remembering that the total air requirement is the sum of the average air consumption for pneumatic equipment, not the maximum for each, the objective of any control strategy is to shut off unneeded compressors or delay bringing on additional compressors until needed. All compressors that are on should be running at full-load, except for one, which should handle trim duty. Positioning of the control loop is also important; reducing and controlling the system pressure downstream of the primary receiver results in reduced energy consumption of up to $10 \%$ or more (LBNL et al., 1998). Radgen and Blaustein (2001) report energy savings for sophisticated controls to be $12 \%$ annually. Start/stop, load/unload, throttling, multi-step, variable speed and network controls are options for compressor controls and described below. 
Start/stop (on/off) is the simplest control available and can be applied to small reciprocating or rotary screw compressors. For start/stop controls, the motor driving the compressor is turned on or off in response to the discharge pressure of the machine. They are used for applications with very low duty cycles. Applications with frequent cycling will cause the motor to overheat. Typical payback for start/stop controls is 1 to 2 years (CADDET, 1997).

Load/unload control, or constant speed control, allows the motor to run continuously but unloads the compressor when the discharge pressure is adequate. In most cases, unloaded rotary screw compressors still consume 15 to $35 \%$ of full-load power when fully unloaded, while delivering no useful work (LBNL et al., 1998). Hence, load/unload controls may be inefficient and require ample receiver volume.

Modulating or throttling controls allows the output of a compressor to be varied to meet flow requirements by closing down the inlet valve and restricting inlet air to the compressor. Throttling controls are applied to centrifugal and rotary screw compressors.

Changing the compressor control to a variable speed control has saved up to $8 \%$ per year (CADDET, 1997).

Multi-step or part-load controls can operate in two or more partially loaded conditions. Output pressures can be closely controlled without requiring the compressor to start/stop or load/unload.

Properly sized regulators. Regulators sometimes contribute to the biggest savings in compressed air systems. By properly sizing regulators, compressed air will be saved that is otherwise wasted as excess air. Also, it is advisable to specify pressure regulators that close when failing.

Sizing pipe diameter correctly. Inadequate pipe sizing can cause pressure losses, increase leaks and increase generating costs. Pipes must be sized correctly for optimal performance or resized to fit the current compressor system. Increasing pipe diameter typically reduces annual energy consumption by $3 \%$ (Radgen and Blaustein, 2001).

Heat recovery for water preheating. As much as 80 to $93 \%$ of the electrical energy used by an industrial air compressor is converted into heat. In many cases, a heat recovery unit can recover 50 to $90 \%$ of the available thermal energy for space heating, industrial process heating, water heating, makeup air heating, boiler makeup water preheating, industrial drying, industrial cleaning processes, heat pumps, laundries or preheating aspirated air for oil burners (Parekh, 2000). It has been estimated that approximately $50 \mathrm{kBtu} /$ hour of energy is available for each $100 \mathrm{ft}^{3} / \mathrm{min}$ of capacity (at full load) (LBNL et al., 1998). Paybacks are typically less than one year. Heat recovery for space heating is not as common with water-cooled compressors because an extra stage of heat exchange is required and the temperature of the available heat is lower. With large water-cooled compressors, recovery efficiencies of 50 to $60 \%$ are typical (LBNL et al., 1998). Implementing this measure recovers up to $20 \%$ of the energy used in compressed air systems annually for space heating (Radgen and Blaustein, 2001).

Natural gas engine-driven air compressors. Gas engine-driven air compressors can replace electric compressors with some advantages and disadvantages. Gas engine-driven compressors are more expensive but may have lower overall operating costs, depending on the relative costs of electricity and gas. Variable speed capability is standard for gas-fired compressors, offering a high efficiency over a wide range of loads. Heat can be recovered from the engine jacket and exhaust system. This technology is new; it has currently penetrated less than $1 \%$ of the total air compressor market, and has some drawbacks. Gas compressors need more maintenance, have a shorter useful life, and sustain a greater likelihood of downtime. 
Systems improvements. Adding additional compressors should be considered only after a complete system evaluation. In many cases, compressed air systems' efficiency could be managed and reconfigured to operate more efficiently without purchasing additional compressors. System improvements utilize many of the other measures discussed above.

\section{Compressor motors}

Motors are important in HVAC systems as well, and are discussed in detail in the section called motors. Below are a few examples of their use with compressors.

Adjustable speed drives (ASDs). Implementing adjustable speed drives in rotary compressor systems has saved $15 \%$ of the annual compressed air energy consumption (Radgen and Blaustein, 2001).

High efficiency motors. Installing high efficiency motors in compressor systems reduces annual energy consumption by 2\%, and has a payback of less than 3 years (Radgen and Blaustein, 2001). For compressor systems, the largest savings in motor performance are typically found in small machines operating less than 10kW (Radgen and Blaustein, 2001).

\subsubsection{Lighting}

Lighting is used either to provide overall ambient light throughout the refining, storage and office spaces or to provide low bay and task lighting to specific areas. High-intensity discharge (HID) sources are used for the former, including metal halide, high-pressure sodium and mercury vapor lamps. Fluorescent, compact fluorescent (CFL) and incandescent lights are typically used for task lighting and offices. In addition, lighting controls should be used in all areas of the plant.

Lighting controls. Lights can be shut off during non-working hours by automatic controls, such as occupancy sensors, which turn off lights when a space becomes unoccupied. Manual controls can also be used in addition to automatic controls to save additional energy in small areas.

When lighting placement is combined with controls, lighting can be reduced throughout the day. The following schematic details a possible method for placing luminaries.

Figure 11. Lighting placement and controls

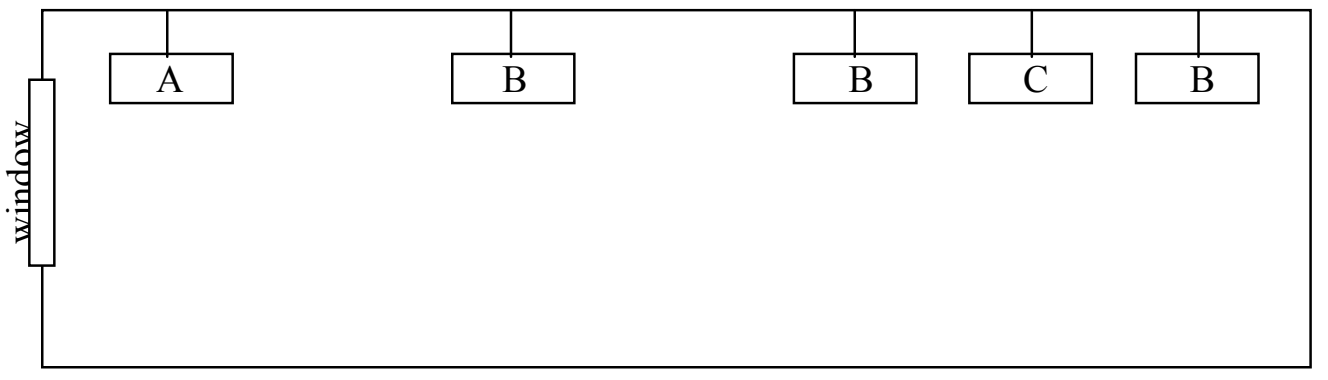

Note: During the brightest part of the day, only row $\mathrm{C}$ needs to be on. When daylight levels drop, all B rows should be turned on to replace row C. Only at night or very dark days would it be necessary to have rows A and B on (Cayless and Marsden, 1983). These methods can also be used as a control strategy on a retrofit by adapting the luminaries already present. (For example, turn on the lighting in the rows away from the windows during the brightest parts of the day and supplemental rows later.)

Daylighting. Daylighting is the efficient use of natural light in order to minimize the need for artificial light in buildings. Increasing levels of daylight within rooms reduces electrical lighting loads by up to $70 \%$ (CADDET, 2001). Daylighting differs from other energy efficiency measures because its features are integral to the architecture of a building, and so it is applied primarily to new buildings and incorporated at the design stage. Daylighting can be combined with lighting controls to maximize its 
benefits. Because of its variability, daylighting is usually combined with artificial lighting to provide the necessary illumination on cloudy days or after dark. Daylighting technologies include properly placed and shaded windows, atria, angular or traditional (flat) rooflights, clerestories, light shelves and light ducts. Clerestories, light shelves and light ducts utilize angles of the sun and redirect light with walls or reflectors. Some problems associated with daylighting on industrial buildings have been identified due to the structure of the building. On flat roofed industrial plant buildings, some daylights have been found to leak and fog from exposure to ultraviolet (UV) after a number of years.

Several daylighting systems have been installed around the world with energy saving success. For example, an Australian school incorporated daylighting features at no extra cost, realizing immediate paybacks and energy savings of 70\% of the normal lighting costs (CADDET, 2001).

Replace incandescent lights with fluorescent lights or compact fluorescent lights. The fluorescent lamp lasts roughly ten times longer than an incandescent light and is 3 times more effective (EPA, 2001a; Honda, 2001).

Westin Hotels and Resorts' St. Francis Hotel in San Francisco, California replaced 1,600 incandescent lamps with 1,600 compact fluorescent lights and reduced their electricity used for lighting by $82.3 \%$. Replacing the lights cost $\$ 35,915$ but saved $\$ 85,200$ annually, yielding a payback of about 5 months (EPA, 2001). Honda's Marysville Auto Plant, Ohio replaced 200 fluorescent lights with 58 metal halide bulbs and found a reduction in electricity usage (Honda, 2001). Honda also claimed the amount of light increased by 118 percent resulting in higher quality visual inspections at the production line.

Replace T-12 tubes by T-8 tubes or metal halides. T-12 refers to the diameter in $1 / 8$ inch increments (T-12 means 12/8 inch or $3.8 \mathrm{~cm}$ diameter tubes). The initial output for T-12 lights is high, but energy consumption is also high. T-12 tubes have poor efficacy, lamp life, lumen depreciation and color rendering index. Because of this, maintenance and energy costs are high. Replacing T-12 lamps with T-8 lamps (smaller diameter) approximately doubles the efficacy of the former (DEQ, 2001). It is important to remember, however, to work both with the suppliers and manufacturers on the system as a whole through each step of the process. There are a number of T8 lights and ballasts and the correct combination should be chosen for each system.

Ford North American paint shops retrofitted eleven of their twenty-one paint shops and saw lighting costs reduced by more than 50\% (DEQ, 2001). Initial light levels were lower, but because depreciation is less, the maintained light level is equal and the new lamps last two to three times longer. Energy savings totaled 17.5 million $\mathrm{kWh}$ annually; operation savings were $\$ 500,000$ per year. The Gillette Company manufacturing facility in Santa Monica, California replaced 4300 T-12 lamps with 496 metal halide lamps in addition to replacing 10 manual switches with 10 daylight switches (EPA, 2001). They reduced electricity use by $58 \%$ and saved $\$ 128,608$ annually. The total project cost was $\$ 176,534$, producing a payback of less than 1.5 years.

Replace mercury lights by metal halide or high pressure sodium lights (most efficient). In industries where color rendition is critical, metal halide lamps save 50\% compared to mercury or fluorescent lamps (Price and Ross, 1989). Where color rendition is not critical, high pressure sodium lamps offer energy savings of 50 to $60 \%$ compared to mercury lamps (Price and Ross, 1989). High pressure sodium and metal halide lamps also produce less heat, reducing HVAC loads. In addition to energy reductions, the metal halide lights provide better lighting, provide better distribution of light across work surfaces, improve color rendition and reduce operating costs (GM, 2001).

Replace standard metal halide HID with high-intensity fluorescent lights. Traditional HID lighting can be replaced with high-intensity fluorescent lighting. These new systems incorporate high efficiency fluorescent lamps, electronic ballasts and high-efficacy fixtures that maximize output to the work space. 
Advantages of the new system are many: lower energy consumption, lower lumen depreciation over the lifetime of the lamp, better dimming options, faster start-up and restrike capability, better color rendition, higher pupil lumens ratings and less glare (Martin et al., 2000a). High-intensity fluorescent systems yield $50 \%$ electricity savings over standard metal halide HID. Dimming controls that are impractical in the metal halide HIDs save significant energy in the new system. Retrofitted systems cost about $\$ 185$ per fixture, including installation costs (Martin et al., 2000a). In addition to energy savings and better lighting qualities, high-intensity fluorescents may help improve productivity and have reduced maintenance costs.

Replace magnetic ballasts with electronic ballasts. A ballast is a mechanism that regulates the amount of electricity required to start a lighting fixture and maintain a steady output of light. Electronic ballasts save 12 to 25 percent power over their magnetic predecessors (EPA, 2001). Electronic ballasts have dimming capabilities as well (Eley et al., 1993). If automatic daylight sensing, occupancy sensing and manual dimming are included with the ballasts, savings can be greater than 65\% (Turiel et al., 1995).

Reflectors. A reflector is a highly polished "mirror-like" component that directs light downward, reducing light loss within a fixture. Reflectors can minimize required wattage effectively.

Light emitting diodes (LEDs) or radium lights. One way to reduce energy costs is simply switching from incandescent lamps to LEDs or radium strips in exit sign lighting. LEDs use about $90 \%$ less energy than conventional exit signs (Anaheim Public Utilities, 2001). A 1998 Lighting Research Center survey found that about 80 percent of exit signs being sold use LEDs (LRC, 2001). In addition to exit signs, LEDs are increasingly being used for path marking and emergency way finding systems. Their long life and cool operation allows them to be embedded in plastic materials, which makes them perfect for these applications (LRC, 2001). Radium strips use no energy at all and can be used similarly.

System improvements. By combining several of the lighting measures above, light system improvements can be the most effective and comprehensive way to reduce lighting energy. High frequency ballasts and specular reflectors can be combined with $50 \%$ fewer efficient high-frequency fluorescent tubes and produce $90 \%$ as much light while saving 50 to $60 \%$ of the energy formerly used (Price and Ross, 1989). An office building in Michigan reworked their lighting system using highefficiency fluorescent ballasts and reduced lighting load by $50 \%$ and total building electrical load by nearly 10\% (Price and Ross, 1989). Similar results were obtained in a manufacturing facility when replacing fluorescent fixtures with metal halide lamps. Often these system improvements improve lighting as well as decrease energy consumption.

Reducing system voltage may also save energy. One U.S. automobile manufacturer put in reduced voltage HID lights and found a 30\% reduction in lighting. Electric City is one of the suppliers of EnergySaver, a unit that attaches to a central panel switch (controllable by computer) and constricts the flow of electricity to fixtures, thereby reducing voltage and saving energy, with an imperceptible loss of light. Bristol Park Industries has patented another lighting voltage controller called the Wattman ${ }^{\circ}$ Lighting Voltage Controller that works with high intensity discharge (HID) and fluorescent lighting systems with similar energy saving results (Bristol Park Industries, 2002).

\subsubsection{Heating, Ventilation and Air Conditioning (HVAC)}

HVAC includes heating, ventilation and air conditioning systems. Many of the measures applicable to HVAC systems have been discussed under motors, compressed air and heat and steam distribution. A few additional measures are discussed below.

Electronic controls. Electronic controls can be as simple as on/off switches to be switched off during non-operating hours. 
Non-production hours setback temperatures. Setting building temperatures lower during the winter or higher during the summer over the weekend and during non-production times for appropriate buildings (e.g. office buildings during the weekend) can save energy by reducing heating or cooling needs.

Ventilation and cooling system design improvements. New local ventilation and cooling systems and controls respond to current conditions in their plant, better matching ventilation or cooling output to demand. Three types of cooling systems exist: intermittent air supply systems where air is chilled only when workers are present; variable air volume (VAV) systems with constant temperature for local cooling; or variable air temperature (VAT) with constant volume for local cooling. The intermittent air supply system and the VAV system can easily be added to existing air-conditioning systems with additional units. The VAT system, however, requires a new system and should only be installed in new workshops. In addition to reducing running costs of cooling systems and reducing energy use, these systems also improve the working environment.

\subsubsection{Materials handling/tools}

High efficiency belts (cog belts). Belts make up a variable, but significant portion of the total motor drive in most plants. Standard vee belts tend to stretch, slip, bend and compress, which lead to a loss of efficiency (CIPEC, 2001b). Replacing standard vee belts with cog belts can save energy and money, even as a retrofit. Cog belts run cooler, last longer, require less maintenance and have an efficiency that is about 2\% higher than standard vee belts (DOE, 2001c; CIPEC, 2001b). Upgrading to high-torque cog belts results in up to $6 \%$ savings over standard vee belts (CIPEC, 2001b). Motor load reductions of 2 to $10 \%$ have been shown from replacing vee belts with cog belts (Price and Ross, 1989). CIPEC (2001b) estimates the payback for replacing standard belts with more efficient ones to be 6 months to 3 years. A case study in the corn wet milling industry (US) estimated the cost for using more efficient belts at $\$ 29,660$, savings of $\$ 17,250$ in electricity (or $1 \%$ ) per year, and an average payback of about 1.7 years (IAC, 2001). ${ }^{10}$ Another case study in the Industrial Assessment Center (IAC) database estimated a smaller system would cost $\$ 1,406$ and save $\$ 709$ annually in electricity $(0.2 \%)$, but also have a payback of under 2 years.

\subsubsection{Heat and steam distribution}

Boilers are the heart of the steam generation system, and generally, substantial efficiency improvements are feasible. The main efficiency measures are listed below. These measures center around improved process control, reduced heat loss and improved heat recovery. In addition to the measures below, it is important to note that new boilers should usually be constructed in a custom configuration. Pre-designed boilers are often out-of-date designs that cannot be tuned to the needs of a particular steam system (Ganapathy, 1994).

Boilers - improve process control. Flue gas monitors maintain optimum flame temperature and monitor carbon monoxide (CO), oxygen and smoke. The oxygen content of the exhaust gas is a combination of excess air (which is deliberately introduced to improve safety or reduce emissions) and air infiltration (air leaking into the boiler). By combining an oxygen monitor with an intake airflow monitor, it is possible to detect even small leaks. A small 1\% air infiltration will result in $20 \%$ higher oxygen readings. A higher $\mathrm{CO}$ or smoke content in the exhaust gas is a sign that there is insufficient air to complete the fuel burning. Using a combination of $\mathrm{CO}$ and oxygen readings, it is possible to optimize the fuel/air mixture for high flame temperature (and thus the best energy efficiency) and lower air pollutant emissions. It is assumed that this measure can be applied to large boilers only because small boilers will not make up the initial capital cost as easily. 
Boilers - reduce flue gas quantities. Often excessive flue gas results from leaks in the boiler and the flue. This reduces the heat transferred to the steam, and increases pumping requirements. These leaks are often easily repaired. Savings amount to $2-5 \%$ (DOE, 2001b). This measure differs from flue gas monitoring in that it consists of a periodic repair based on visual inspection. The savings from this measure and from flue gas monitoring are not cumulative, as they both address the same losses.

Boilers - reduce excess air. The more air is used to burn the fuel, the more heat is wasted in heating this air rather than in producing steam. Air slightly in excess of the ideal stochiometric fuel/air ratio is required for safety, and to reduce $\mathrm{NO}_{\mathrm{x}}$ emissions, but approximately $15 \%$ is adequate (DOE, 2001b; Ganapathy, 1994). Poorly maintained boilers may have up to $140 \%$ excess air, but this is rare. Reducing this boiler back down to $15 \%$ even without continuous automatic monitoring would save $8 \%$ of total fuel use. The vast majority of boilers already operate at $15 \%$ excess air or lower, and thus this measure is not considered significant (Zeitz, 1997). A rule of thumb often used is that boiler efficiency can be increased by $1 \%$ for each $15 \%$ reduction in excess air or $40^{\circ} \mathrm{F}\left(22^{\circ} \mathrm{C}\right)$ reduction in stack gas temperature (DOE, 2001b). CIPEC (2001a) estimates reducing oxygen $\left(\mathrm{O}_{2}\right)$ in the flue gas by $1 \%$ increases boiler efficiency by $2.5 \%$. One case study in the corn wet milling industry reduced boiler excess air and reported a payback of less than 3 months (IAC, 2001) ${ }^{10}$. This corresponds to a savings of about $1 \%$ fuel oil.

Boilers - correct sizing in design. Correctly designing the system at the proper steam pressure can save energy by reducing stack temperature, reducing piping radiation losses and reducing leaks in traps and other sources. In a study done in Canada on 30 boiler plants, savings from this measure have ranged from $3 \%$ to $8 \%$ of the total gas consumption (Griffin, 2000). Savings were greatest when the pressure was reduced below 70 psig.

Boilers - improve insulation. It is possible to use new materials that insulate better, and have a lower heat capacity (and thus warm up faster). Savings of 6-26\% can be achieved if this improved insulation is combined with improved heater circuit controls. Improved control is required to maintain the output temperature range of the old firebrick system. Because of the ceramic fiber's lower heat capacity, the output temperature is more vulnerable to temperature fluctuations in the heating elements (Caffal, 1995). An additional benefit is that heating is more rapid when starting the boiler.

Boilers - maintenance. A simple maintenance program to ensure that all components of the boiler are operating at peak performance may result in substantial savings. In the absence of a good maintenance system, the burners and condensate return systems can wear or get out of adjustment. These factors may end up costing a steam system up to $20-30 \%$ of initial efficiency over 2-3 years (DOE, 2001b). It is estimated that $10 \%$ energy savings on average are possible (DOE, 2001b). Improved maintenance may also reduce the emission of criteria air pollutants.

Fouling of the fireside of the boiler tubes or scaling on the waterside of the boiler should also be controlled. Fouling and scaling are more of a problem with coal fed boilers than natural gas or oil fed ones. (Boilers that burn solid fuels like coal should be checked more often as they have a higher fouling tendency than liquid fuel boilers do). Tests show a soot layer of 0.03 inches $(0.8 \mathrm{~mm})$ reduces heat transfer by $9.5 \%$, while a 0.18 inch $(4.5 \mathrm{~mm}$ ) layer reduces heat transfer by $69 \%$ (CIPEC, 2001a). For scaling, 0.04 inches $(1 \mathrm{~mm})$ of buildup can increase fuel consumption by $2 \%$ (CIPEC, 2001a).

Boilers - recover heat from flue gas. According to CIPEC (2001a), heat recovery from the flue gas is the best opportunity for heat recovery in the boilerhouse. Heat from flue gasses can be used to preheat boiler feed water in an economizer. While this measure is common in large boilers, there is often still room for more heat recovery, especially in smaller boilers. The limiting factor for flue gas heat recovery is that one must ensure that the economizer wall temperature does not drop below the dew point of acids in the flue gas (such as sulfuric acid in sulfur-containing fossil fuels). Traditionally this has been done by keeping 
the flue gases exiting the economizer at a temperature significantly above the acid dew point. In fact, the economizer wall temperature is much more dependent on the feed water temperature than the flue gas temperature because of the high heat transfer coefficient of water. As a result, it makes more sense to preheat the feed water to close to the acid dew point before it enters the economizer. This allows the economizer to be designed so that the flue gas exiting the economizer is just barely above the acid dew point. $1 \%$ of fuel use is saved for every $45^{\circ} \mathrm{F}\left(25^{\circ} \mathrm{C}\right)$ reduction in exhaust gas temperature (Ganapathy, 1994). Since exhaust gas temperatures are already quite low but can still take advantage of using the higher temperature feed water mentioned above, savings are estimated to be $1 \%$.

McCain Foods (UK) implemented a heat recovery project at their food factory that included installation of an economizer (Best Practice Programme, 2002b). The new economizer saved 1.97 MW of natural gas per year, saving $£ 67,000$ annually $(\$ 109,000,1998$ U.S.). With installation costs of $166,800(\$ 272,000$ 1998 US), the payback was 2.5 years. Current operating specification of the economizer has increased savings to $£ 102,000$ ( $\$ 166,0001998$ US) annually and improved the payback to 1.6 years.

Tunnel Refineries in Greenwich (UK) wet mills wheat and corn to produce a variety of syrups and starches. They use exhaust gas from the steam boilers in two of their dryers. After building a new CHP plant, the boilers became waste heat boilers but maintained supply to the dryers. Use of the boiler offgases as a dryer heat source had a payback of less than 2 years (Best Practice Programme, 1997).

Boilers - return condensate. Reusing the hot condensate in the boiler saves energy, reduces the need for treated boiler feed water and reclaims water at $100^{\circ} \mathrm{C}\left(212^{\circ} \mathrm{F}\right)$ sensible heat savings. Usually fresh water must be treated to remove solids that may accumulate in the boiler, and returning condensate may substantially reduce the amount of purchased chemical required to accomplish this treatment. The fact that this measure can save substantial energy costs and purchased chemicals costs makes building a return piping system attractive. This measure has, however, already been implemented in most of the sites where it is easy to accomplish. It is assumed that a $10 \%$ energy savings and payback of about 1.1 years is possible (DOE, 2001b).

If no steam main is handy, it is often possible to use the condensate flash to heat water by direct contact, using a simple "shower bath" arrangement (Lyle, 1946).

Boilers - recover steam from blowdown. When the water is blown from the high-pressure boiler tank, the pressure reduction often produces substantial amounts of steam. This steam is low grade, but can be used for space heating and feed water preheating. It is assumed that this measure saves $1.3 \%$ of boiler fuel use in small boilers ${ }^{12}$. One case study in the corn wet milling industry (U.S.) indicated that recovering exhaust steam would cost $\$ 1,690$ to implement and save $\$ 1,145$ annually in fuel oil, resulting in a payback of about 1.5 years (IAC, 2001). ${ }^{10}$ This corresponds to a savings of $0.5 \%$ natural gas. Einstein et al. (2001) estimate an overall payback of 2.7 years. In addition to energy savings, blowdown recovery may reduce the potential for corrosion damage in piping in the steam system. Operating expense may increase slightly with this system.

Boilers - replace obsolete burners by new optimized boilers. Replacing inefficient coal-fired boilers with new boilers increases energy efficiency and reduces emissions.

Steam and hot water distribution systems are often quite extensive and can be major contributors to energy losses at any industrial plant. The purpose of steam distribution is simple: to get steam from the

\footnotetext{
${ }^{12}$ Based on the following assumptions: $10 \%$ of boiler water is blown down (DOE, 2001b) and 13\% of the energy can be recovered from this (Johnston, 1995).
} 
boiler to the process where it will be used. The methods for reducing energy losses are correspondingly simple: retain more heat and recover it after it has been used.

Distribution - improve insulation. Using more insulating material or using the best insulation material for the application can save energy in steam systems. Crucial factors in choosing insulating material include low thermal conductivity, dimensional stability under temperature change, resistance to water absorption and resistance to combustion. Other characteristics of insulating material may also be important depending on the application. These characteristics include tolerance of large temperature variation and system vibration and compressive strength where insulation is load bearing (Baen and Barth, 1994). According to data from the U.S. Department of Energy's Steam Challenge program, improving insulation of the existing stock of heat distribution systems would save an average of 3-13\% with an average payback of 1.1 years (DOE, 2001b; Einstein et al., 2001). One case study in the corn wet milling industry (U.S.) indicated that insulation of the steam and hot water lines would result in about $0.4 \%$ savings in natural gas, with a payback of less than 8 months (IAC, 2001) ${ }^{10}$. Two others indicated insulating bare equipment would have even greater savings (up to $2 \%$ natural gas) with paybacks from 4 months to 1.5 years (IAC, 2001). ${ }^{10}$ One case study indicated insulating electric oil heaters resulted in an almost immediate payback, although overall relative savings were small (about $0.1 \%$ electricity savings) (IAC, 2001). ${ }^{10}$ CIPEC (2001a) estimates that insulating a 10 foot $(3 \mathrm{~m})$ long by 4 inch $(10 \mathrm{~cm})$ steam pipe can be paid back in less than 6 months.

Distribution - maintain insulation. It is often found that after heat distribution systems have undergone some form of repair, the insulation is not replaced. In addition, some types of insulation may become brittle or rot under normal wear. As a result, introducing a regular inspection and maintenance system for insulation saves energy (Zeitz, 1997). Exact energy savings and payback periods are unknown and vary based on the existing practices.

Distribution - improve steam traps. Using modern thermostatic element steam traps may reduce energy use while improving reliability. The main efficiency advantages offered by these traps are that they open when the temperature is very close to that of the saturated steam (within $4^{\circ} \mathrm{F}$ or $2^{\circ} \mathrm{C}$ ), purge noncondensable gases after each opening and are open on startup to allow a fast steam system warm-up. These traps also have the advantage of being highly reliable and useable for a wide variety of steam pressures (Alesson, 1995). The exact savings and market penetration potential in the corn wet milling industry are unknown. One disadvantage to thermostatic steam traps is that testing is trickier and therefore maintenance is more difficult than on bucket traps.

Distribution - maintain steam traps. A simple program of checking steam traps to ensure they are operating properly can save significant amounts of energy for very little money. If the steam traps are not regularly monitored, 15 to $20 \%$ of the traps may be malfunctioning. Energy savings for a regular system of steam trap checks and follow-up maintenance is conservatively estimated at 10\% (DOE, 2001b; Jones 1997; Bloss, 1997). Einstein et al. (2001) estimate a payback of less than one year for this measure. It is even economical to hire a specialist to check steam traps (Blanchard, 2002). Although this measure offers a quick payback, it is often not implemented because maintenance and energy costs are separately budgeted. In addition to energy and cost savings, proper functioning of steam traps will reduce the risk of corrosion in the steam distribution system, saving even more in the long term.

Distribution - monitor steam traps automatically. Attaching automated monitors to steam traps in conjunction with a maintenance program can save even more energy without significant added cost. This system is an improvement over steam trap maintenance alone, because it gives quicker notice of steam trap failure, and can detect when a steam trap is not performing at peak efficiency. Using automatic monitoring is conservatively estimated to give an additional 5\% energy savings over steam trap 
maintenance alone with a payback of 1 year $^{13}$ (Johnston, 1995; Jones, 1997). Systems that are able to implement steam trap maintenance are also likely to be able to implement automatic monitoring. There may, however, be some small additional operations and maintenance costs to maintain the monitors.

Distribution - repair leaks. As with steam traps, the distribution pipes themselves often have leaks that (on average) go unnoticed without a program of regular inspection and maintenance. In addition to saving $3 \%$ of energy costs, having such a program may reduce the likelihood of having to repair major leaks, thus saving even more in the long term (DOE, 2001b).

Distribution - recover flash steam. When a steam trap purges condensate from a pressurized steam distribution system to ambient pressure, flash steam is produced. As with flash steam produced by boiler blowdown, this steam can be used for space heating or feed water preheating (Johnston, 1995). The potential for this measure is extremely site dependent, as it is unlikely that a producer will want to build an entirely new system of pipes to transport this low grade steam to some places where it can be used. If, on the other hand, the areas where low-grade heat is useful were very close to the steam traps anyway, this measure would be easy to implement and could save considerable energy.

\subsection{Steeping}

All energy efficiency measures in the steeping stage are in the research, development and/or testing stages. See the Future Technology section for further discussion (Section 5.8).

\subsection{Fermentation and Ethanol Production}

After producing starch, some wet milling plants convert it to ethanol. The measures in this section will be applicable only to these ethanol-producing plants.

Improving yeast fermentation. Improving the yeast in the fermentation stages at some plants may lower energy costs. Yeast that can work in higher ethanol concentrations is projected to lower the energy costs of distilling alcohol (Hohmann and Rendleman, 1993). Immobilized yeast, for example, is a technique that suspends yeast in a gel so that a continuous stream of the material (glucose) being fermented passes through the gel. This method speeds the fermentation process, lowers energy requirements and increases ethanol yields (Hohmann and Rendleman, 1993). The use of immobilized yeast is currently being used in the beer brewing industry in a few industrial scale applications. It is also being used in ethanol production in Brazil with increased fermentation rates 1.2 to 2.5 times that of free yeasts (Wendhausen et al., 2001).

Bacterial fermentation. A possible substitute for improved yeast is the bacterium Z. mobilis. In tests, Z. mobilis has raised alcohol yields slightly, allowed fermentation at higher temperatures, required less cooling and thus reduced energy requirements and had a greater conversion efficiency (Hohmann and Rendleman, 1993). One group projects production cost savings at 2 cents per gallon of ethanol produced, mostly in capital costs because the savings from reduced capacity requirements per bushel of feedstock would outweigh the costs of the new equipment needed (Hohmann and Rendleman, 1993). Others suggest operation costs savings of 1.1 to 3.1 cents per gallon (Krishnan et al., 2000). Drawbacks to the use of Z. mobilis bacteria are that it is less stable than yeast and more sensitive to changes in $\mathrm{pH}$ and temperature.

\footnotetext{
${ }^{13}$ Calculated based on a UK payback of 0.75 years. The US payback is longer because energy prices in the US are lower, while capital costs are similar.
} 
Another benefit is the decreased water use due to the capacity to ferment a more concentrated solution (Krishnan et al., 2000). When using a fluidized bed reactor, capital costs are also projected to decrease (Krishnan et al., 2000).

Molecular Sieves. Molecular sieves can be used in dehydrating ethanol instead of evaporation. Most modern molecular sieve dehydrators use a process called pressure swing adsorption to remove water from a vaporized feed stream (Jacques et al., 1999). In ethanol dehydration, water is removed from ethanol. High pressure is applied to the feed stream that is passed through an adsorbent with a strong affinity for water and little affinity for ethanol, thus removing the water but allowing the ethanol to pass. After the ethanol stream passes through, water is removed by lowering the pressure, regenerating the sieve.

If the feed vapor comes directly from the rectifier column of the starch purification stage, the only energy required by the molecular sieve dehydrator is the steam required to superheat the vapor to bed operating temperatures, equal to 0.1 to $0.2 \mathrm{lbs}$ of steam per gallon of anhydrous ethanol, and the electricity to operate the pumps, $0.02-0.03 \mathrm{Wh} / \mathrm{gal}$. In addition, the system will require energy to redistill the liquid that results during regeneration, though this can be supplied from the stored heat of adsorption, and electricity to operate the cooling tower and air compressor. A properly designed molecular sieve system with a feed containing $5 \%$ water will require a total of $4 \mathrm{kBtu} / \mathrm{gal}$ anhydrous ethanol to dry to $0.25 \%$ water (Jacques et al., 1999). According to Lorenz and Morris (1995), for the same feed and product, a rectification and solvent extraction (evaporation) system would require $96 \mathrm{kBtu} /$ gallon of ethanol produced, eight times the energy of the molecular sieve technique.

In addition to energy savings, an advantage to using molecular sieves is that they can operate at a wide range of specifications. They can be applied to all facilities with production capacities of up to 100 million gal/year of ethanol. Molecular sieve adsorption technology is being used in one large plant in Brazil with a capacity of over 60 million gallons/year since 1993 (Jacques et al., 1999). They can be used to dehydrate ethanol containing up to $20 \%$ water and can dehydrate down to a purity of $20 \mathrm{ppm}$.

\subsection{Mechanical dewatering}

Energy requirements for removing moisture from germ, fiber and gluten by mechanic dewatering (pressing, filtering, sedimentation, etc.) are generally insignificant compared to evaporation (Best Practice Programme, 1997). Hence, as much moisture as possible should be removed mechanically before materials are sent into a dryer, especially when the initial moisture content is high.

Germ is easy to dewater by squeezing it inside a screw press screen barrel. Fiber is much more abrasive and thin or stringy and, therefore, more difficult to press. Gluten is a fine material that does not lend itself to any conventional screw press operation and is generally dewatered by vacuum filtration in the U.S. (Wideman, 2001).

Decanters are used for wheat, potato and starch dewatering. By reducing the torque on the conveyor transporting the solid phase, decanters become more efficient (Stroyer, 2002). The Plough Tile with its curved tip is a good example of how to reduce torque. The curved tip cuts solids during transportation, unlike its predecessor with sharp edges, increasing its overall energy efficiency.

Germ dewatering. Screw presses are used almost exclusively to dewater germ (Wideman, 2001). They reduce germ moisture from 80 to $90 \%$ to less than $50 \%$. Three different screw presses can dewater germ: compression ratio, compressed plug or screen disc press. Screen disc presses have the smallest energy requirements but also the smallest capacity, $10 \mathrm{HP}$ for 30,000 bu/day. Of the other two, compressed plug presses require less energy than compression ratio presses because of the lower squeeze required on the 
germ. Capacity for both is 20,000 to $120,000 \mathrm{bu}$ /day. However, only 20 to $40 \mathrm{HP}$ is required for compressed plug whereas 40 to $125 \mathrm{HP}$ is required for compression ratio presses. Therefore, if a compressed plug press replaces a compression ratio press, savings of 20 to $85 \mathrm{HP}$ (360 to $1500 \mathrm{kWh} / \mathrm{bu}$ ) can be achieved, equaling a savings of 50 to $70 \%$. In addition, no periodic maintenance is required for compressed plug presses. For a conventional compression ratio, the period between maintenance stops is usually over one year.

Fiber dewatering. Single screw presses are currently used almost exclusively to mechanically dewater fiber, though twin screw presses are available (Wideman, 2001). Fiber enters each of the presses with an 80 to $90 \%$ moisture content and leaves the screw process with about $60 \%$. Each has a recommended maintenance period of once per year. Capacity for single screw presses is 20,000 to $75,000 \mathrm{bu} /$ day using 40 to $125 \mathrm{HP}$. Twin screw press capacity is less on both accounts, just 13,333 to 40,000 bu/day, using 50150 HP. Twin roll presses and solid bowl centrifuges have also been used.

The British Sugar Beet Factory at Wissington (UK) operates six presses and three rotary dryers to dry its pulp (Best Practice Programme, 1997). Water is expelled from wet beet pulp by a mechanical screw press at $8.69 \mathrm{~kg} / \mathrm{s}$, consuming energy at a rate of $23 \mathrm{~kJ} / \mathrm{kg}$ of water $(10 \mathrm{Btu} / \mathrm{lbs})$. Then the dryers remove 6.88 $\mathrm{kg} / \mathrm{s}$, consuming energy at a rate of $2,907 \mathrm{~kJ} / \mathrm{kg}$ of water $(1,250 \mathrm{Btu} / \mathrm{lbs})$. Using mechanical dewatering saved 55.8\% in primary energy use (Best Practice Programme, 1997).

Starch dewatering filters. The material fed into a starch dryer is typically dewatered with a centrifuge or hydrocyclone system. Larox has developed a filter that can dewater the starch cake before being sent to the dryer with a higher throughput, lower energy use and lower moisture content than the conventional systems (Larox, 2002). The Larox Pressure Filter allows constant pressure to be applied, independent of starch cake thickness, reducing the moisture of the dewatered starch to about $90 \%$ of a typical centrifuge.

Table 9: Energy savings from dewatering (due to a $1 \%$ reduction in dryer feed moisture) ${ }^{1}$

\begin{tabular}{|rlll|}
\hline & Germ & Fiber & Gluten \\
\hline Dewatering method & Screw press & Screw press & Rotary vacuum filter \\
Feed moisture & $50 \%$ & $60 \%$ & $60 \%$ \\
Type of dryer replacing & Steam tube & Flash & Flash \\
Discharge moisture & $3 \%$ & $20 \%$ & $10 \%$ \\
Lbs $\mathrm{H}_{2} \mathrm{O} /$ bushel $(-1 \%)$ & 0.1400 & 0.3367 & 0.1422 \\
\% of dryer load & $4.05 \%$ & $4.88 \%$ & $4.39 \%$ \\
Dryer savings/year & $\$ 34,000^{2}$ & $\$ 93,000^{3}$ & $\$ 39,000^{3}$ \\
Additional Evaporation Capacity/Year & $\$ 10,000^{4}$ & $\$ 23,000^{4}$ & $\$ 10,000^{4}$ \\
Net energy savings/year & $\$ 24,000$ & $\$ 70,000$ & $\$ 29,000$ \\
\hline
\end{tabular}

${ }^{1}$ Based on 100,000 bu/day grind, $15 \%$ corn moisture and 343 operating days/year. Savings estimated for a $1 \%$ reduction in the dryer feed moisture for energy only; no additional credit has been taken for increased dryer capacity, although savings would be accrued here as well.

${ }^{2}$ Steam $\$ 5 / 1000 \mathrm{lb}, 1.4 \mathrm{lb} / \mathrm{lb}$ evaporation

${ }^{3}$ Natural gas $\$ 6 / \mathrm{Mbtu}, 1350 \mathrm{Btu} / \mathrm{lb}$ evaporation

${ }^{4}$ Steam $\$ 5 / 1000 \mathrm{lb}, 0.4 \mathrm{lb} / \mathrm{lb}$ evaporation

Taken from Wiseman, 2001.

The filter replaces two washing centrifuges and one dewatering centrifuge, simplifying the process, reducing maintenance costs and reducing required space amounts. Larox claims their filters require only $10 \%$ of the installed power of a conventional centrifuge dewatering system. They estimate that at $\$ 0.03 / \mathrm{kW}$, the Larox Pressure Filter saves over $\$ 25,000$ per year with electricity savings of $640,000 \mathrm{~kW}$ annually. In addition, less water is used in the process, smaller initial investment is required for new installations and by increasing throughput, overall plant capacity is increased (Larox, 2002). N. B. Love 
Ltd (Australia), Goodmand Fielder Ind. Ltd. (Australia) and ABR Foods Ltd. (UK) have installed Larox filters and found reduced operational costs.

\subsection{Drying technology}

Because of the temperatures used in steeping and the extensive drying and evaporation required in corn wet milling, drying technology, as well as heat and steam distribution systems (see Section 5.1.7) are an important part of the plant. For evaporators, the major sources of heat loss are excessive venting, radiation or convection losses, poor vacuum system performance, air leakage, water leakage, fouling and poor separator efficiency (Singh, 1986). Some of these are addressed below. Many of the measures in this section are cross-cutting and have been either applied successfully in corn wet milling or in another related industry (e.g. other food processing industries) with similar requirements.

Process integration/pinch technology. Process integration or pinch technology refers to the exploitation of potential synergies that are inherent in any system that consists of multiple components working together. In plants that have multiple heating and cooling demands, the use of process integration techniques may significantly improve efficiencies.

Developed in the early 1970s, pinch technology is now an established methodology for continuous processes (Linnhoff, 1992; Caddet, 1993). The methodology involves the linking of hot and cold streams in a process in a thermodynamic optimal way (i.e. not over the so-called "pinch"). Process integration is the art of ensuring that the components are well suited and matched in terms of size, function and capability. Pinch Analysis takes a systematic approach to identifying and correcting the performance limiting constraint (or pinch) in any manufacturing process (Kumana, 2000a). It was developed originally in the late 1970s at the University of Manchester in England and other places (Linnhoff, 1993) in response to the energy crisis of the 1970s and the need to reduce steam and fuel consumption in oil refineries and chemical plants by optimizing the design of heat exchanger networks. Since then, the pinch approach has been extended to resource conservation in general, whether the resource is capital, time, labor, electrical power, water or a specific chemical species such as hydrogen.

The critical innovation in applying pinch analysis was the development of "composite curves" for heating and cooling, which represent the overall thermal energy demand and availability profiles for the process as a whole. When these two curves are drawn on a temperature-enthalpy graph, they reveal the location of the process pinch (the point of closest temperature approach), and the minimum thermodynamic heating and cooling requirements. These are called the energy targets. The methodology involves first identifying the targets and then following a systematic procedure for designing heat exchanger networks to achieve these targets. The optimum approach temperature at the pinch is determined by balancing the capitalenergy tradeoffs to achieve the desired payback. The procedure applies equally well to new designs as well as retrofit of existing plants.

The analytical approach to this analysis has been well documented in the literature (Kumana, 2000b; Smith, 1995; Shenoy, 1994). Energy savings potential using pinch analysis far exceeds that from wellknown conventional techniques such as heat recovery from boiler flue gas, insulation and steam trap management. Kumana (2000c) has reviewed pinch analyses in about 20 US corn wet milling plants and found cost savings potentials varying between 8 and 40\%, and payback periods ranging from 1.5 to 3 years. He also notes water savings utilizing pinch technology (for water) have been on the order of 20 to $25 \%$ through reuse by simple piping changes.

The American Fructose, Inc., Decatur, Alabama corn wet milling plant, advised by the US DOE Office of Industrial Technologies, participated in a process integration study and used the ideas of process 
integration to cut costs and save energy. In 1991, the plant managers installed a new heat pump and began saving \$300,000 annually in coal and natural gas costs (DOE, 1993). If the plant is expanded, further savings are expected. The payback for the heat pump installation is slightly more than one year. In addition, increased efficiency has allowed the plant managers to shut down an existing heater and avoid a new cooling tower. $\mathrm{NO}_{\mathrm{x}}$ emissions are reduced by 42 tons per year. Installations of heat pumps in other industries have had similar results, with paybacks between 8 months and 2 years (DOE, 1993).

Another example of integration was at a refinery expansion at the Dimmitt, Texas plant, now owned by Cargill. In addition to the three multiple effect evaporators, a steam turbine driven mechanical vapor recompression evaporator was added to handle the most dilute streams (see multiple effect evaporators and mechanical vapor recompression sections for more information on these technologies) (Blanchard, 2002). The turbine back-pressure supplied 15 psig steam to the multiple effect evaporators. A 400 psig boiler was needed for the turbine but the costs were still economically justified (Blanchard, 2002).

GEA Barr-Rosin has developed several heat integration systems that utilized recycled exhaust gases, regenerative thermal oxidizers (RTO, see RTOs in Section 5.7 for more information) and waste heat evaporators. These systems have been implemented at National Starch \& Chemical Co. and at Grain Processing Group with success. They reported lower energy consumption for the drying system, good product quality, elimination of odor from the feed dryer (by using the RTO), flexibility and robustness of the system during normal operation and upsets, reduced volume of exhaust gas to the atmosphere and no required high temperature heat exchangers (Svonja, 2000). Details of the components of these systems are described in the "Reusing waste heat" section.

Controls on heaters between steps. One hundred (100) psig steam heaters are often used between steeps because they are small and cheap (Blanchard, 2002). When properly controlled, most of the time these heaters should be unnecessary and turned off. It is important, therefore, that good controls are used in conjunction with the heaters.

Reusing waste heat. Waste heat from the starch dryer can be reused. There are two ways of recovering this heat: recuperation via heat exchangers or direct recycle back into the dryer. When using heat exchangers, a number of factors should be considered in addition to savings from energy efficiency: extra fan power may be required, dust may damage the heat exchanger surfaces and energy integration may increase the complexity of start-up and shutdown operations and limit flexibility (Best Practice Programme, 1997). In exhaust recycling, the recycle gas must be completely free of dust if there is a risk of it being ignited in the heat source. The changed humidity-temperature profiles should be checked to ensure they do not adversely affect the quality of the product. Simple gas burners may have problems igniting or with stability in direct systems if high levels of recycling cause high humidity and low oxygen levels. Equilibrium levels of impurities may build up, and if sulfur is carried over from earlier steeping, dew point corrosion may be a risk. However, odors are concentrated in direct or indirect recycling and are easier to remove. If the problems can be overcome, recycling may be a cost-effective way to save energy that would otherwise be wasted.

GEA Barr-Rosin (Barr-Rosin) has developed a number of dryers and dryer systems that recycle waste heat. One such system integrates the gluten dryers with a waste heat evaporator (WHE) and a regenerative thermal oxidizer (RTO) (see Section 5.7) (Svonja, 2001). Generally, this system reuses the energy put into some of the steepwater evaporators and the heat input to the RTO to dry the light steepwater and gluten. The WHE uses the latent heat given up by the vapor in the steepwater to evaporate light steepwater in earlier stages or in the RTO. By combining the WHE with the RTO, the exhaust contains less water vapor and the size of the RTO is reduced. The hot RTO exhaust provides $50 \%$ of the heat for the gluten dryer (Svonja, 2000). In addition to saving energy, Barr-Rosin claims the system achieves great flexibility of operation, eliminates odor and reduces exhaust volume. In the Barr-Rosin system, 
convective dryers were chosen because they produced the best product quality by minimizing heat damage. However, other types can be used and Barr-Rosin provides detail for each dryer type available for reusing waste heat, including direct fired feed and corn gluten meal dryers, rotary feed dryer and fluidized bed dryer (for germ drying), as well as WHE and RTO (Svonja, 2001).

Another system developed by Barr-Rosin is a closed exhaust gas recycle on the direct gas fired rotary dryer treating the dewatered corn fiber mixed with steep liquor ("heavy steepwater"). In this system, the dryer exhaust is recycled back to the air heater as dilution air; the only fresh air used is that for combustion. According to Barr-Rosin, in addition to saving energy by recovering the heat in the recycled exhaust gas, other benefits are accrued. Total mass of emissions and final exhaust are less because the exhaust gas is recycled, emission control equipment is less costly and the operation is safer because the oxygen content of the drying medium is low (Svonja, 2000).

Barr-Rosin has also created a similar recycle system for germ drying. They use a direct gas fired fluidized bed dryer (see "Replace dryer with more efficient dryer" section). The dryer recycles most of the exhaust gases as "dilution air" to supplement drying medium; the only fresh air inlets to the system are burner combustion air, cooling air and possible leaks (Svonja, 2000).

Another case study in the corn wet milling industry (Maine) indicated that heat recovery would cost $\$ 46,000$ to implement and save $\$ 20,829$ annually in fuel oil, resulting in a payback of about 2.2 years (IAC, 2001). ${ }^{10}$

Replace dryer with more efficient dryer. Some dryers are more efficient than others, particularly when they can recapture otherwise lost waste heat. Direct dryers are typically more efficient than indirect dryers. Typical efficiencies for direct and indirect dryers are listed in Table 10. However, water formed during combustion in direct heating may decrease the efficiency of drying.

Table 10: Efficiencies of dryers using direct and indirect heating

\begin{tabular}{|lc|}
\hline Dryer Type & Typical Efficiency* \\
\hline Direct heating & $95-98 \%$ \\
Indirect, steam/air & $85 \%$ \\
Indirect, thermal fluid/air & $85 \%$ \\
Indirect, air/air & $70-80 \%$ \\
\hline
\end{tabular}

Natural gas is the preferred fuel for directly drying corn products. In addition to being cost-effective, it is less polluting and less contaminating for the products.

Fluidized bed dryers are mainly suitable for drying granular solids and operated best on solids with a narrow particle size distribution. For this reason, they are particularly suitable for drying germ. CPC Nederland BV in Sas van Gent (the Netherlands) replaced a conventional steam-heated rotating pipe bundle dryer (indirect heated rotary dryer) with a fluidized bed dryer for germ drying (Mercer, 1994). The dryer in this project used flue gases from a combined heat and power unit already installed. The hot exhaust gases from the CHP-unit are blown through a bed of the corn germ. A perforated grid supports the germ and ensures an even distribution of the gases. The dried product is continuously removed and the suspended residue is extracted using cyclonic separators. The CHP unit provides gases at $266^{\circ} \mathrm{F}\left(130^{\circ} \mathrm{C}\right)$ to the fluidized bed dryer, which are extracted by fans using $260 \mathrm{~kW}$ of power. No additional heat is required. The energy saved due to the difference in energy saved and additional energy required by the fans is $63 \%$, over $2.5 \mathrm{GJ} /$ tonne (LHV) of germ produced, equivalent to $2.4 \mathrm{MBtu} /$ ton germ (HHV). 
Investment costs were $\$ 1.6$ million (U.S.) and annual savings were $\$ 270,000$ (U.S.), giving a payback of 6.4 years. Under US conditions, the payback period will depend on the fuel costs for the particular site. The expected lifetime of the dryer is 15 years. Improvements could also be made in the process to better utilize the heat by optimizing the relationship between bed surface area, bed height, gas flow and the average residence time of the germ in the bed. Heat from the dryer exhaust at $190^{\circ} \mathrm{F}\left(88^{\circ} \mathrm{C}\right)$ could also be recovered again for use elsewhere in the milling process. If these were included, the payback period would drop below the 6 years of the original project.

APV manufactures an evaporation system specifically designed for the evaporation of highly viscous liquids, such as concentrating sugar solutions to extremely high solids content (up to $98 \%$ has been achieved) or concentration of high solids corn syrups (APV, 2002). Their system, called the APV Paravap, is designed to operate as a climbing film evaporator with evaporation taking place in plate passages. APV notes that most Paravap designs do not require liquid recirculation and can be used with temperature sensitive products.

Plate heat exchanger (PHE). Plate heat exchangers may effectively replace shell and tube heat exchangers where no extreme temperatures or pressures are required. PHEs have higher heat transfer efficiencies, lower operational, installation and investment costs, high flexibility and produce higher product quality because of shorter residence times (Krook, 2001). Alfa Laval produces the AlfaVap plate evaporator for evaporation of sugar products. Over 600 AlfaVaps have been installed throughout the world. Plate evaporators like the AlfaVaps are eventually expected to replace standard falling film evaporators in the starch industry.

Direct Use of Gas Turbine Offgases for Drying. In the production process, both fibers and gluten are dried using hot air, heated directly by gas burners. Currently, gas burners are used, with or without low$\mathrm{NO}_{\mathrm{x}}$ features. It is feasible to use the fluegas of a gas turbine to provide the heat, while cogenerating power. If an existing gas turbine is onsite, the fluegas can be transported to the drier, if this layout is feasible for the specific plant. In large capacity plants, a separate gas turbine could be constructed close to the drier. $\mathrm{NO}_{\mathrm{x}}$ emissions of gas turbines vary widely. Tests in the Netherlands have shown that the flue gases do not affect the drying air and product quality negatively, depending on the type of gas turbine selected (Buijze, 1998). Bypass of the gas turbines makes it possible to maintain the turbine and run the drying process (Buijze, 1998).

The Cerestar plant in Sas van Gent (the Netherlands) is currently one of the largest corn wet milling operations in Europe. In 1998, Cerestar investigated the use of two gas turbines to dry gluten and replace a steam drier. The gluten quality is not affected by the use of flue gases. The study found that the use of the gas turbines was feasible and would result in savings of 190,000 MBtu/year (Buijze, 1998). The savings are equivalent to $10-14 \%$ of the total fuel consumption on-site.

Avebe is a major starch producer in Europe, using potatoes as the feedstock. The Avebe plant in Gasselternijveen (the Netherlands) uses a steam-injected gas turbine (STIG) installation to provide both power and heat for the plant. The use of a STIG enables the user to inject excess steam in the turbine to boost power production at specific times. Still, the gas turbine was often running at less than full load, reducing the efficiency of the turbine. A study showed that it is more efficient to use the waste heat (i.e. flue gases) from the gas turbine directly to dry the protein rich cattle feed by-product. The excess flue gases are mixed with air and used directly for the drying process. The project was expected to result in savings of 55,000 MBtu/year (or 12\% of total fuel consumption) with investments of $\$ 600,000$ (1995). Under conditions in the Netherlands in 1995, this resulted in a simple payback period of 2.5 years (NOVEM, 1995). 
Multiple effect evaporators. Multiple effect evaporators are more energy-efficient than single effect evaporators because earlier stages reuse the heat from later stages. Table 11 lists approximate efficiencies for typical installations of one through five stages of multiple effect evaporators.

Table 11: Multiple effect evaporator efficiencies*

\begin{tabular}{|cc|}
\hline & $\mathrm{Lb} \mathrm{H}_{2} \mathrm{O}$ evaporated/lb Steam \\
\hline Single effect & 0.95 \\
Double effect & 1.75 \\
Triple effect & 2.5 \\
Quadruple effect & 3.25 \\
Quintuple effect & 4.2 \\
*Efficiencies will vary with pressure of the latent heat of steam and \\
numbers given are approximations for typical installations. Older \\
Estimates are given in Singh (1986). \\
Source: Blanchard, 1992
\end{tabular}

There is a tradeoff between the operational savings and the added capital costs from additional effects. In addition, when an effect is added, temperature at the beginning stage must be greater to accommodate the required temperature differential for drying. Because corn products are sensitive to high temperatures, higher effects may not be an option. According to one vendor, in general when the evaporation rate is above 3,000 lbs/hr (1,350 kg/hr), multiple effect evaporation should be considered (APV, 2002).

Local supply sources of energy may dictate what type of drying technique is used. In cases where thermal heat is produced by onsite cogeneration, thermal vapor recompressors may be much cheaper and practical to use. Multiple effect evaporators are already often used in concentrating steepwater (as discussed in Section 3), but are being replaced in some cases by mechanical vapor recompression (discussed below).

Process integration may also help to improve the efficiency of multiple evaporators. (See Process integration/pinch technology section, above.)

Thermal and Mechanical Vapor Recompression. Thermal and mechanical vapor-recompression (TVR and MVR) are process designs that reuse the water vapor produced during the evaporation process by recompressing it using thermal or mechanical means. Potential use of each design depends on such characteristics as viscosity, heat sensitivity and the desired level of concentration or purity of the product to be evaporated. Also important are the energy resources, and labor, operating and maintenance capabilities of a particular plant. Because of compression limitations and the high costs of evaporation under vacuum, vapor recompression units are mainly applicable where the product is not too concentrated and can be boiled under atmospheric or moderate vacuum conditions (Blanchard, 1992).

With significant boiling point elevation or vacuum, the size of the vapor recompression equipment is unrealizable. The corn wet milling industry does use some mechanical vapor recompression. While a MVR has relatively high capital costs compared to other evaporators, it requires fewer vessels than multiple-effect evaporators resulting in lower overall installation costs. In regions where water is scarce, MVR or TVR is a particularly good option; the reuse of the vapor of the process significantly reduces water requirements (Macek, 1992). MVR requires almost no cooling water, whereas a steam heated system requires about 6 U.S. gal $/ \mathrm{lb}$ steam $\left(0.05 \mathrm{~m}^{3} / \mathrm{kg}\right.$ steam $)$ According to one vendor, mechanical vapor recompression is the most thermodynamically efficient technique to evaporate water, equivalent to an evaporator of over 100 effects (in theory) or 30 to 55 effects (in practice) (APV, 2002). They estimate for medium to large sized evaporators, the payback for the additional capital of an MVR is 1 to 2 years. 
Corn Products International's Stockton, California plant had originally installed a mechanical vapor recompression unit, which was converted to thermal vapor recompression after a CHP plant was constructed. The new CHP system provides low-cost steam (compared to the costs of power in California) for the recompression unit. Generally, if low-cost steam is available at a medium pressure of about 100 psig, TVR should be considered across one, two or three effects (APV, 2002). APV claims that this is the simplest and least costly technique for enhancing evaporator efficiency (APV, 2002). As available steam pressure decreases, however, so does the effectiveness of the evaporator.

American Fructose's (now Cargill's) corn wet milling plant in Decatur, Alabama installed mechanical vapor recompression in 1991. The new heat pump saves the company $\$ 300,000$ in energy costs (coal and natural gas) annually. The economic payback period for the heat pump installation is short, just over one year. The increase in plant efficiency resulting from the changes has enabled plant management to shut down an existing heater and to circumvent the need for a new cooling tower. The associated environmental benefits include a reduction in NOx emissions by 42 tonnes per year.

Cerestar Benelux (Sas van Gent, the Netherlands) installed a MVR unit of $21 \mathrm{MWh}$ in 1986 when constructing a new plant on their existing site. The installation resulted in savings of 280,000 MBtu/year (or $15-20 \%$ of the total energy consumption). The extra investments compared to a three-effect evaporator were approximately $\$ 2$ million (1986), resulting in a simple payback period of less than 2 years. Under current U.S. conditions, the payback period would be longer than 2 years. The reliability of the MVR installation has been high.

Other industries have also successfully implemented both mechanical and thermal vapor recompression systems. The dairy company Sunmöre Meieri (Norway) used mechanical vapor recompression to concentrate the basic ingredients of brown cheese (cream, milk and whey) from $11 \%$ dry matter to $55 \%$ dry matter. By using MVR, the plant used $0.032 \mathrm{kWh}$ of electricity per kg of steam evaporated, compared to $0.450 \mathrm{kWh}$ of fuel per $\mathrm{kg}$. This resulted in savings of $27 \mathrm{GWh}$ per year (Berntsson and Franck, 1997). MVR was also used in the dairy industry in Japan at the Nishi-Shunbetsu plant. Their system combined the principles of both MVR and multi-effect evaporation in a quadruple-effect MVR evaporator. Similar to corn wet milling, it was necessary to control the maximum temperatures to avoid scorching the milk and contaminating the surfaces of the heat transfer pipes in the evaporator. The coefficient of performance was 22 and the system operated successfully with an overhaul of the compressor every two years. The project cost was $\$ 1,500,000$ (1984 U.S.) (Berntsson and Franck, 1997).

In the chemical industry, MVR is used to compress the overhead top vapors in the distillation column at the Shell Nederland Chemie plant in Pernis (the Netherlands). By using MVR instead of cooling the vapors, not only is steam saved in the heating, but cooling water is also eliminated and a better split between products was realized (Berntsson and Franck, 1997). The total costs for the investment and installation of the MVR system were $\$ 9.6$ million (1997 U.S.). At natural gas prices of $0.152 / \mathrm{m}^{3}$ and electricity costs of $0.069 / \mathrm{kWh}$, savings from energy were $\$ 4.9$ million (1997 U.S.), yielding a payback of 2 years.

Operations and maintenance. A simple maintenance program to ensure that all components of the drying system are operating at peak performance may result in substantial savings. Some maintenance measures are listed below:

- Check to make sure fuel/air ratio controllers are functioning properly and without hysteresis (the ratio should be the same whether the fuel rate is being increased or decreased);

- Check heat exchangers and dryers for fouling, leaks and blockages that may impair preheating or heat recovery fuel; 
- Ensure that fuel and air ports and flues are clear. Tunnel Refineries in Greenwich (UK), a corn wet and wheat milling company, unblocked a heat recovery unit using compressed air, clean water and a dilute acetic solution. They found a payback less than two weeks.;

- Ensure that fans are operating properly;

- Check the furnace pressure control;

- Optimize the performance of set points;

- Insulate equipment for minimum heat loss;

- Use proper air-to-fuel ratio.

Improve process control. Monitoring the outlet temperature and moisture levels and controlling the dryer feed conditions and temperature may save energy in drying and narrow the range of product dryness, thus improving product quality. Model Predictive Control (MPC) is being applied to a number of food industries, including corn wet milling (Morris, 1998). MPC is a multivariable control strategy that uses a mathematical model embedded in a control-system to predict the future effects of current control efforts. In this way the controller can predict process behavior and proactively optimize control in real time, and hence, continuously. In corn wet milling, it can be used to optimize the plant's evaporator and dryer systems.

Anchor Products, Ltd., the manufacturing arm of the New Zealand Dairy Group (Hamilton, New Zealand) operates an advanced system using MPC (Morris, 1998). In 1994, Anchor opened a new milk powder plant at Waitoa (New Zealand) and selected the "Process Perfecter" developed by Pavilion Technologies (based in Austin, Texas) for their MPC system, replacing the programmable logic controllers (PLCs) and supervisory control and data acquisition (SCADA). The three evaporators at Waitoa are mechanical vapor recompression, falling film and thermal vapor recompression to concentrate milk from $9 \%$ total solids to $50 \%$ total solids. The new MPC's were found to minimize energy consumption, improve product quality and reduce variability in concentrate density by up to $70 \%$. The project increased capacity of two evaporators by $7.4 \%$ and one by $8.2 \%$. It has achieved a NPV of $\$ 1.6$ million, exceeding the target of $\$ 1$ million, with an IRR of $77.3 \%$. Another system, the Connoisseur adaptive MPC system, was installed at a Kiwi Dairy plant (New Zealand), controlling process temperature, pressure and product flow and density saved \$200,000 per year through improved product quality, reduced rework and lower energy costs (Morris, 1998). A major U.S. starch refiner is currently applying the Connoisseur system; deviation of product moisture content has been improved by a factor of three (Morris, 1998).

Tunnel Refineries, corn wet and wheat millers in Greenwich (UK) began monitoring for variability in moisture levels as a part of its ISO 9002 quality assurance program. Adopting appropriate controls to account for this variability improved quality, conserved energy and resulted in a payback that was immediate (Best Practice Programme, 1997).

Simpler dryer control systems have been applied in a number of industries. For example, Laporte Earths' Fullers Earth Works (UK) dries raw earth or clod from a moisture content of 32-39\% down to several different moisture levels. They found implementing a control system with a feedback loop to the feed stream saved them $6 \%$ on drying from energy savings alone, and an extra $7 \%$ savings due to improved product consistency. They found savings of $0.2 \mathrm{GJ} /$ tonne (or $0.2 \mathrm{MBtu} /$ ton), yielding a payback of just 14 months (Best Practice Programme, 1997).

British Sugar operates nine sugar beet processing plants in England. Similar to corn wet milling, after sugar extraction, the spent beet pulp is dried for cattle feed. Rotary dryers dry approximately 700,000 tonnes per year of pulp from $60 \%$ (wet) to $10 \%$ moisture. In order to improve product quality, save energy and/or increase throughput, they used model-based predictive control to link feed moisture, product moisture, tail end temperature and other drying parameters. Investment costs were about 50,000 
GBP (\$76,000 1997 U.S.) per factory yielding a payback of about 5 months (Best Practice Programme, 1997).

Reduction of air supply rate. The vapor-to-air ratio in the exhaust gas of a dryer should be maximized to increase efficiency of the dryer. To dry a fluid, the vapor stream must exit at a higher heat content than it entered or no drying will occur. The air stream, however, needs only to carry heat to the product and blow the resulting vapor out of the dryer. Hence, by properly adjusting the vapor content of the exiting airstream, heat lost to the air can be minimized.

Challenging customer demand. Feed products are usually dried to a certain specification before being shipped to customers. In California, this is not necessary because the feed goes directly to farms for food. Less drying of the product saves energy and money for the corn wet miller. At Tunnel Refineries in Greenwich (UK), the corn wet millers questioned the need of drying of pelleted animal feed products. After some market research, they were able to convince customers to accept the feed in its undried, natural form. Tunnel Refineries completely eliminated the drying and pelleting operations, saving significantly in energy and costs (Best Practice Programme, 1997). Payback was immediate.

\subsection{Membranes}

Removing water at various stages of the corn wet milling process is a major energy consumer in the corn wet milling industry. Membrane separation processes could potentially be a suitable energy-efficient alternative in various stages of the production process. Membranes are selective barriers that allow the passage of certain species in a fluid, based on the size of the molecules. In practice, the feed solution is pumped across a membrane at a given pressure. Some of the solution (only aqueous solutions are discussed) passes through the membrane and is called the filtrate or permeate; the remaining solution, which will have a higher concentration of the retained materials, is called the concentrate or retenate. In the most restrictive use of membrane separation, nearly all ions and solutes are retained and only water passes. This is called reverse osmosis.

Membranes offer a method of removing water from solution that has important advantages over evaporation or distillation. Not only is there no heat required for the separation (except in pervaporation systems), but there is no change of phase, so latent heat requirements are avoided. Therefore, significant energy savings are observed; even up to $90 \%$ savings have been reported (Rausch, 2002b). However, in some cases, high pressures and recirculation rates require a significant amount of energy and may not result in net savings.

Fortunately, membranes generally offer also other benefits in addition to energy savings. Since exposure to heat is reduced, nutritional quality and digestibility is conventionally thought to be improved (Rausch, 2002b). Membranes give plants greater control over the production of alcohol and separation of the various products (Hohmann and Rendleman, 1993). They often produce better yields and with fewer moving parts, are generally more reliable. Recovery and reuse of water generally reduces overall plant water needs. For example, Kollacks and Rekers (1988) reported on a reverse osmosis (RO) system used for steepwater concentration. This system saved as much as 175 liters per ton of corn (1.3 gallons per bushel) and 53 to $59 \%$ steam. The use of ultrafiltration in conjunction with enzymes for production of starch conversion products has been shown to be more efficient than enzymatic batch processes alone (Slominska et al., 2000).

Membranes may experience biofouling or fragility of the membrane surface (CERF, 1997), although they may prevent surface fouling of evaporators downstream (Rausch, 2002b). In addition, for facility retrofits, capital costs may be a deterrent. Other disadvantages include limits on operating pressures that prevent 
implementation in certain processes and potential delays in bringing membranes online dues to problems with documentation for food safety by regulators.

In addition to the above-mentioned benefits, membranes offer other advantages to standard filtration methods like rotary vacuum precoat filters (RVPF) using diatomaceous earth. Membranes are less costly, do not have large disposal requirements and have lower labor and maintenance costs than these filtration methods. Membranes do not need to be replaced as often as the filters and the wear and tear created by abrasive materials like diatomaceous earth does not exist for membranes. Other benefits like increased product recovery and reduced carbon requirements downstream have also been discussed (Singh and Cheryan, 1998).

There are numerous applications of membranes in the corn wet milling process, such as steepwater concentration (or supplemental pre-concentration) by reverse osmosis (RO), reducing chemical oxygen demand (COD) in evaporator overhead, solvent recovery and oil purification in the corn oil refining stage, production of protein concentrates and isolates, enzyme modification in membrane reactors, starch washing, concentrating starch and recovering fresh water by RO (Singh and Cheryan, 1997). Below we discuss a few of these opportunities that have been implemented in industry and those that have energysaving potential. According to the Corn Refiners Association, the new applications of membranes will be gluten thickening, mill stream thickening, starch water clarifying, waste treatment sludge recovery and still bottoms concentration (CRA, 2000a).

\subsubsection{Membranes for Steepwater Concentration}

Reverse osmosis (RO). RO can be used to partially remove water from the steepwater prior to the evaporation phase. As solutions become more concentrated, the effectiveness of RO diminishes ${ }^{14}$. Therefore, RO is best used to concentrate the solution to a certain point before it is passed into an evaporating system. In practice, RO is most effective at increasing the concentration of steepwater to 14$18 \%$ total solids content, or up to a pressure difference of $200 \mathrm{psi}$ (Singh and Cheryan, 1997). Then a mechanical vapor recompression (MVR) system can be used to attain the $50 \%$ solids content of the final product. Generally, not all water can be eliminated by RO and some evaporation is still required.

A plant processing 70,000 bushels of corn per day generates roughly 350,000 gallons of steepwater per day. An optimized system using a hybrid of RO and MVR may lead to significant energy savings over using MVR alone. Table 12 shows a comparison of the energy requirements of the two systems.

Table 12: Energy requirements for concentrating 350,000 gallons of steepwater to corn steep liquor using mechanical vapor recompression (MVR) or using MVR in combination with reverse osmosis $(\mathrm{RO})$.

\begin{tabular}{|lccc|}
\hline & $\begin{array}{c}\text { Electricity } \\
\text { (MWh) }\end{array}$ & $\begin{array}{c}\text { Thermal Energy } \\
\text { (TBtu) }\end{array}$ & $\begin{array}{c}\text { Primary Energy }^{\mathbf{a}} \\
\text { (TBtu) }\end{array}$ \\
\hline MVR evaporator & 42 & 233 & 721 \\
RO + MVR evaporator & 12 & 93 & 236 \\
\hline \% savings & $\mathbf{7 0}$ & $\mathbf{6 0}$ & $\mathbf{6 7}$ \\
\hline
\end{tabular}

${ }^{\mathrm{a}}$ This is based on assuming electricity is generated at 33\% efficiency and steam is generated at $80 \%$ efficiency. Source: Gienger and Ray, 1988

\footnotetext{
${ }^{14}$ A characteristic of all solutions is the "osmotic pressure," which increases as the concentration of solutes in the solution increases. For reverse osmosis to occur, the pressure applied to the solution passing over the membrane must be greater than the osmotic pressure of the solution. The difference between these two pressures gives the driving force of the reverse osmosis. As the solution becomes more concentrated, the driving force of the RO diminishes.
} 
Others suggest using other membrane processes like ultrafiltration (UF), nanofiltration (NF) or a combination of membranes as an alternative for RO/MVR (Singh and Cheryan, 1997).

Microfilration (MF). MF combined with evaporation of steepwater uses less energy than just evaporation (Rausch et al., 2000). In addition, using a membrane to concentrate the steepwater before evaporation causes less fouling in the evaporator increasing its efficiency, reducing maintenance costs associated with cleaning, reducing downtime and lost capacity during evaporator cleanout (Rausch et al., 2000). According to one study, light steepwater can be easily concentrated six times with a membrane. For a plant operating at 2,500 million tons per day (about 89,000 bushels per day), light steepwater that has been concentrated by MF can be combined with corn gluten meal to produce a product having $60 \%$ protein content and an increase in yield of over 13\% (17 million tons per day) (Rausch et al., 2000). At typical U.S. corn gluten meal prices of $\$ 0.26 / \mathrm{kg}(\$ 0.09 /$ ton), this increase is valued at $\$ 1.6$ million per year. In addition, evaporators using MF are more efficient and their costs would be reduced, less downtown is expected for the evaporators and increased nutritional value is expected from higher levels of soluble nutrients in the gluten meal.

\subsubsection{Membranes to Recycle Starch Wash Water, Reduce Water Used in Steeping}

As discussed earlier, reducing the amount of water used throughout the system means that less water will need to be removed from the final products, and therefore will reduce the energy intensity. Fresh water enters in corn wet milling at the last stage of starch washing. This water needs to be extremely pure, so that the final product contains no impurities. Membranes and RO can be used upstream in the process to recover some of the water used and reuse it at the starch washing stage.

After both germ and fiber have been removed from the mill stream, and before gluten and starch are separated out, the stream goes through a "mill stream thickener." This process is essentially a centrifuge designed to increase the density of the mill stream and smooth out fluctuations in density (see Figure 5). The overflow from this process is water-containing soluble material but virtually no insoluble material. Standard practice is to send this flow over to the steeping tanks. If instead this water is treated with membrane filtration and reverse osmosis, the stream can be separated into highly pure water and a concentrated stream. The water is used for starch washing and the stream of concentrated solubles is sent to the steep tanks. Not only is the demand for fresh water reduced, but also less water needs to be removed during steep evaporation.

Applying this approach at a corn wet mill in 1981 resulted in reduced energy use, an increased concentration of total solids in the steepwater to $20 \%$ and no adverse effect on starch quality (Singh and Cheryan, 1997). The process of using RO and UF to remove dissolved and suspended material and reduce evaporation requirements resulted in energy savings of more than 54\% (Singh and Cheryan, 1997). Applying this to our estimates of fuel used for steepwater evaporation in a typical corn wet milling plant, producing about 100,000 bushels per day (see Table 5), this saves about $8.4 \mathrm{lb} / \mathrm{bu}$ of steam $(10,500$ $\mathrm{Btu} / \mathrm{bu})$.

\subsubsection{Membranes to Concentrate Corn Syrups}

In making corn syrups, the product of enzyme or acid treatments generally has $30-34 \%$ solid content. This is usually evaporated to $40-45 \%$ solids, at which point the syrup undergoes carbon treatment to remove impurities before final evaporation (if needed) to attain the concentration of the commercial product. The standard approach is to use mechanical vapor recompression. Using RO or other membrane processes could eliminate these intermediate evaporators (Singh and Cheryan, 1998). As mentioned above in the membranes for steepwater concentration section (section 5.8.3), at higher concentrations the effectiveness of RO diminishes. The way to overcome this is by increasing the pressure on the membrane system. Hence, to obtain a reasonable driving force across the membrane, the final stage of the RO system will probably need to operate at about 103.4 bar (1500 psi). However, increased operating pressures will lead 
to increased power consumption. Still, using membranes in this process will lead to net energy savings, while also minimizing the thermal degradation of the sugars. Exact energy savings, if this technology were applied in industrial practice are currently unavailable.

\subsubsection{Membranes to Purify Corn Syrups}

Simms (1998) stated that one of the most common uses of membranes in corn wet milling is removing residual oils, proteins and colorants from corn syrup. Historically, a rotary vacuum filter coated with diatomaceous earth (DE) removes the material. Using membranes avoids the cost of disposal of DE, as well as the costs associated with recoating the vacuum filter, a high maintenance operation. In addition to avoided operation and disposal costs, microfiltration (MF) produces syrups with higher clarity. In a syrup line operating at $500 \mathrm{gal} / \mathrm{min}(2,000 \mathrm{~L} / \mathrm{min})$, annual savings of over $\$ 2$ million were reported (Simms, 1998). In 1997, approximately $75 \%$ of U.S. produced corn syrup was clarified using membrane filtration (Simms, 1998).

\subsection{Pollution control}

Regenerative Thermal Oxidizers (RTOs). RTOs operate by heating incoming foul gas and cooling outgoing oxidized gas through a series of ceramic beds (Svonja, 2001). Clean exhaust gases purge the unoxidized gas into the oxidation chamber prior to regeneration. Heat transfer through the regeneration beds from the clean oxidized gas to the incoming gas ensures the net temperature rise across the unit is lower than a conventional, direct fired oxidizer.

RTOs are well established in other industries that treat airstreams with relatively low concentrations of organic solvents. Their advantage is that they can raise the temperature of the airstreams up to incineration levels of $800^{\circ} \mathrm{C}\left(1500^{\circ} \mathrm{F}\right)$ with greater energy efficiencies than conventional technologies, up to $95 \%$, because the heat is recycled (Svonja, 2001). Thermal oxidation is also well established as the best method for eliminating odor from the exhausts of feed dryers that dry the feed products, including corn gluten feed, corn gluten meal and corn germ. A small number have been installed in corn wet milling plants.

Rayovac Corporation in Fennimore, Wisconsin produces and packages primary and rechargeable alkaline batteries. In 1999, they needed to replace two worn, direct-fired thermal oxidizers (Anon., 2002). They upgraded to a "Millennium" RTO from MEGTEC Systems (De Pere, Wisconsin). The installation was completed in one 24-hour shutdown and the RTO unit was found to achieve the high energy savings expected, delivering thermal efficiencies of $95 \%$. Energy savings, compared to the two thermal oxidizers the RTO replaced, were at or above $60 \%$.

\subsection{Future Technologies.}

This section includes a description of some technologies that may hold promise for the future but are still currently in the research, development or demonstration phases.

\subsubsection{Motors}

Switched reluctance drives. Switched reluctance drives are an old technology that is being improved, incorporating adjustable speed drives and high efficiency motors. The switched reluctance motor offers variable speed capacity and precision control, in addition to higher torque and efficiency (Martin et al., 2000a). Because this is an emerging technology, there are not any documented case studies describing implementation and results. 


\subsubsection{Feed streams}

The main feed stream to a wet milling plant is corn. Depending on the type of corn received, the product mix will contain different amounts of starch, oil, fiber and protein, to turn into syrups, oil and animal feeds. In addition, the milling process must be modified to handle varying amounts of these products. Selecting a specific type of corn hybrid is one possibility for saving energy and money, and increasing productivity.

Corn hybrids. By paying a premium, corn purchasers can buy a specific type of corn or hybrid. Buying a specific hybrid of corn assures a certain mix of components or softness of kernel, and helps to better define the corn wet milling process and its requirements. Hence, it is possible to decrease operations and maintenance costs, increase yield and quality of higher value products, decrease capital costs and save energy. GMO hybrids are not an option for companies that sell to Europe or others who will not risk introducing GMO corn on site.

Some types of corn require less energy to grind or have better starch-protein separation (because of a larger density in particle size difference between these two products). If the early grinding or separation is more effective, steps later in the process will also require less water, energy and recycling. In addition to energy savings, higher quality corn may have higher yields and superior quality of more valuable products like starch. A value of $1 \%$ starch yield increase adds approximately $\$ 0.03$ per bushel (Eckhoff, 1995). Specified product contents (like high protein level) can also be predicted and met. Operations and maintenance costs will be reduced. Differences in milling quality of corn (percentage of products and coproducts) may cause wide fluctuations in mill performance and increase operation and maintenance costs. For example, if a coproduct stream exceeds the design capacity, the grind mill throughput must be decreased. A 100,000 bushel a day plant with a 5\% average reduction in grind capacity a year will increase their operations costs by about $\$ 0.09$ per bushel (Eckhoff, 1995). Reduced process fluctuations will also decrease equipment failure and stop/startup times. Finally, reducing the need to put in extra equipment to handle wide fluctuations caused by unpredictable corn feed mixes may reduce capital costs. It is estimated that as much as $10 \%$ of the capital lay-out of a corn wet milling plant is for handling fluctuations (Eckhoff, 1995).

\subsubsection{Steeping}

The main requirement for the steeping stage is to get the incoming corn up to steep temperature, which can be done by heating hydraulic transport water with low pressure waste steam. Energy saving measures in the steeping stage generally focus on reducing the time the corn spends in the steeping tanks. Corn is soaked in the steeping stage at high temperatures $\left(120^{\circ} \mathrm{F}\right.$ or $\left.50^{\circ} \mathrm{C}\right)$ for up to 50 hours. Reducing the steep time reduces the energy required to heat and maintain the corn and steepwater at $120^{\circ} \mathrm{F}$. As shown in Table 5 (on page 20), steeping requirements are a small portion of total primary energy us (3\%), however changes to the first step of the process could have a greater effect downstream. In addition, there are often other benefits, as discussed below.

Using enzymes during steeping to reduce steep time. The use of enzymes during steeping is a technology that is currently being developed. Recent research indicates a two-stage steeping process using proteases may reduce conventional steep time by 67 to $83 \%$ (Johnston and Singh, 2001). Johnston and Singh (2001) found that the corn kernel requires a hydration step of two to four hours at $48^{\circ} \mathrm{C}$ to $52^{\circ} \mathrm{C}$ $\left(118^{\circ} \mathrm{C}\right.$ to $\left.126^{\circ} \mathrm{F}\right)$ before grinding so that the germ is penetrable and pliable enough that it does not break when the corn is coarsely ground. Without the hydration step, steep times were not significantly reduced. In addition to shortening the steep time and decreasing energy, other benefits are likely for this technology (Johnston and Singh, 2001). One important benefit is that $\mathrm{SO}_{2}$ is not required for this process, eliminating the associated environmental control problems (Singh, 2002b). Shorter processing times will either increase plant capacity or decrease capital investment in steep tanks. Broken as well as unbroken 
grains can be processed by either soaking broken kernels for less time than the unbroken kernels, or by simply adding the broken kernels to the unbroken ones in the second stage of the steeping process. The reduced processing time may ultimately significantly increase the productivity of the input corn over conventional steeping for the same corn input. Finally, soaking water from the modified process contains a relatively low level of dissolved solids compared to conventional steep water, up to $90 \%$ less, and can potentially be reused after filtration, eliminating the need for evaporators and reducing water usage.

The enzymatic steeping process is currently being researched and tested in conjunction with corn wet milling plants and hence, we have no cost or energy savings data for actual implementation at this time. Enzymes are already extensively being used and perfected in wheat starch separation processes (Frandsen and Olsen, 2000).

Intermittent Milling and Dynamic Steeping (IMDS). In this process, the corn kernels are soaked for a short time, and then ground to reduce particle size and reduce diffusional limitations before continued soaking. The steeping time can be reduced significantly (to 3-7 hours total), and the overall starch yields observed can be higher if lactic acid and $\mathrm{SO}_{2}$ are used (Eckhoff and Dowd, 1999; Lopes-Filho et al., 1997). Recovered starch may be $1 \%$ more and recovered protein $3-4 \%$ more than in the conventional wet milling process. There are some energy savings since the steep water is not maintained at approximately $50^{\circ} \mathrm{C}\left(120^{\circ} \mathrm{F}\right)$ for as long. Additional energy requirements for grinding are unknown.

The main benefits, in addition to reduced energy, are the increased yield and the reduced capital requirements, since fewer tanks are needed for steeping. This capital cost is significant because these tanks are high quality tanks to avoid corrosion from the sulfur dioxide used in the process. One drawback to IMDS, however, is that the percentage of oil in the germ is reduced by $5 \%$, and there is slight germ damage (5-10\%) (Singh, 1999). Table 13 summarizes the data for IMDS.

Table 13: Intermittent Milling and Dynamic Steeping (IMDS) compared to conventional steeping.

\begin{tabular}{|rl|}
\hline & IMDS compared to conventional steeping \\
\hline Starch yields & $101 \%$ \\
Protein yields & $103-104 \%$ \\
Germ oil yields & $95 \%$ \\
Operating costs & $\$ 160,000$ savings \\
Capital costs & $\$ 7.0$ million savings \\
\hline
\end{tabular}

Use of gaseous sulfur dioxide. There are environmental and health concerns with the use of gaseous $\mathrm{SO}_{2}$. If these can be overcome, however, there are many benefits to this process. Sulfur dioxide $\left(\mathrm{SO}_{2}\right)$ in gaseous form diffuses inside the corn kernel 100 times faster than $\mathrm{SO}_{2}$ in water. In about 5 minutes, the gaseous $\mathrm{SO}_{2}$ quickly reacts and cleaves the disulfide bonds inside the kernel releasing the starch. Only another 8 hours is required for hydration, significantly less than traditional steeping times. It is important to note that lactic acid must be added to the steep after the gaseous $\mathrm{SO}_{2}$ is added. Lactic acid not only prepares the corn for milling, but also prepares the steepwater for evaporation. In absence of this fermentation, the evaporators may foul in a matter of hours (Blanchard, 2002).

Yields using gaseous $\mathrm{SO}_{2}$ for 8 hours of steeping produced the same yield as those in conventional steeping using liquid $\mathrm{SO}_{2}$ for 24 hours or more (Singh, 1999). The reduction in the time spent in the 
steeping tank at elevated temperatures lowers the energy required and either lowers the capital costs or increases capacity. With smaller and/or fewer tanks required for steeping, a gaseous plant would save $\$ 8$ million over a conventional liquid $\mathrm{SO}_{2}$ plant, with a $\mathrm{ROI}$ of $28 \%$ (Singh, 1999).

Alkali steeping. Using alkali (such as $\mathrm{NaOH}$ ) instead of $\mathrm{SO}_{2}$ to steep corn can shorten steep time and reduce capital cost and energy. Alkali wet milling of corn involves the removal of the pericarp (the outer hard layer of the kernel), cracking the pericarp-free corn in a roller mill, and then steeping the corn in an alkali solution. Alkali solutions remove the pericarp by dissolving the connecting material between the pericarp and the inner layer. Without the pericarp, diffusion of water and chemicals is made possible, shortening steeping times. Cracking the pericarp-free corn in a roller mill further reduces kernel size and steeping time. Following steeping, the remainder of the alkali corn wet milling procedure is the same as the conventional corn wet milling process.

Preliminary analyses show that the total investment for a 2,667 tonne/day (105,000 bushel/day) wet milling plant would be reduced by $23 \%$ using the alkali process instead of the conventional $\mathrm{SO}_{2}$ process (Yang et al., 2000). Studies have shown advantages to the alkali process also includes much lower steeping times (down to only 1 hour), elimination of steepwater evaporation (a much greater cost than steeping costs), addition of another high value coproduct (pericarp), higher and purer starch yields (approximately 1.8\% higher yields) and lower capital and energy costs (Yang et al., 2000; Singh and Eckhoff, 1997; Eckhoff et al., 1999; Singh, 2002b). Potential drawbacks from the alkali process, depending on the conditions and alkali used, include altered characteristics of the starch, gluten meal, germ and steepwater products and creation of a new waste alkali stream. $\mathrm{NaOH}$ water treatment can be difficult because of the uncertainty where it will end up. If it ends up in the gluten fraction, the gluten may not dewater properly. According to Yang et al. (2000), the highest starch yield was obtained when steeping corn in $0.5 \% \mathrm{NaOH}$ for 1 hour at $45^{\circ} \mathrm{C}\left(113^{\circ} \mathrm{F}\right)$.

Corn hybrids. The use of certain corn hybrids requires shorter steeping times (Hohmann and Rendleman, 1993). This reduction in the time spent in the steeping tank at elevated temperatures lowers the energy required. In addition, smaller or fewer tanks are needed for the steeping stage and capital costs are reduced. See Section 5.8.2 for more information. In addition to the measures in Section 5.2, several emerging technologies are currently being researched and developed and are discussed in this section.

\subsubsection{Fermentation and ethanol production.}

In addition to the measures discussed in Section 5.3, enzyme hydrolysis is a promising technology in the fermentation and ethanol production stage and is discussed in this section. This measure is only applicable to the corn wet milling plants that produce ethanol from starch.

Enzymes used for hydrolysis. Enzyme hydrolysis is typically a two-step process involving different catalysts: liquefaction followed by saccharification (Paolucci-Jeanjean et al., 1999). In liquefaction, starch is suspended or dispersed in an aqueous medium, gelatinized by heat-treatment and partially hydrolyzed using an alpha-amylase. In saccharification, low molecular weight hydrolysates (glucose or maltose) are produced.

Enzymes used in the liquefaction process have been shown to improve starch hydrolysis by a factor of four, expedite the liquefaction process and improve feed product quality (Konieczny-Janda et al., 2001). Currently workable enzymes for this process are still expensive and further improvements are necessary for liquefaction by enzymes to be economically viable. One option being considered is blending the enzyme of choice with common enzymes used in the ethanol process to provide a cheaper process. Further research is necessary. 
Another option being studied is one-step hydrolysis, either using saccharifying enzymes that directly hydrolyze native starch into glucose or maltose or using liquefying enzymes able to produce sufficient low-molecular weight hydrolysates (Paolucci-Jeanjean et al., 1999). Saccharifying enzymes that directly hydrolyze native starch into glucose or maltose have been discovered (Paolucci-Jeanjean et al., 1999). A continuous recycle membrane reactor (CRMR) that couples the enzymatic reactor with ultrafiltration separation also has been shown to be effective (Paolucci-Jeanjean et al., 1999). The CRMR starch process recycles and reuses enzymes, offering economic advantages over processes that do not recycle, and eliminates inactivation and separation steps, reducing investment and processing costs. The main disadvantage of CRMR is in flux limitations due to concentration polarization and membrane fouling. 


\section{Summary and Conclusions.}

Within the food and kindred products group (SIC 20), corn wet milling is the most energy intensive industry, using 15\% of the total energy consumed. Energy costs are the largest operating cost for corn wet millers in the United States. A typical corn wet milling plant in the United States spends approximately \$15 to \$25 million per year on energy, making energy efficiency improvement an important way to reduce costs and increase predictable earnings, especially in times of high energy-price volatility.

There are a variety of opportunities available at individual plants to reduce energy consumption cost effectively in the corn wet milling industry, both in utilities and in the processes. This report has identified almost 100 energy-efficient practices and technologies that could be applied to corn refining. Specific energy savings are provided for each efficiency measure based on case studies that describe implementation of the measures as well as provide references to technical literature. If available, typical payback periods were also given. Tables 14 and 15 list these measures.

Table 14: Cross-cutting energy efficiency measures for the corn wet milling industry.

\begin{tabular}{|c|c|}
\hline \multicolumn{2}{|c|}{ General Equipment/Utility Approaches } \\
\hline Energy management systems and programs & Alternative fuels \\
\hline Combined heat and power & Anaerobic wastewater treatment \\
\hline \multicolumn{2}{|c|}{ Motors } \\
\hline Sizing & Adjustable speed drives \\
\hline Higher efficiency motors & Variable voltage controls \\
\hline Switched reluctance drives ${ }^{1}$ & \\
\hline \multicolumn{2}{|c|}{ Pumps } \\
\hline Operations and maintenance & Adjustable speed drives \\
\hline Monitoring & Avoid throttling valves \\
\hline Reduce need & Correct sizing of pipes \\
\hline More efficient pump & Replace belt drives \\
\hline Correct sizing of pump(s) & Precision castings, surface coatings or polishing \\
\hline Use multiple pumps & Sealings \\
\hline Trimming impeller (or shaving sheaves) & Curtailing leakage through clearance reduction \\
\hline Controls & \\
\hline \multicolumn{2}{|c|}{ Compressed air } \\
\hline Maintenance & Properly size regulators \\
\hline Monitoring & Pipe diameter sizing \\
\hline Leak reduction & Heat recovery \\
\hline Inlet air temperature reduction & Natural gas engine-driven air compressors \\
\hline Pressure dew point maximization (air intake) & System improvements \\
\hline \multicolumn{2}{|c|}{ Compressor motors } \\
\hline Adjustable speed drives & Higher efficiency motors \\
\hline \multicolumn{2}{|c|}{ Lighting } \\
\hline Controls & Replace metal halide HID with high-intensity \\
\hline Daylighting & fluorescents \\
\hline Replace incandescents with fluorescents or CFLs & Replace magnetic with electronic ballasts \\
\hline Replace T-12 with T-8 or metal halides & Reflectors \\
\hline Replace mercury with metal halide or high & Light emitting diodes (LEDs) or radium strips \\
\hline pressure sodium & System improvements \\
\hline \multicolumn{2}{|c|}{ Materials handling/tools } \\
\hline \multicolumn{2}{|l|}{ High efficiency belts } \\
\hline \multicolumn{2}{|c|}{ HVAC } \\
\hline Electronic controls & Ventilation and cooling design improvements \\
\hline
\end{tabular}




\begin{tabular}{|ll|}
\hline \multicolumn{2}{|l|}{ Non-production hours setback temperatures } \\
\hline \multicolumn{2}{|c|}{ Heat and steam distribution-Boilers } \\
\hline Improve process control & Boiler maintenance \\
Reduce flue gas & Recover heat from flue gas \\
Reduce excess air & Return condensate \\
Correct sizing in design & Recover steam from blowdown \\
Improve insulation & Replace obsolete burners by new optimized \\
& boilers \\
\hline & Heat and steam distribution-Distribution \\
\hline Improve insulation & Monitor steam traps automatically \\
Maintain insulation & Repair leaks \\
Improve steam traps & Recover flash steam \\
Maintain steam traps & \\
\hline
\end{tabular}

Included in Future technologies, Section 5.8.

Table 15: Process-related energy efficiency measures for the corn wet milling industry.

\begin{tabular}{|c|c|}
\hline \multicolumn{2}{|c|}{ Feed Streams } \\
\hline Corn hybrids ${ }^{1}$ & \\
\hline \multicolumn{2}{|c|}{ Steeping } \\
\hline $\begin{array}{l}\text { Intermittent milling and dynamic steeping }^{1} \\
\text { Use of gaseous sulfur dioxide }^{1}\end{array}$ & $\begin{array}{l}\text { Alkali steeping }^{1} \\
\text { Use enzymes during steeping to reduce time }\end{array}$ \\
\hline \multicolumn{2}{|c|}{ Fermentation and Ethanol Production } \\
\hline $\begin{array}{l}\text { Improving yeast fermentation } \\
\text { Bacterial fermentation }\end{array}$ & $\begin{array}{l}\text { Molecular sieves } \\
\text { Enzymes used for hydrolysis }{ }^{1}\end{array}$ \\
\hline \multicolumn{2}{|c|}{ Mechanical Dewatering } \\
\hline $\begin{array}{l}\text { Germ dewatering } \\
\text { Starch dewatering filters }\end{array}$ & Fiber dewatering \\
\hline \multicolumn{2}{|c|}{ Drying Technology } \\
\hline $\begin{array}{l}\text { Process integration/pinch technology } \\
\text { Controls on heaters between steps } \\
\text { Reusing waste heat } \\
\text { Replacing dryer with more efficient one } \\
\text { Regenerative thermal oxidizers } \\
\text { Direct use of gas turbine offgases for drying }\end{array}$ & $\begin{array}{l}\text { Multiple effect evaporators } \\
\text { Thermal and mechanical vapor recompression } \\
\text { Operations and maintenance } \\
\text { Improve process control } \\
\text { Reduction in air supply rate } \\
\text { Challenging customer demand }\end{array}$ \\
\hline \multicolumn{2}{|c|}{ Membranes } \\
\hline $\begin{array}{l}\text { Reverse osmosis (RO) for steepwater } \\
\text { concentration } \\
\text { Microfiltration }(\mathrm{MF}) \text { for steepwater } \\
\text { concentration }\end{array}$ & $\begin{array}{l}\text { RO or other membrane to concentrate syrups } \\
\text { Membranes to purify syrups } \\
\text { Membrane filtration or RO to recycle starch } \\
\text { wash water or reduce water in steeping }\end{array}$ \\
\hline
\end{tabular}

Cross-cutting utility energy efficiency measures that do not interfere with the corn wet milling process show immediate potential for cost-effective energy savings were also presented. Sixty-eight different cross-cutting energy efficiency improvement measures that can reduce energy consumption in the supply and use of motors, pumps, compressed air, lighting, hot water and steam distribution, hot water and steam generation, power supply and HVAC were identified. While savings of some of the individual measures may be relatively small, the cumulative effect of these measures may potentially be large. Generally, the majority of these measures have relatively short paybacks. The degree of implementation of these measures will vary by plant and end-use and continuous evaluation for these opportunities will help to identify further cost-savings. 
For process-specific measures, some new technologies reduce energy and improve product quality consistency or yield. Twenty-nine different energy efficient practices and technologies in steeping, dewatering, drying, membranes and fermentation and ethanol production were highlighted. Six of these measures are still being developed and are included in the future technology section (Section 5.8). Implementation of most of the other measures will be part of strategic investments and innovation at the corn wet milling plants. Selected technologies will have large additional benefits including product quality improvement.

Further research on the economics of the measures for individual corn wet milling plants, as part of an energy management program, is needed to assess the potential impact of selected technologies at individual corn wet milling plants. 


\section{Acknowledgements.}

This work was supported by the Climate Protection Partnerships Division of the U.S. Environmental Protection Agency as part of its ENERGY STAR program by EPA Contract DW-89-93934401-1 through the U.S. Department of Energy Contract under No. DE-AC03-76SF00098.

Many people inside and outside the industry provided helpful insights in the preparation of the report. We would like to thank Gregg Willis of Corn Products International, Inc (Stockton, California) for increasing our understanding of the production process in the corn wet milling industry. We especially thank Jennifer Snyder of the Corn Refiners Association (CRA) for organizing the review process by the corn wet milling industry. We thank all industry representatives of the corn wet milling industry for their important and insightful comments and suggestions provided through the CRA. We also thank Willem van Zanten (NOVEM, the Netherlands) for providing information on demonstration projects in the Netherlands. We would also like to thank Drs. Steven R. Eckhoff and Vijay Singh for providing helpful suggestions and data for the report, as well as Paul Blanchard for his review of an earlier version of the report.

Despite all their efforts, any remaining errors are the responsibility of the authors. The views expressed in this paper do not necessarily reflect those of the U.S. Environmental Protection Agency, the U.S. Department of Energy or the U.S. Government. 


\section{References.}

Alesson, T. (1995). All Steam Traps are not Equal. Hydrocarbon Processing. Gulf Publishing Co., Houston, TX.

Anaheim Public Utilities. (2001). http://www.anaheim.net/utilities/adv_svc_prog/led_exit_sign/howitworks.html.

Anonymous (2002). Batteries Included. Pollution Prevention Casebook Archives, June 2, 2002. Available at http://www.pollutionengineering.com/archives/2002/0602/0602_Casebook.asp.

Anonymous (1996). RTO Retrofit Cuts Costs, Increases Destruction Efficiency. Pollution Prevention Casebook Archives, October 1, 1996. URL: http://www.pollutionengineering.com/archives/1996/pol1001.96/10acase.htm.

APV. (2002). Evaporation Handbook, supplied by the vendor.

Baen, P. R. and R. E. Barth. (1994). Insulate Heat Tracing Systems Correctly. Chemical Engineering Progress. September: 41-46.

Berntsson, T. and Franck, P-A. (1997). Learning from Experiences with Industrial Heat Pumps. Centre for the Analysis and Dissemination of Demonstrated Energy Technologies (CADDET). Analyses Series No. 23, September 1997.

Best Practice Programme. (1996a). General Information Report 41: Variable Flow Control. Available for download at http://www.energy-efficiency.gov.uk/index.cfm

Best Practice Programme. (1996b). Good Practice Case Study 300: Energy Savings by Reducing the Size of a Pump Impeller. Available for download at http://www.energy-efficiency.gov.uk/index.cfm.

Best Practice Programme. (1997). Good Practice Guide 149: Rotary Drying in the Food and Drink Industry. Available for download at http://www.energy-efficiency.gov.uk/index.cfm

Best Practice Programme. (1998). Good Practice Guide 249: Energy Savings in Industrial Water Pumping Systems. Available for download at http://www.energy-efficiency.gov.uk/index.cfm

Best Practice Programme. (2002a). Case Study 164: Variable Speed Drives on a Flour Mill Extract Fan. Available for download at http://www.energy-efficiency.gov.uk/index.cfm

Best Practice Programme. (2002b). Final Profile 29: Integrated Heat Recovery in a Food Factory. Available for download at http://www.energy-efficiency.gov.uk/index.cfm

Blanchard, P. H. (1992). Technology of Corn Wet Milling and Associated Processes. Elsevier, Amsterdam.

Blanchard, P.H. (2002). Personal written communication.

Bloss, D., R. Bockwinkel and N. Rivers. (1997). Capturing Energy Savings with Steam Traps. Proc. ACEEE Summer Study on Energy Efficiency in Industry, American Council for an Energy Efficient Economy, Washington DC.

Buijze, M. (1998). "Haalbaarheidsstudie naar Integratie van Twee Stuks Gasturbines" (Feasibility Study for Intgreation of two Gas Turbines), Netherlands Organization of Energy and Environment, Sittard, the Netherlands.

Bureau of Economic Analysis (2001). Shipments of Manufacturing Industries, available at http://www.bea.gov/bea/dn2/gpo.htm.

Caffal, C. (1995). Energy Management in Industry. Centre for the Analysis and Dissemination of Demonstrated Energy Technologies (CADDET), the Netherlands. Analyses series 17, December. 
California Energy Commission (CEC) and the Office of Industrial Technologies (OIT), Energy Efficiency and Renewable Energy, U. S. Department of Energy. (2001). Case Study: Pump System Improvement Saves Energy and Improves Production at a Construction Aggregates Company. August.

California Energy Commission (CEC) and the Office of Industrial Technologies (OIT), Energy Efficiency and Renewable Energy, U. S. Department of Energy. (2002). Case Study: Pump System Controls Upgrade Saves Energy at a Network Equipment Manufacturing Company's Corporate Campus. January.

Canadian Industry Program for Energy Conservation (CIPEC). (2001a). Boilers and Heaters, Improving Energy Efficiency. Natural Resources Canada, Office of Energy Efficiency. August.

Canadian Industry Program for Energy Conservation (CIPEC). (2001b). Energy Efficiency Opportunity Guide in the Lime Industry - Canadian Lime Institute. Natural Resources Canada, Office of Energy Efficiency.

Castellow, C., C. E. Bonnyman, H. G. Peach, J. C. Ghislain, P. A. Noel, M. A. Kurtz, J. Malinowski, and M. Kushler. (c. 1997). Energy Efficiency in Automotive and Steel Plants.

Cayless, M. A. and A. M. Marsden (Eds.). (1983). Lamps and Lighting. Edward Arnold, London.

Centre for the Analysis and Dissemination of Demonstrated Energy Technologies (CADDET). (1991). Energy from a Flour Mill Waste Water. Case study CA-90-105.

Caddet. (1993). Proceedings IEA Workshop on Process Integration, International Experiences and Future Opportunities, Sittard, the Netherlands.

Centre for the Analysis and Dissemination of Demonstrated Energy Technologies (CADDET). (1994). High Efficiency Motors for Fans and Pumps. Case study UK94.502/2B.FO5.

Centre for the Analysis and Dissemination of Demonstrated Energy Technologies (CADDET). (1995). Utilisation of Hydrogen Sulphide Laden Biogas in a Process Integrated After Burner. Infostore Case study NL-2000-505.

Centre for the Analysis and Dissemination of Demonstrated Energy Technologies (CADDET). (1997). Saving Energy with Efficient Compressed Air Systems. Maxi Brochure 06.

Centre for the Analysis and Dissemination of Demonstrated Energy Technologies (CADDET). (2001). Saving Energy with Daylighting Systems. Maxi Brochure 14.

Civil Engineering Research Foundation (CERF). (1997). Clean Technologies in U.S. Industries: Focus on Food Processing. Report prepared for the United States Asia Environmental Partnership (US-AEP), www.usaep.org/reports/food.htm.

Copper Development Association (CDA). (2000). Cummins engine company saves $\$ 200,000$ per Year with EnergyEfficient Motors. Case Study A6046.

Copper Development Association (CDA). (2001). High-Efficiency Copper-Wound Motors Mean Energy and Dollar Savings. http://energy.copper.org/motorad.html.

Corn Refiners Association (CRA). (2000a). Corn Annual 2000.

Corn Refiners Association (CRA). (2000b). Tapping the Treasure. August 2000.

Corn Refiners Association (CRA). (2001). Corn Annual 2001. Using data from the USDA.

Corn Refiners Association (CRA). (2002). Information on corn wet milling. http://www.corn.org. 
Department of Commerce (DOC), U.S. Bureau of the Census. 1999. Wet Corn Milling 1997 Economic Census, Manufacturing Industry Series. EC97M-3112D

Department of Energy (DOE). (1993). (Prepared for) Office of Industrial Technologies, Energy Efficiency and Renewable Energy. (Produced by National Renewable Energy Laboratory and Energetics, Inc.) Industrial heat Pumps Improve Plant Efficiency and Recover Wasted Energy Resources. DOE/CH10093-144. February. http://es.epa.gov/techinfo/facts/pumps.html

Department of Energy (DOE). (1999). Office of Industrial Technologies, Energy Efficiency and Renewable Energy. The Technology Roadmap for Plant/Crop-Based Renewable Resources 2020. Available on the web at http://www.oit.doe.gov/agriculture/.

Department of Energy (DOE). (2001a). Office of Industrial Technologies, Energy Efficiency and Renewable Energy. Best Practices Program.

Department of Energy (DOE). (2001b). Office of Industrial Technologies, Energy Efficiency and Renewable Energy. Best Practices Program. Information on steam. http://www.oit.doe.gov/ bestpractices/steam/

Department of Energy (DOE). (2001c). Office of Industrial Technologies, Energy Efficiency and Renewable Energy. Replace Vee Belts with Cogged or Synchronous Belt Drives. http://www.oit.doe.gov/bestpractices/explore_library/pdfs/motor3.pdf

Department of Environmental Quality (DEQ), State of Michigan. (2001). Paint Booth Lighting Retrofit Reduces Energy Consumption at Ford Manufacturing Plants. (Ford Motor Company Pollution Prevention Case Studies).

http://www.deq.state.mi.us/ead/p2sect/auto/ford/fmc031.pdf

Drescher, S., N. Rao, J. Kozak, and M. Okos. (1997). A Review of Energy Use in the Food Industry. 1997 ACEEE Summer Study for Industry: 29-39.

Easton Consultants, Inc. (1995). Strategies to Promote Energy-Efficient Motor Systems in North America's OEM Markets. Stamford, CT.

Eckhoff, S. (1991). Improving Corn Milling Technology. Wet Milling Notes, No. 11. University of Illinois at Urbana-Champaign, May 1991.

Eckhoff, S. (1995). The Future of Commodity Corn. Wet Milling Notes, No. 11. University of Illinois at UrbanaChampaign, March 1995.

Eckhoff, S. (2001). Personal written communication.

Eckhoff, S. (2002a). Wet Milling Short Course, "Corn Wet Milling in the $21^{\text {st }}$ Century" presentation. University of Illinois, Urbana, IL, May 2002.

Eckhoff, S. (2002b). Wet Milling Short Course, "Factors Affecting Corn Millability" presentation. University of Illinois, Urbana, IL, May 2002.

Eckhoff, S. (2002c). Personal communication.

Eckhoff, S. R., L. Du, P. Yang, K. D. Rausch, D. L. Wang, B. h. Li and M. E. Tumbleson. (1999). Comparison between Alkali and Conventional Corn Wet-Milling: 100-g Procedures. Cereal Chemistry. 76 (1): 96-99.

Eckhoff, S. R. and M. Dowd. (1999). Intermittent Milling and Dynamic Steeping (IMDS) Process for Starch Recovery from Corn. Illinois Marketing Board, USDA Specific Cooperative Agreement. 
Einstein, D., E. Worrell and M. Khrushch. (2001). Steam Systems in Industry: Energy Use and Energy Efficiency Improvement Potentials. In: 2001 American Council for an Energy Efficient Economy Proceedings of the 2001 ACEEE Summer Study on Energy Efficiency in Industry.

Eley, C. and T. M. Tolen, of Eley Associates; J. R. Benya of Luminae Souter Lighting Design; F. Rubinstein and R. Verderber of Lawrence Berkeley Laboratory. (1993). Advanced Lighting Guidelines: 1993. Prepared for the Department of Energy (DOE), California Energy Commission (CEC) and Electric Power Research Institute (EPRI).

Elliot, N. R. of the American Council for an Energy Efficient Economy (ACEEE). (1994). Electricity Consumption and the Potential for Electric Energy Savings in the Manufacturing Sector. Washington, D.C.

Energy Information Administration (EIA), U.S. Department of Energy. (1994). In: Manufacturing Consumption of Energy 1991. EIA, Office of Energy Markets and End Use, Washington, DC.

Energy Information Administration (EIA), U.S. Department of Energy. (1997). In: Manufacturing Consumption of Energy 1994. EIA, Office of Energy Markets and End Use, Washington, DC.

Energy Information Administration (EIA), U.S. Department of Energy. (2001). Manufacturing Consumption of Energy 1998. EIA, Office of Energy Markets and End Use, Washington, DC

Energy Nexus Group, 2002a. "Technology Characterization: Gas Turbines”, Energy Nexus Group, Arlington, VA, February 2002.

Energy Nexus Group, 2002b. "Technology Characterization: Steam Turbines”, Energy Nexus Group, Arlington, VA, March 2002.

Environmental Protection Agency (EPA). (2001). Green Lights Program (Currently part of the ENERGY STAR Program). http://www.epa.gov/region07/specinit/p2/volprog/grnlight.htm.

Flygt, ITT Industries. (2002). Case Study: Flygt Helps City of Milford Meet the Challenge. Available at www.flygt.com.

Frandsen, T. P. and H. S. Olsen (2000). New Enzyme Developments for Wheat Starch Processing. Lecture of the $51^{\text {st }}$ Starch Convention 2000 (Association of Cereal Chemists) (Referate der 51 Stärke-Tagung 2000). Available at http://www.agfdt.de.

Ganapathy, V. (1994). Understand Steam Generator Performance. Chemical Engineering Progress. December.

Ganapathy, V. (1995). Recover Heat from Waste Incineration. Hydrocarbon Processing. 74(9) September.

General Motors. (2001). Resource Conservation/Pollution Prevention/Energy Management. General Motors website. http://www.gm.com/company/environment or

http://www.gm.com/ company/gmability/environment/env annual report/ehsreport/html/sec07/content03.htm

Gienger, J. K. and R. J. Ray. (1988). Membrane-based Hybrid Processes. AIChE Symposium Series, 84:168.

Grant, S., B. Burke, R. Landine, A. Cocci and R. Landine. (1997). Anaerobic Pretreatment and SBR Polishing of Corn Wet Milling Wastewater: a Case Study. 1997 Annual International Meeting of the American Society of Agricultural Engineers, Minneapolis, MN. 10-14 August 1997.

Griffin, B. (2000). The Enbridge Consumers Gas "Steam Saver" Program ("as found" performance and fuel savings projects from audits of 30 steam plants). In: Twenty-second National Industrial Energy Technology Conference Proceedings. Houston, Texas. April 5-6: 203-213.

Heck, R. M. R. J. Farrauto and M. Durilla. (1998). Pollution Engineering. Employing Metal Catalysts for VOC Emission Control. April. Available at http://www.pollutionengineering.com/. 
Hohmann, N. and C. M. Rendleman. (1993). Emerging Technologies in Ethanol Production. U.S. Department of Agriculture, Economic Research Service. Agricultural Information Bulletin No. 663. January.

Honda. (2001). Honda of America Manufacturing, Marysville, Ohio, case study.

http://solstice.crest.org/efficiency/pboosters/ohio/html/honda.html

Hovstadius, G. of ITT Fluid Technology Corporation. (2002). Personal communication.

Howe, B. and B. Scales. (1995). Assessing Processes for Compressed Air Efficiency. E Source Tech Update. November.

Hydraulic Institute and Europump. (2001). Pump Life Cycle Costs: A Guide to LCC Analysis for Pumping Systems. Parsippany, NJ.

Hydraulic Institute. (1994). Efficiency Prediction Method for Centrifugal Pumps. Parsippany, NJ.

Hydraulic Institute. (2002). Website, http://www.pumps.org/.

Industrial Assessment Center (IAC). (2001). Industrial Assessment Center Database version 8.1. http://oipeawww.rutgers.edu/database/db f.html.

Ingersoll Rand. (2001). Air Solutions Group-Compressed Air Systems Energy Reduction Basics. http://www.air.ingersoll-rand.com/NEW/pedwards.htm. June 2001.

Jacques, K. A., T. P. Lyons and D. R. Kelsall (editors). (1999). The Alcohol Textbook, $3^{\text {rd }}$ Edition. A Reference for the Beverage, Fuel and Industrial Alcohol Industries. Nottingham University Press, Nottingham, UK.

Johnston, B. (1995). 5 Ways to Greener Steam. The Chemical Engineer 594 (August 17): 24-27.

Johnston, D. B. and V. Singh. (2001). Use of Proteases to Reduce Steep Time and $\mathrm{SO}_{2}$ Requirements in a Corn WetMilling Process. Cereal Chemistry, 78 (4): 405-411.

Jones, Ted. (1997). Steam Partnership: Improving Steam Efficiency through Marketplace Partnerships. Proceedings of ACEEE Summer Study on Energy Efficiency in Industry, American Council for an Energy Efficient Economy, Washington D.C.

Kollacks, W. A. and C. J. N. Rekers. (1988). Five Years Experience with Application of Reverse Osmosis on Light Middlings in a Wet Corn Mill. Starch/Stärke. 40 (1988): 88-94.

Konieczny-Janda, G., C. E. Pilgrim and E. Singley. (2001). The Application of Phytase in Ethanol Production from Grain. Lecture of the 52 ${ }^{\text {nd }}$ Starch Convention 2001 (Association of Cereal Chemists). Available at http://www.agfdt.de.

Krishnan, M. S., F. Taylor, B. H. Davison and N. P. Nghiem. (2000). Economic Analysis of Fuel Ethanol Production from Corn Starch using Fluidized-bed Reactors. Bioresource Technology. 75(2000): 99-105.

Kröner, G. (2002). Experiences with the Production of Organic Starch and Gluten. Lecture of the $53^{\text {rd }}$ Starch Convention 2002 (Association of Cereal Chemists). Available at http://www.agfdt.de.

Krook, R. (2001). The Use of Plate Heat Exchangers and Evaporators in the Starch Process. Lecture of the 52 ${ }^{\text {nd }}$ Starch Convention 2001 (Association of Cereal Chemists). Available at http://www.agfdt.de.

Kumana, J. (2000a). Personal communication, 2000. 
Kumana, J. (2000b). Pinch Analysis - What, When, Why, How. Additional publications available by contacting jkumana@aol.com

Kumana, J. (2000c). Process Integration in the Food Industry. January 2000 Feature Article, available at the Pinchtechnology.com website: http://www.envirotechnet.com/pinchtechnology.com/PDF/jan_2000_feature.pdf

Larox Group. (2002). Personal written communication from Reiner Weidner, president, Larox North America.

Lawrence Berkeley National Laboratory (LBNL) and Resource Dynamics Corporation. (1998). Improving Compressed Air System Performance, a Sourcebook for Industry. Prepared for the U.S. Department of Energy, Motor Challenge Program.

Lawrence Berkeley National Laboratory (LBNL), Resource Dynamics Corporation and the Hydraulic Institute. (1999). Improving Pumping System Performance: A Sourcebook for Industry. Prepared for the U.S. Department of Energy Motor Challenge Program.

Le Roux, L. D. and N. J. Kehl. (1999). Overview of Starch Processing Plant Effluent Treatment with the Biothane UASB and EGSB Processes. International Starch Technology Conference Program Proceedings. June 7-9. Urbana, Illinois: 118.

Lighting Research Center (LRC). (2001). Lighting Futures. LEDs: From Indicators to Illuminators? 3(4): http://www.lrc.rpi.edu/Futures/LF-LEDs/index.html.

Linnhoff, B., D.W. Townsend, D. Boland, G.F. Hewitt, B.E.A. Thomas, A. R. Guy, R.H. Marsland (1992). A User Guide on Process Integration for the Efficient Use of Energy (1992 edition), Institution of Chemical Engineers, Rugby, UK.

Linnhoff, B. (1993). Pinch Analysis: A State-of-the-Art Overview. Chemical Engineering 71 (AS): pp.503-522.

Lopes-Filho, J. F., P. Buriak, M. E. Tumbleson, S. R. Eckhoff. (1997). Intermittent Milling and Dynamic Steeping Process for Corn Starch Recovery. Cereal Chemistry 74 (5): 633-638.

Lorenz, D and D. Morris. (1995). How much Energy does it Take to Make a Gallon of Ethanol? Institute for LocalSelf Reliance (ILSR). August. Available for order at http://www.ilsr.org/pubs/pubscarbo.html

Lyle, O. (1946). The Efficient Use of Steam.

Macek, S.J. (1996). “Operation \& Maintenance” Chemical Engineering 1299 p.139-141 (1992).

Martin, N., M. Ruth, and L. Price of Lawrence Berkeley National Laboratory (LBNL) and R. N. Elliott, A. M. Shipley, and J. Thorne of the American Council for an Energy Efficient Economy (ACEEE). (2000a). Emerging Energy-Efficient Industrial Technologies. October.

Martin, N, N. Anglani, D. Einstein, M. Khrushch, E. Worrell and L.K. Price. (2000b). Opportunities to Improve Energy Efficiency and Reduce Greenhouse Gas Emissions in the U.S. Pulp and Paper Industry. LBNL-46141.

Matz, S. A. (1991). The Chemistry and Technology of Cereals as Food and Feed. $2^{\text {nd }}$ edition. Pen. Tech International Inc., USA. Chapter 15.

Mercer, A. (1994). Learning from Experiences with Industrial Drying Technologies. Centre for the Analysis and Dissemination of Demonstrated Energy Technologies (CADDET). CADDET Analysis Series No. 12. July 1994.

Morris, C. E. (1998). Food Engineers Apply Predictive Control. Food Engineering. December: 53-56.

National Corn Growers Association (NCGA). 2002. Information about corn. http://www.ncga.com 
National Electrical Manufacturers Association (NEMA). (2001). http://www.nema.org.

Netherlands Organization for Energy and the Environment (NOVEM). (1993). Energiebeheersmaatrgelen in de Zetmeelindustrie (Energy Management Measures in the Starch Industry), Project Description, Netherlands Organization of Energy and Environment, Sittard, the Netherlands.

Netherlands Organization for Energy and the Environment (NOVEM). (1994). Energy Management Measures in the Production of Starch.

Netherlands Organization for Energy and the Environment (NOVEM). (1995). Benutting Turbine-afgassen voor het Drogen van Eiwit in de Zetmeelindustrie (Using Turbine Fluegases for Drying of Protein in the Starch Industry), Netherlands Organization of Energy and Environment, Sittard, the Netherlands.

Netherlands Organization for Energy and the Environment (NOVEM). (1996). Energiebeheer maatrgelen in de Zetmeelindustrie (Energy Management Measures in the Starch Industry), Project Results, Netherlands Organization of Energy and Environment, Sittard, the Netherlands.

Office of Industrial Technologies (OIT), Energy Efficiency and Renewable Energy, U. S. Department of Energy. (2002a). Pumps: Cost Reduction Strategies. Available at the website www.oit.doe.gov/bestpractices.

Office of Industrial Technologies (OIT), Energy Efficiency and Renewable Energy, U. S. Department of Energy. (2002b). Pump System Optimization Saves Energy and Improves Productivity at Daishowa America Paper Mill. Best Practices Case Study on Forest Products, available at www.oit.doe.gov/bestpractices.

Paolucci-Jeanjean, D., M. -P. Belleville, G. M. Rios and N. Zakhia. (1999). Why on Earth Can People Need Continuous Recycle Membrane Reactors for Starch Hydrolysis? Starch/Stärke. 51 (1): 25-32.

Parekh, P. (2000). Investment Grade Compressed Air System Audit, Analysis and Upgrade. In: Twenty-second National Industrial Energy Technology Conference Proceedings. Houston, Texas. April 5-6: 270-279.

Price, A. and M.H. Ross. (1989). Reducing Industrial Electricity Costs - an Automotive Case Study. The Electricity Journal. July: 40-51.

Radgen, P. and E. Blaustein (eds.). (2001). Compressed Air Systems in the European Union, Energy, Emissions, Savings Potential and Policy Actions. Germany.

Rausch, K. D., S. K. Singh and S. R. Eckhoff. (1993). Magnesium Bisulfite and Sodium Bisulfite as Alternative Steeping Agents for Wet Milling. Note. American Association of Cereal Chemists, Inc. 70 (4): 489-490.

Rausch, K. D., C. J. Thomspon, R. L. Simms, R. L. Belyea, V. Singh, M.E. Tumbleson and S. R. Eckhoff. (2000). Enhanced Processing of Maize Wet-mill Corn Products Using Stainless Steel Microfiltration Membranes. Lecture of the $51^{\text {st }}$ Starch Convention 2000 (Association of Cereal Chemists) (Referate der 51 Stärke-Tagung 2000). Available at http://www.agfdt.de.

Rausch, K. (2002a). Wet Milling Short Course, "Coproducts” presentation. University of Illinois, Urbana, IL, May 2002 .

Rausch, K. D. (2002b). Front End to Backpipe: Membrane Technology in the Starch Processing Industry. Starch/Stärke. 54 (2002): 273-84.

Scales, B. (2002). Personal written communication.

Shapouri, J., J. A. Duffield and M. S. Groboski. (1995). Estimating the Net Energy Balance of Corn Ethanol. An Economic Research Service Report. U.S. Department of Agriculture. Agricultural Economic Report Number 721. July. Available at http://www.ethanol-gec.org/corn_eth.htm. 
Shenoy, U. (1994). Heat Exchanger Network Synthesis. Houston, TX: Gulf Publishing Company.

Simms, R. L. (1998). New Membrane Application in Corn Wet Milling Proceedings of the $16^{\text {th }}$ Annual Membrane Technology/Separations Planning Conference. Newton, MA.

Singh, N. and M. Cheryan. (1997). Membrane Technology in Corn Wet Milling. American Association of Cereal Chemists, Inc. 42 (7): 520-525 (July).

Singh, N. and M. Cheryan. (1998). Membrane Technology in Corn Refining and Bioproduct-Processing. Starch/Stärke. 50 (1): 16-23.

Singh, R. P. (ed). (1986). Energy in Food Processing. Elsevier, Amsterdam, the Netherlands, pp 239-244.

Singh, V. (1999). Technology of Corn Starch Production. International Starch Technology Conference Program Proceedings. June 7-9. Urbana, Illinois: 50-62.

Singh, V. (2002a). Wet Milling Short Course, "Modeling the Millhouse" presentation. University of Illinois, Urbana, IL, May 2002.

Singh, V. (2002b). Wet Milling Short Course, "Alternative Milling Methods" presentation. University of Illinois, Urbana, IL, May 2002.

Singh, V. and S. R. Eckhoff. (1997). Dewatering of Alkali Wet-Milled Corn Gluten Meal Using Stainless Steel Microfiltration Membranes. Wet Milling Notes, No. 16. University of Illinois at Urbana-Champaign, October 1997.

Slominska, L., A. Szostek and A. Grześkowiak. (2000). Studies on Enzymatic Continuous Production of Cyclodextrin in an Ultrafiltration Membrane Bioreactor. Lecture of the $51^{\text {st }}$ Starch Convention 2000 (Association of Cereal Chemists) (Referate der 51 Stärke-Tagung 2000). Available at http://www.agfdt.de.

Smith, R. (1995). Chemical Process Design. New York, NY: McGraw-Hill Inc.

Stroyer, B. (2002). New Developments in Decanter-Technology and Its Application in the Starch Industry. Lecture of the $53^{\text {rd }}$ Starch Convention 2002 (Association of Cereal Chemists). Available at http://www.agfdt.de.

Svonja, G. (2000). Experiences in Operating an Integrated Feed House. GEA Barr-Rosin publication, March 23, 2000 .

Svonja, G. (2001). Dryer and Evaporator Combinations. The Second Annual International Starch Technology Conference Program Proceedings. University of Illinois, June 3-6, 2001.

Turiel, I., B. Atkinson, s. Boghosian, P. Chan, J. Jennings, J. Lutz, J. McMahon, and G. Rosenquist. (1995). Evaluation of Advanced Technologies for Residential Appliances and Residential and Commercial Lighting. Lawrence Berkeley National Laboratory. January.

Tutterow, V. (1999). Energy Efficiency in Pumping Systems: Experience and Trends in the Pulp and Paper Industry. American Council for an Energy Efficient Economy (ACEEE).

Tutterow, V., D. Casada and A. McKane. (2000). "Profiting from your Pumping System," In Proceedings of the Pump Users Expo 2000. September. Louisville, KY: Pumps \& Systems Magazine and Randall Publishing Company.

United States Department of Agriculture (USDA), Economic Research Service. (1992). U.S. Corn Sweetener Statistical Compendium Stock \#94002. Available online at http://usda.mannlib.cornell.edu/ (under specialty agriculture/sugars and sweeteners). 
United States Department of Agriculture (USDA), Economic Research Service. (2002). Electronic Output Report Feed Report, 11/14/02.

Wendhausen, R., A. Fregonesi, P. J. S. Morgan, I. Joekes, J. Augusto, R. Rodrigues, E. Tonella and K. Althoff. (2001). Continuous Fermentation of Sugar Cane Syrup Using Immobilized Yeast Cells. Journal of Bioscience and Bioengineering. 91(1): 48-52.

Wideman, J. (2000). Wet Milling Short Course presentation. University of Illinois, Urbana, IL, 2000.

Wideman, J. (2001). Mill House Dewatering Equipment Germ, Fiber and Gluten. The Second Annual International Starch Technology Conference Program Proceedings. University of Illinois, June 3-6, 2001.

Xenergy, Inc. (1998). United States Industrial Electric Motor Systems Market Opportunities Assessment. U.S. Department of Energy's Office of Industrial Technology and Oak Ridge National Laboratory. Massachusetts.

Yang, P., L. Du, D. L. Wang, B. H. Li, K. D. Rausch, P. Buriak and S. R. Eckhoff. (2000). Effects of Alkali Debranning, Roller Mill Cracking and Gap Setting, and Alkali Steeping conditions on Milling Yields from a Dent Corn Hybrid. Cereal Chemistry. 77 (2): 128-132.

Yang, P., L. E. Pruiett, P. Buriak and M. Tumbleson. (1999). Adding Lactic Acid during Steeping Corn with Different Initial Moisture Contents on Steepwater Profiles and Starch Yield. International Starch Technology Conference Program Proceedings. June 7-9. Urbana, Illinois: 144.

Zeitz, Ronald A. ed. 1997. CIBO Energy Efficiency Handbook. Council of Industrial Boiler Owners, Burke, Virginia. 
Appendix A: Estimated corn wet milling company capacities grouped by main product

\begin{tabular}{|c|c|c|c|}
\hline Main Product & Company & Location & $\begin{array}{l}\text { Grind rate } \\
\text { (Bu/day) }\end{array}$ \\
\hline \multirow[t]{4}{*}{ Specialty starch } & \multirow[t]{2}{*}{ National Starch \& Chemical Company } & Indianapolis, IN & 63,000 \\
\hline & & N. Kansas City, MO & 49,000 \\
\hline & Penford Products Company & Cedar Rapids, IA & 65,000 \\
\hline & Colorado Sweet Gold LLC & Golden, $\mathrm{CO}$ & 15,000 \\
\hline Ethanol only & Williams Bioenergy & Pekin, IL & 125,000 \\
\hline \multirow[t]{23}{*}{ Complete line } & \multirow[t]{3}{*}{ Archer Daniels Midland Company } & Decatur, IL & 450,000 \\
\hline & & Cedar Rapids, IA & 400,000 \\
\hline & & Clinton, IA & 350,000 \\
\hline & \multirow[t]{2}{*}{ (formerly Minnesota Corn Processors) } & Marshall, MN & 200,000 \\
\hline & & Columbus, NE & 225,000 \\
\hline & \multirow[t]{5}{*}{ Cargill } & Blair, NB & 250,000 \\
\hline & & Dayton, $\mathrm{OH}$ & 180,000 \\
\hline & & Eddyville, IA & 235,000 \\
\hline & & Memphis, TN & 150,000 \\
\hline & & Cedar Rapids, IA & 105,000 \\
\hline & \multirow[t]{3}{*}{ (formerly Cerestar) } & Decatur, AL & 80,000 \\
\hline & & Dimmitt, TX & 60,000 \\
\hline & & Hammond, IN & 83,000 \\
\hline & \multirow[t]{3}{*}{ Corn Products International, Inc. } & Argo, IL & 225,000 \\
\hline & & Stockton, $\mathrm{Ca}$ & 70,000 \\
\hline & & Winston-Salem, NC & 75,000 \\
\hline & \multirow[t]{4}{*}{ A. E. Staley Manufacturing Company } & Decatur, IL & 260,000 \\
\hline & & Lafayette, IN & 225,000 \\
\hline & & Lafayette, IN & 55,000 \\
\hline & & Loudon, TN & 125,000 \\
\hline & \multirow{3}{*}{$\begin{array}{l}\text { Roquette America, Inc. } \\
\text { Grain Processing Corporation }\end{array}$} & Keokuk, IA & 120,000 \\
\hline & & Muscatine, IA & 200,000 \\
\hline & & Washington, IN & 100,000 \\
\hline
\end{tabular}

Source: Eckhoff, 2002c 
Appendix B: Corn wet milling companies' headquarters, plant locations and products ${ }^{\text {a }}$

\begin{tabular}{|c|c|c|c|c|c|c|c|}
\hline Company \& Headquarters & Plant locations & Starch & $\begin{array}{c}\text { HFCS \& other } \\
\text { refinery products }\end{array}$ & $\begin{array}{l}\text { Oil, crude } \\
\text { or refined }\end{array}$ & \begin{tabular}{|l|} 
Corn gluten \\
feed or meal
\end{tabular} & Ethanol & $\begin{array}{c}\text { Other fermentation } \\
\text { products }^{c}\end{array}$ \\
\hline $\begin{array}{l}\text { A. E. Staley Manufacturing Company } \\
\text { Decatur, IL }\end{array}$ & $\begin{array}{|ll|}\text { 1. } & \text { Decatur, IL } \\
\text { 2. } & \text { Lafayette, IN } \\
\text { 3. } & \text { Lafayette, IN } \\
\text { 4. } & \text { Loudon, TN } \\
\text { 5. } & \text { Morrisville, PA }\end{array}$ & $\mathbf{X}$ & $\mathbf{X}$ & $\mathbf{X}$ & $\mathbf{X}$ & $\mathbf{X}$ & $\mathbf{X}$ \\
\hline $\begin{array}{l}\text { Archer Daniels Midland Company } \\
\text { Decatur, IL }\end{array}$ & \begin{tabular}{|ll} 
6. & Cedar Rapids, IA \\
7. & Clinton, IA \\
8. & Decatur, IL \\
9. & Montezuma, NY \\
\end{tabular} & $\mathbf{X}$ & $\mathbf{X}$ & $\mathbf{X}$ & $\mathbf{X}$ & $\mathbf{X}$ & $\mathbf{X}$ \\
\hline $\begin{array}{l}\text { Cargill, Inc. } \\
\quad \text { Minneapolis, MN }\end{array}$ & \begin{tabular}{|l|} 
10. Blair, NE \\
11. Cedar Rapids, IA \\
12. Dayton, OH \\
13. Eddyville, IA \\
14. Memphis, TN \\
15. Wahpeton, ND
\end{tabular} & $\mathbf{X}$ & $\mathbf{X}$ & $\mathbf{X}$ & $\mathbf{X}$ & $\mathbf{X}$ & $\mathbf{X}$ \\
\hline $\begin{array}{l}\text { Cerestar USA, Inc (now owned by Cargill) } \\
\text { Hammond, IN }\end{array}$ & $\begin{array}{l}\text { 16. Decatur, } \mathrm{AL} \\
\text { 17. Dimmitt, TX } \\
\text { 18. Hammond, IN }\end{array}$ & $\mathbf{X}$ & $\mathbf{X}$ & & $\mathbf{X}$ & & $\mathbf{X}$ \\
\hline $\begin{array}{l}\text { Colorado Sweet Gold LLC } \\
\text { Johnstown, Colorado }\end{array}$ & 19. Johnstown, CO & $\mathbf{X}$ & $\mathbf{X}$ & & $\mathbf{X}$ & & \\
\hline $\begin{array}{l}\text { Corn Products International, Incorporated } \\
\text { Bedford Park, IL }\end{array}$ & $\begin{array}{l}\text { 20. Bedford Park, IL } \\
\text { 21. Stockton, CA } \\
\text { 22. Winton-Salem, NC }\end{array}$ & $\mathbf{X}$ & $\mathbf{X}$ & $\mathbf{X}$ & $\mathbf{X}$ & & $\mathbf{X}$ \\
\hline $\begin{array}{l}\text { Grain Processing Corporation } \\
\text { Muscatine, IA }\end{array}$ & $\begin{array}{l}\text { 23. Muscatine, IA } \\
\text { 24. Washington, IA }\end{array}$ & $\mathbf{X}$ & $\mathbf{X}$ & & $\mathbf{X}$ & $\mathbf{X}$ & \\
\hline $\begin{array}{l}\text { Minnesota Corn Processors (now owned by ADM) } \\
\text { Marshall, MN }\end{array}$ & $\begin{array}{l}\text { 25. Columbus, NE } \\
\text { 26. Marshall, } \mathrm{MN}\end{array}$ & $\mathbf{X}$ & $\mathbf{X}$ & & $\mathbf{X}$ & $\mathbf{X}$ & \\
\hline $\begin{array}{l}\text { National Starch \& Chemical Company } \\
\text { Bridgewater, NJ }\end{array}$ & \begin{tabular}{|l|} 
27. Indianapolis, IN \\
28. N. Kansas City, MO
\end{tabular} & $\mathbf{X}$ & & & $\mathbf{X}$ & & \\
\hline $\begin{array}{l}\text { Penford Products Company } \\
\text { Cedar Rapids, IA }\end{array}$ & 29. Cedar Rapids, IA & $\mathbf{X}$ & & & $\mathbf{X}$ & & \\
\hline $\begin{array}{l}\text { Roquette America, Incorporated } \\
\text { Keokuk, IA }\end{array}$ & 30. Keokuk, IA & $\mathbf{X}$ & $\mathbf{X}$ & & $\mathbf{X}$ & & $\mathbf{X}$ \\
\hline
\end{tabular}

${ }^{a}$ Includes only companies in SIC 2046 or NAICS 311221.

${ }^{\mathrm{b}}$ Includes glucose syrups, maltodextrins, dextrose (monohydrate and anhydrous), HFCS-42, HFCS-55 and crystalline fructose. HFCS=high fructose corn syrups

${ }^{\mathrm{c}}$ Includes citric acid, lactic acid, lysine, tryptophan, xanthum gum, erythritol, sorbitol, xylitol, mannitol, maltitol, hygrogenated starch hydrolysates and glucose hydrolysates

d Archer Daniels Midland Company's Montezuma, NY and A.E. Staley Manufacturing Company's Morrisville, PA plants were closed in 1986.

Source: USDA, 1992; Company websites. 


\section{Appendix C: Employee tasks for energy efficiency}

One of the key steps to a successful energy management program is the involvement of all personnel. Staff may be trained in both skills and the general approach to energy efficiency in day-to-day practices. Personnel at all levels should be aware of energy use and objectives for efficiency. By passing information to everyone, each employee may be able to save energy every day. In addition, performance results should be regularly evaluated and communicated to all personnel, recognizing high performers. Examples of some simple tasks employees can do include the following (Caffal, 1995):

- Report leaks of water (both process water and dripping taps), steam and compressed air and ensure they are repaired quickly.

- Check to make sure the pressure and temperature of equipment is not set too high.

- Carry out regular maintenance of energy consuming equipment.

- Ensure that the insulation on process heating equipment is effective.

- Switch off motors, fans and machines when they are not being used and it does not affect production, quality or safety.

- Switch off unnecessary lights and relying on daylighting whenever possible.

- Use weekend and night setbacks on HVAC in any unused offices or conditioned buildings.

- Look for unoccupied, heated or cooled areas and switch off heating or cooling.

- Check that heating controls are not set too high or cooling controls set too low. In this situation, windows and doors are often left open to lower temperatures instead of lowering the heating.

- Prevent drafts from badly fitting seals, windows and doors, and hence, leakage of cool or warm air. 
Appendix D: Energy management system assessment for best practices in energy efficiency

\begin{tabular}{|c|c|c|c|c|c|c|c|}
\hline & \multicolumn{2}{|c|}{ ORGANIZATION } & \multicolumn{2}{|c|}{ SYSTEMS MONITORING } & \multicolumn{2}{|c|}{ TECHNOLOGY } & \multirow{2}{*}{$\begin{array}{c}\text { O \& M } \\
\text { Operation \& } \\
\text { Maintenance }\end{array}$} \\
\hline & Accountability & Organization & $\begin{array}{c}\text { Monitoring \& } \\
\text { Targeting }\end{array}$ & $\begin{array}{c}\text { Utilities } \\
\text { Management }\end{array}$ & Reviews & Plans & \\
\hline 0 & $\begin{array}{l}\text { No awareness of } \\
\text { responsibility for energy } \\
\text { usage. Energy not } \\
\text { specifically discussed in } \\
\text { meetings. }\end{array}$ & $\begin{array}{l}\text { No energy manager or } \\
\text { "energy champion." }\end{array}$ & $\begin{array}{l}\text { Energy efficiency of } \\
\text { processes on site not } \\
\text { determined. Few process } \\
\text { parameters monitored } \\
\text { regularly. }\end{array}$ & $\begin{array}{l}\text { No utilities } \\
\text { consumption } \\
\text { monitoring. }\end{array}$ & $\begin{array}{l}\text { No specific } \\
\text { reviews held. }\end{array}$ & $\begin{array}{l}\text { No energy } \\
\text { improvement } \\
\text { plans published. }\end{array}$ & $\begin{array}{l}\text { No written procedures } \\
\text { for practices affecting } \\
\text { energy efficiency. }\end{array}$ \\
\hline 1 & $\begin{array}{l}\text { Operations staff aware of } \\
\text { the energy efficiency } \\
\text { performance objective of } \\
\text { the site. }\end{array}$ & $\begin{array}{l}\text { Energy manager is } \\
\text { combined with other } \\
\text { tasks and roles such } \\
\text { that less than } 10 \% \text { of } \\
\text { one person's time is } \\
\text { given to specific energy } \\
\text { activities. }\end{array}$ & $\begin{array}{l}\text { Energy efficiency of site } \\
\text { determined monthly or } \\
\text { yearly. Site annual } \\
\text { energy efficiency target } \\
\text { set. Some significant } \\
\text { process parameters are } \\
\text { monitored. }\end{array}$ & $\begin{array}{l}\text { Utilities (like } \\
\text { power and fuel } \\
\text { consumption) } \\
\text { monitored on } \\
\text { overall site } \\
\text { basis. }\end{array}$ & $\begin{array}{l}\text { Energy only } \\
\text { reviewed as part } \\
\text { of other type } \\
\text { reviews }\end{array}$ & $\begin{array}{l}\text { Energy } \\
\text { improvement } \\
\text { plans published } \\
\text { but based on an } \\
\text { arbitrary } \\
\text { assessment of } \\
\text { opportunities. }\end{array}$ & $\begin{array}{l}\text { No procedures } \\
\text { available to operating } \\
\text { staff. }\end{array}$ \\
\hline 2 & $\begin{array}{l}\text { Energy efficiency } \\
\text { performance indicators } \\
\text { are produced and } \\
\text { available to operations } \\
\text { staff. Periodic energy } \\
\text { campaigns. Intermittent } \\
\text { energy review meetings. }\end{array}$ & $\begin{array}{l}\text { Energy manager } \\
\text { appointed giving } \\
\text { greater than } 10 \% \text { of } \\
\text { time to task. Occasional } \\
\text { training in energy } \\
\text { related issues. }\end{array}$ & $\begin{array}{l}\text { Weekly trend monitoring } \\
\text { of energy efficiency of } \\
\text { processes and of site, } \\
\text { monitored against targets. } \\
\text { Process parameters } \\
\text { monitored against target. }\end{array}$ & $\begin{array}{l}\text { Weekly } \\
\text { monitoring of } \\
\text { steam/power } \\
\text { balance. }\end{array}$ & $\begin{array}{l}\text { Infrequent } \\
\text { energy review. }\end{array}$ & $\begin{array}{l}\text { Energy } \\
\text { performance } \\
\text { plan published } \\
\text { based on } \\
\text { estimate of } \\
\text { opportunities. }\end{array}$ & $\begin{array}{l}\text { Procedures available } \\
\text { to operators but not } \\
\text { recently reviewed. }\end{array}$ \\
\hline 3 & $\begin{array}{l}\text { Energy efficiency } \\
\text { performance parameter } \\
\text { determined for all energy } \\
\text { consuming areas. } \\
\text { Operations staff advised } \\
\text { of performance. All } \\
\text { employees aware of } \\
\text { energy policy. } \\
\text { Performance review } \\
\text { meetings held } \\
\text { once/month. }\end{array}$ & $\begin{array}{l}\text { Energy manager in } \\
\text { place greater than } 30 \% \\
\text { of time given to task. } \\
\text { Adhoc training } \\
\text { arranged. Energy } \\
\text { performance reported to } \\
\text { management. }\end{array}$ & $\begin{array}{l}\text { Daily trend monitoring of } \\
\text { energy efficiency of } \\
\text { processes and of site, } \\
\text { monitored against target. } \\
\text { Process parameters } \\
\text { monitored against targets. }\end{array}$ & $\begin{array}{l}\text { Daily } \\
\text { monitoring of } \\
\text { steam/power. } \\
\text { Steam \& fuel } \\
\text { balances } \\
\text { adjusted daily. }\end{array}$ & $\begin{array}{l}\text { Regular } \\
\text { plant/site } \\
\text { energy reviews } \\
\text { carried out. }\end{array}$ & $\begin{array}{l}\text { A five-year } \\
\text { energy } \\
\text { improvement } \\
\text { plan is } \\
\text { published based } \\
\text { on identified } \\
\text { opportunities } \\
\text { from energy } \\
\text { review. }\end{array}$ & $\begin{array}{l}\text { Procedures available } \\
\text { to operators and } \\
\text { reviewed in the last } \\
\text { three years. }\end{array}$ \\
\hline
\end{tabular}




\begin{tabular}{|c|c|c|c|c|c|c|c|}
\hline \multicolumn{3}{|c|}{ ORGANIZATION } & \multicolumn{2}{|c|}{ SYSTEMS MONITORING } & \multicolumn{2}{|c|}{ TECHNOLOGY } & \multirow{2}{*}{$\begin{array}{c}\mathrm{O} \mathrm{\&} \mathrm{M} \\
\text { Operation \& } \\
\text { Maintenance }\end{array}$} \\
\hline & Accountability & Organization & $\begin{array}{l}\text { Monitoring \& } \\
\text { Targeting }\end{array}$ & $\begin{array}{c}\text { Utilities } \\
\text { Management }\end{array}$ & Reviews & Plans & \\
\hline 4 & $\begin{array}{l}\text { Energy efficiency } \\
\text { performance parameter } \\
\text { included in personal } \\
\text { performance appraisals. } \\
\text { All staff involved in site } \\
\text { energy targets and } \\
\text { improvement plans. } \\
\text { Regular weekly meeting } \\
\text { to review performance. }\end{array}$ & $\begin{array}{l}\text { An energy manager is } \\
\text { in place giving greater } \\
\text { than } 50 \% \text { time to task. } \\
\text { Energy training to take } \\
\text { place regularly. Energy } \\
\text { performance reported to } \\
\text { management and } \\
\text { actions followed up. }\end{array}$ & $\begin{array}{l}\text { Same as } 3 \text {, with } \\
\text { additional participation in } \\
\text { energy efficiency target } \\
\text { setting. Process } \\
\text { parameters trended. }\end{array}$ & $\begin{array}{l}\text { Real time } \\
\text { monitoring of } \\
\text { fuel, steam and } \\
\text { steam/power } \\
\text { balance. } \\
\text { Optimum } \\
\text { balances } \\
\text { maintained. }\end{array}$ & $\begin{array}{l}\text { Site wide } \\
\text { energy studies } \\
\text { carried out at } \\
\text { least every five } \\
\text { years with } \\
\text { follow up } \\
\text { actions } \\
\text { progressed to } \\
\text { completion }\end{array}$ & $\begin{array}{l}\text { A ten year } \\
\text { energy } \\
\text { improvement } \\
\text { plan based on } \\
\text { review is } \\
\text { published and } \\
\text { integrated into } \\
\text { the Business } \\
\text { Plan. }\end{array}$ & $\begin{array}{l}\text { Procedures are } \\
\text { reviewed regularly and } \\
\text { updated to incorporate } \\
\text { the best practices. } \\
\text { Used regularly by } \\
\text { operators and } \\
\text { supervisors. }\end{array}$ \\
\hline
\end{tabular}




\title{
Appendix E: Support Programs for Industrial Energy Efficiency Improvement
}

This appendix provides a list of energy efficiency supports available to industry. A brief description of the program or tool is given, as well as information on its target audience and the URL for the program. Included are federal and state programs. Use the URL to obtain more information from each of these sources. An attempt was made to provide as complete a list as possible; however, information in this listing may change with the passage of time.

\section{Tools for Self-Assessment}

\author{
Steam System Assessment Tool \\ Description: $\quad$ Software package to evaluate energy efficiency improvement projects for \\ steam systems. It includes an economic analysis capability. \\ Target Group: $\quad$ Any industry operating a steam system \\ Format: Downloadable software package (13.6 MB) \\ Contact: $\quad$ U.S. Department of Energy, Office of Industrial Technologies \\ URL: $\quad$ http://www.oit.doe.gov/bestpractices/steam/ssat.html \\ Steam System Scoping Tool \\ Description: $\quad$ Spreadsheet tool for plant managers to identify energy efficiency \\ opportunities in industrial steam systems. \\ Target Group: $\quad$ Any industrial steam system operator \\ Format: Downloadable software (Excel) \\ Contact: $\quad$ U.S. Department of Energy, Office of Industrial Technologies \\ URL: $\quad$ http://www.oit.doe.gov/bestpractices/steam/docs/steamtool.xls
}

\author{
MotorMaster+ \\ Description: $\quad$ Energy-efficient motor selection and management tool, including a catalog \\ of over 20,000 AC motors. It contains motor inventory management tools, \\ maintenance log tracking, efficiency analysis, savings evaluation, energy \\ accounting and environmental reporting capabilities. \\ Target Group: $\quad$ Any industry \\ Format: $\quad$ Downloadable Software (can also be ordered on CD) \\ Contact: $\quad$ U.S. Department of Energy, Office of Industrial Technologies \\ URL: $\quad$ http://mm3.energy.wsu.edu/mmplus/default.stm
}

\begin{abstract}
ASDMaster: Adjustable Speed Drive Evaluation Methodology and Application
Description:

Software program helps to determine the economic feasibility of an adjustable speed drive application, predict how much electrical energy may be saved by using an ASD, and search a database of standard drives.

Target Group: $\quad$ Any industry

Format: $\quad$ Software package (not free)

Contact: $\quad$ EPRI, (800) 832-7322

URL: $\quad$ http://www.epri-peac.com/products/asdmaster/asdmaster.html
\end{abstract}

AirMaster:+ Compressed Air System Assessment and Analysis Software

Description: Modeling tool that maximizes the efficiency and performance of compressed air systems through improved operations and maintenance practices 
$\begin{array}{ll}\text { Target Group: } & \text { Any industry operating a compressed air system } \\ \text { Format: } & \text { Downloadable software } \\ \text { Contact: } & \text { U.S. Department of Energy, Office of Industrial Technologies } \\ \text { URL: } & \text { http://www.compressedairchallenge.org/ }\end{array}$

\section{Pump System Assessment Tool (PSAT)}

Description: The tool helps industrial users assess the efficiency of pumping system operations. PSAT uses achievable pump performance data from Hydraulic Institute standards and motor performance data from the MotorMaster+ database to calculate potential energy and associated cost savings.

Target Group: $\quad$ Any industrial pump user

Format: $\quad$ Downloadable software

Contact: $\quad$ U.S. Department of Energy, Office of Industrial Technologies

URL: $\quad$ http://public.ornl.gov/psat/

\section{ENERGY STAR Portfolio Manager}

Description: Online software tool helps to assess the energy performance of buildings by providing a 1-100 ranking of a building's energy performance relative to the national building market. Measured energy consumption forms the basis of the ranking of performance.

Target Group: $\quad$ Any building user or owner

Format: $\quad$ Online software tool

Contact: $\quad$ U.S. Environmental Protection Agency,

URL: $\quad$ http://www.energystar.gov/index.cfm?c=business.bus_index

\section{Optimization of the insulation of boiler steam lines - 3E Plus}

Description: Downloadable software to determine whether boiler systems can be optimized through the insulation of boiler steam lines. The program calculates the most economical thickness of industrial insulation for a variety of operating conditions. It makes calculations using thermal performance relationships of generic insulation materials included in the software.

Target Group: $\quad$ Energy and plant managers

Format: Downloadable software

Contact: $\quad$ Office of Industrial Technologies, U.S. Department of Energy

URL: $\quad$ http://www.oit.doe.gov/bestpractices/software tools.shtml 


\title{
Assessment and Technical Assistance
}

\author{
Industrial Assessment Centers \\ Description: $\quad$ Small- to medium-sized manufacturing facilities can obtain a free energy \\ and waste assessment. The audit is performed by a team of engineering \\ faculty and students from 30 participating universities in the U.S. and \\ assesses the plant's performance and recommends ways to improve \\ efficiency. \\ Target Group: $\quad$ Small- to medium-sized manufacturing facilities with gross annual sales \\ below $\$ 75$ million and fewer than 500 employees at the plant site. \\ Format: $\quad$ A team of engineering faculty and students visits the plant and prepares a \\ written report with energy efficiency, waste reduction and productivity \\ recommendations. \\ Contact: $\quad$ U.S. Department of Energy, Office of Industrial Technologies \\ URL: $\quad$ http://www.oit.doe.gov/iac/
}

\section{Plant-Wide Audits \\ Description:}

Target Group:

Format:

Contact:

URL:
An industry-defined team conducts an on-site analysis of total energy use and identifies opportunities to save energy in operations and in motor, steam, compressed air and process heating systems. The program covers $50 \%$ of the audit costs.

Large plants

Solicitation (put out regularly by DOE)

U.S. Department of Energy, Office of Industrial Technologies http://www.oit.doe.gov/bestpractices/plant wide assessments.shtml

\author{
Manufacturing Extension Partnership (MEP) \\ Description: $\quad$ MEP is a nationwide network of not-for-profit centers in over 400 \\ locations providing small- and medium-sized manufacturers with technical \\ assistance. A center provides expertise and services tailored to the plant, \\ including a focus on clean production and energy-efficient technology. \\ Target Group: $\quad$ Small- and medium-sized plants \\ Format: $\quad$ Direct contact with local MEP Office \\ Contact: $\quad$ National Institute of Standards and Technology, (301) 975-5020 \\ URL: $\quad$ http://www.mep.nist.gov/ \\ Small Business Development Center (SBDC) \\ Description: $\quad$ The U.S Small Business Administration (SBA) administers the Small \\ Business Development Center Program to provide management assistance \\ to small businesses through 58 local centers. The SBDC Program provides \\ counseling, training and technical assistance in the areas of financial, \\ marketing, production, organization, engineering and technical problems \\ and feasibility studies, if a small business cannot afford consultants. \\ Target Group: $\quad$ Small businesses \\ Format: $\quad$ Direct contact with local SBDC \\ Contact: $\quad$ Small Business Administration, (800) 8-ASK-SBA \\ URL: $\quad$ http://www.sba.gov/sbdc/
}




\author{
ENERGY STAR - Selection and Procurement of Energy-Efficient Products for Business \\ Description: $\quad$ ENERGY STAR identifies and labels energy-efficient office equipment. \\ Look for products that have earned the ENERGY STAR. They meet strict \\ energy efficiency guidelines set by the EPA. Office equipment included \\ such items as computers, copiers, faxes, monitors, multifunction devices, \\ printers, scanners, transformers and water coolers. \\ Target Group: $\quad$ Any user of labeled equipment. \\ Format: Website \\ Contact: $\quad$ U.S. Environmental Protection Agency \\ URL: $\quad$ http://www.energystar.gov/index.cfm?c=business.bus_index
}

\title{
Training
}

\section{Best Practices Program}

Description:

The Best Practices Program of the Office for Industrial Technologies of U.S. DOE provides training and training materials to support the efforts of the program in efficiency improvement of utilities (compressed air, steam) and motor systems (including pumps). Training is provided regularly in different regions. One-day or multi-day trainings are provided for specific elements of the above systems. The Best Practices program also provides training on other industrial energy equipment, often in coordination with conferences. A clearinghouse provides answers to technical questions and on available opportunities: 202-586-2090 or http://www.oit.doe.gov/clearinghouse/

Target Group:

Format:

Contact: Technical support staff, energy and plant managers Various training workshops (one day and multi-day workshops)

URL: Office of Industrial Technologies, U.S. Department of Energy http://www.oit.doe.gov/bestpractices/training/

\section{ENERGY STAR}

Description:

Target Group:

Format:

Contact:

As part of ENERGY STAR's work to promote superior energy management systems, energy managers for the companies that participate in ENERGY STAR are offered the opportunity to network with other energy managers in the partnership. The networking meetings are held monthly and focus on a specific strategic energy management topic to train and strengthen energy managers in the development and implementation of corporate energy management programs.

Corporate and plant energy managers

Web-based teleconference

Climate Protection Partnerships Division, U.S. Environmental Protection Agency

URL: $\quad$ http://www.energystar.gov/ 


\title{
Financial Assistance
}

Below we summarize the major federal programs that provide assistance for energy efficiency investments. Many states also offer funds or tax benefits to assist with energy efficiency projects (see below for State Programs).

\author{
Industries of the Future - U.S. Department of Energy \\ Description: $\quad$ Collaborative R\&D partnerships in nine vital industries. The partnership \\ consists of the development of a technology roadmap for the specific sector \\ and key technologies, and cost-shared funding of research and \\ development projects in these sectors. \\ Target Group: $\quad$ Nine selected industries: agriculture, aluminum, chemicals, forest products, \\ glass, metal casting, mining, petroleum and steel. \\ Format: $\quad$ Solicitations (by sector or technology) \\ Contact: $\quad$ U.S. Department of Energy - Office of Industrial Technologies \\ URL: $\quad$ http://www.oit.doe.gov/industries.shtml

\section{Inventions \& Innovations (I\&I)} \\ Description: The program provides financial assistance through cost-sharing of 1) early \\ development and establishing technical performance of innovative energy- \\ saving ideas and inventions (up to $\$ 75,000$ ) and 2) prototype development \\ or commercialization of a technology (up to $\$ 250,000$ ). Projects are \\ performed by collaborative partnerships and must address industry- \\ specified priorities. \\ Target Group: $\quad$ Any industry (with a focus on energy-intensive industries) \\ Format: \\ Solicitation \\ Contact: $\quad$ U.S. Department of Energy - Office of Industrial Technologies \\ URL: $\quad$ http://www.oit.doe.gov/inventions/
}

National Industrial Competitiveness through Energy, Environment and Economics (NICE 3 ) Description:

Cost-sharing program to promote energy efficiency, clean production and economic competitiveness in industry through state and industry partnerships (large and small business) for projects that develop and demonstrate advances in energy efficiency and clean production technologies. Applicants must submit project proposals through a state energy, pollution prevention or business development office. Non-federal cost share must be at least $50 \%$ of the total cost of the project.

Target Group: $\quad$ Any industry

Format: Solicitation

Contact: $\quad$ U.S. Department of Energy - Office of Industrial Technologies

URL: $\quad$ http://www.oit.doe.gov/nice3/

\author{
Small Business Administration (SBA) \\ Description: $\quad$ The Small Business Administration provides several loan and loan \\ guarantee programs for investments (including energy-efficient process \\ technology) for small businesses. \\ Target Group: $\quad$ Small businesses \\ Format: $\quad$ Direct contact with SBA \\ Contact: $\quad$ Small Business Administration \\ URL: $\quad$ http://www.sba.gov/
}




\section{State and Local Programs}

Many state and local governments have general industry and business development programs that can be used to assist businesses in assessing or financing energy-efficient process technology or buildings. Please contact your state and local government to determine what tax benefits, funding grants, or other assistance they may be able to provide your organization. This list should not be considered comprehensive but instead merely a short list of places to start in the search for project funding. Below we summarize selected programs earmarked specifically for support of energy efficiency activities.

\section{California - Public Interest Energy Research (PIER)}

Description: $\quad$ PIER provides funding for energy efficiency, environmental, and renewable energy projects in the state of California. Although there is a focus on electricity, fossil fuel projects are also eligible.

Target Group: $\quad$ Targeted industries (e.g. food industries) located in California

Format: Solicitation

Contact: $\quad$ California Energy Commission, (916) 654-4637

URL: $\quad$ http://www.energy.ca.gov/pier/funding.html

\section{California - Energy Innovations Small Grant Program (EISG)}

Description: $\quad$ EISG provides small grants for development of innovative energy technologies in California. Grants are limited to $\$ 75,000$.

Target Group: $\quad$ All businesses in California

Format:

Solicitation

Contact:

California Energy Commission, (619) 594-1049

URL: http://www.energy.ca.gov/research/innovations/index.html

\section{Indiana - Industrial Programs}

Description: $\quad$ The Energy Policy Division of the Indiana Department of Commerce operates two industrial programs. The Industrial Energy Efficiency Fund (IEEF) is a zero-interest loan program (up to $\$ 250,000$ ) to help Indiana manufacturers increase the energy efficiency of manufacturing processes. The fund is used to replace or convert existing equipment, or to purchase new equipment as part of a process/plant expansion that will lower energy use. The Distributed Generation Grant Program (DGGP) offers grants of up to $\$ 30,000$ or up to $30 \%$ of eligible costs for distributed generation with an efficiency over $50 \%$ to install and study distributed generation technologies such as fuel cells, micro turbines, cogeneration, combined heat $\&$ power and renewable energy sources. Other programs support can support companies in the use of biomass for energy, research or building efficiency.

Target Group: $\quad$ Any industry located in Indiana

Format: Application year-round for IEEF and in direct contact for DGGP

Contact: Energy Policy Division, (317) 232-8970.

URL: http://www.in.gov/doc/businesses/EP industrial.html

\section{Iowa - Alternate Energy Revolving Loan Program}

Description:

The Alternate Energy Revolving Loan Program (AERLP) was created to promote the development of renewable energy production facilities in the state. 

Target Group: $\quad$ Any potential user of renewable energy
Format: $\quad$ Proposals under $\$ 50,000$ are accepted year-round. Larger proposals are accepted on a quarterly basis.
Contact: $\quad$ Iowa Energy Center, (515) 294-3832
URL: $\quad$ http://www.energy.iastate.edu/funding/aerlp-index.html

\author{
New York - Industry Research and Development Programs \\ Description: $\quad$ The New York State Energy Research \& Development Agency \\ (NYSERDA) operates various financial assistance programs for New \\ York businesses. Different programs focus on specific topics, including \\ process technology, combined heat and power, peak load reduction and \\ control systems. \\ Target Group: $\quad$ Industries located in New York \\ Format: \\ Solicitation \\ Contact: $\quad$ NYSERDA, (866) NYSERDA \\ URL: $\quad$ http://www.nyserda.org/industry/industrialprograms.html
}

\title{
Wisconsin - Focus on Energy \\ Description: $\quad$ Energy advisors offer free services to identify and evaluate energy- saving opportunities, recommend energy efficiency actions, develop an energy management plan for business; and integrate elements from national and state programs. It can also provide training. \\ Target Group: Industries in Wisconsin \\ Format: Open year round \\ Contact: Wisconsin Department of Administration, (800) 762-7077 \\ URL: http://focusonenergy.com/page.jsp?pageId $=4$
}

